\title{
Evaluation of Service Reliability I mpacts of Traffic Signal Priority Strategies for Bus Transit
}

\author{
James Chang \\ Dissertation submitted to the faculty of the Virginia Polytechnic \\ Institute and State University in partial fulfillment of the requirements \\ for the degree of \\ Doctor of Philosophy \\ in \\ Civil and Environmental Engineering \\ Dissertation Research Committee Members \\ John Collura, Chair \\ François Dion \\ Hesham Rakha \\ Samuel C. Tignor \\ Kostas Triantis
}

June 3, 2002

Falls Church, VA

Keywords: bus transit, signal priority, evaluation, simulation 


\title{
Evaluation of Service Reliability I mpacts of Traffic Signal Priority Strategies for Bus Transit
}

\author{
James Chang
}

\section{ABSTRACT}

Recent progress in technology has facilitated the design, testing, and deployment of traffic signal priority strategies for transit buses. However, a clear consensus has not emerged regarding the evaluation of these strategies. Each agency implementing these strategies can have differing goals, and there are often conflicting issues, needs, and concerns among the various stakeholders. This research attempts to assist in the evaluation of such strategies by presenting an evaluation framework and plan that provides a systematic method to assess potential impacts. The results of the research include the development of specific measures corresponding to particular objectives, with descriptions to facilitate their use by agencies evaluating traffic signal priority. The use of this framework and plan is illustrated on the Columbia Pike corridor in Arlington, Virginia with the use of the INTEGRATION simulation package. In building upon prior efforts on this corridor, this work presents a method of simulating conditional granting of priority to late buses in an attempt to investigate the 
impacts of priority on service reliability. Using the measures developed in this research, statistically significant improvements of $3.2 \%$ were found for bus service reliability and $0.9 \%$ for bus efficiency, while negative other traffic-related impacts were found in the form of increases in overall delay to the corridor of $1.0 \%$ on a vehicle basis or $0.6 \%$ on a person basis. Areas identified for future research include extensions to INTEGRATION to permit consideration of real-time conditional priority, further exploration of the relationship between components of bus travel times, and examination of the role of passenger loads on priority operation and impacts. 


\section{ACKNOWLEDGEMENTS}

First and foremost, I would like to express my heartfelt appreciation for the assistance and guidance provided by my advisor, Dr. John Collura. Throughout the course of my doctoral program, at every step, he has given me the support, encouragement, and counsel needed to move forward and successfully reach this stage. He has done so with exceptional patience and caring for my well-being, and I offer my sincerest gratitude. I would also like to thank Dr. François Dion, Dr. Hesham Rakha, Dr. Sam Tignor, and Dr. Kostas Triantis for their willingness to serve on my dissertation committee. They took the time and effort to review various drafts and offer useful feedback on my research. In addition, Dr. Dion offered crucial support with the simulation analysis, from providing a foundation to build upon to answering all of my numerous questions in a helpful and responsive manner. The author also wishes to express appreciation for the support of J.R. Robinson and Amy Tang McElwain, Virginia Department of Transportation, and Tom Jenkins, Federal Highway Administration. 


\section{TABLE OF CONTENTS}

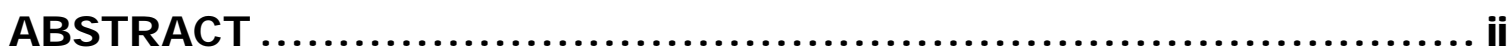

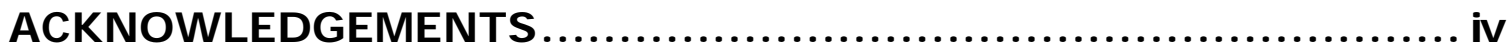

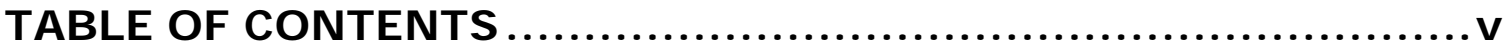

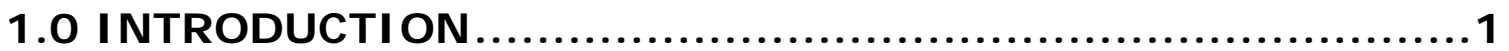

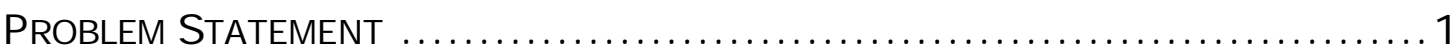

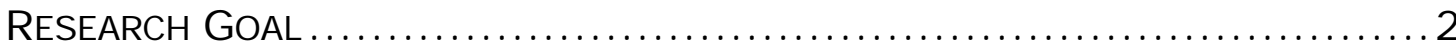

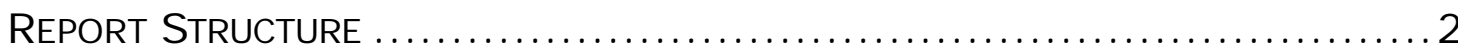

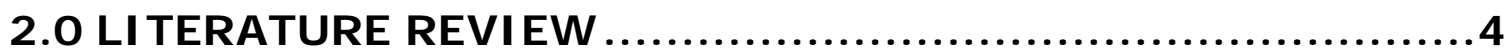

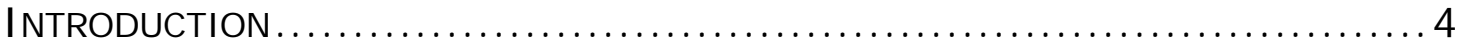

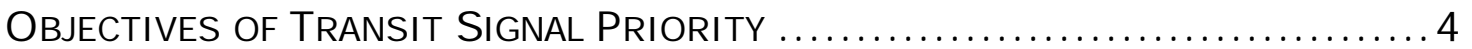

PRIORITY VS. PREEMPTION.............................................. 6

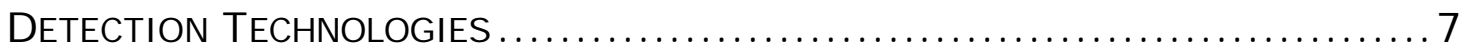

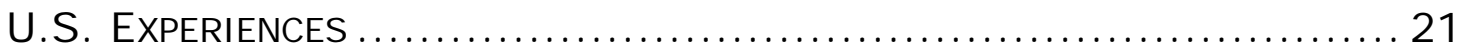

Results / Lessons Learned - Emergency Vehicle Preemption....... 22

Deployments / Results / Lessons Learned - Transit Priority ....... 26

TRANSIT PRIORITY EVALUATION USING SIMULATION ........................ 33

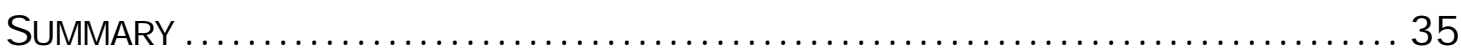

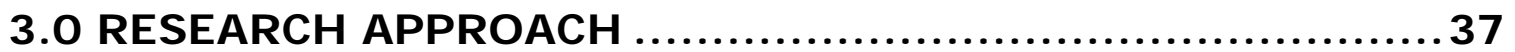

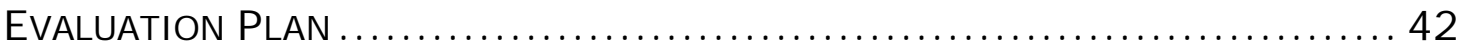

1.0 Bus Service Reliability (transit schedule adherence)..........46

2.0 Bus Efficiency (transit travel time savings) .................. 50

3.0 Other Traffic-Related Impacts .............................. 53

APPLICATION TO SERVICE RELIABILITY (THEORY \& HYPOTHESES) . ............ 57

Columbia Pike Model............................................. 58

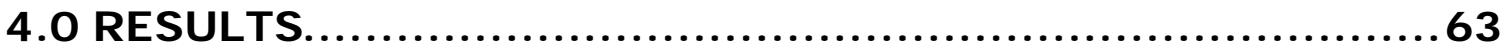

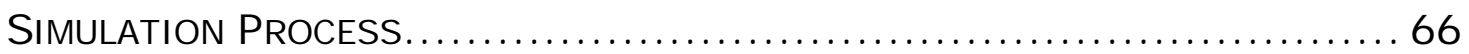

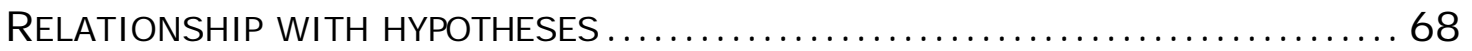

BUS SERVICE RELIABILITY - ARRIVAL RELIABILITY...................... 68

Individual Trip Level Analysis .................................... 69

Analysis of Reliability over a Period of Time ..................... 70

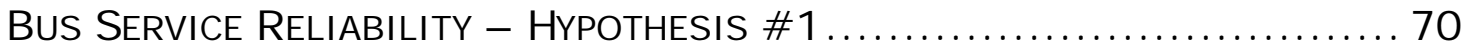

A COMPARISON WITH AUTOS (TIME RELIABILITY) ....................... 74

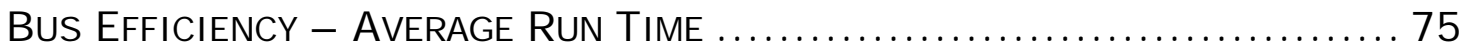

BUS EFFICIENCY - HYPOTHESIS \#2 ................................. 75

OtheR TRAFFIC-RELATED I MPACTS - OVERALL DeLAy (PERSON, VEHICLE) .... 77 
Other TRAFFIC-RELATED I MPACTS - HyPOTHESIS \#3.................... 77

\subsection{SUMMARY / CONCLUSI ONS / RECOMMENDATI ONS ..........81}

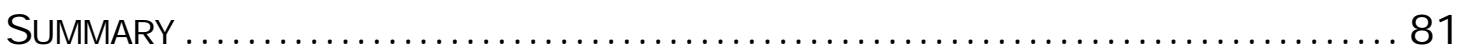

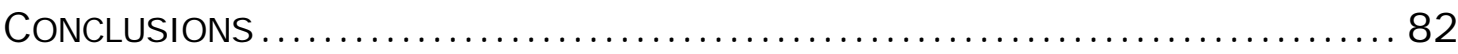

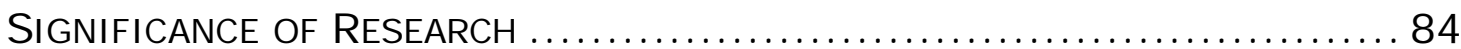

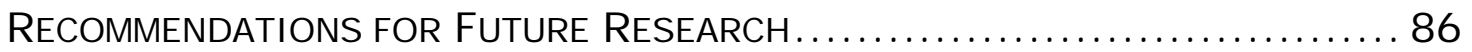

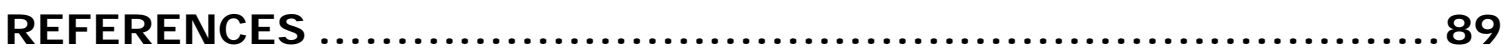

APPENDIX A: BIBLIOGRAPHY (AdDITIONAL BACKGROUND MATERIAL) ....... 93

General................................................... 93

I mplementation / Mechanisms................................. 93

Evaluation ...................................................... 94

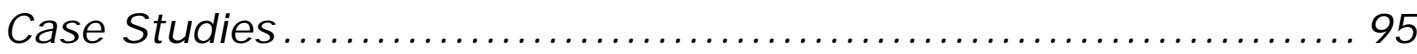

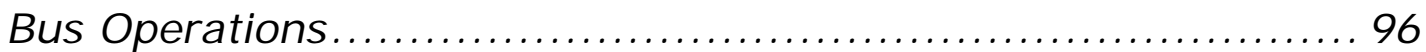

Traffic Operations ............................................ 97

APPENDIX B: MAP OF COLUMBIA PIKE CORRIDOR IN ARLINGTON, VIRGINIA .. 98 APPENDIX C: SCREEN VIEWS OF COLUMBIA PIKE NETWORK IN INTEGRATION

APPENDIX D: DESCRIPTION OF I NTEGRATION MODELING APPROACH ...... 102 APPENDIX E: SELECTED EXCERPTS FROM I NTEGRATI ON I NPUT/OUTPUT FILES 104

APPENDIX F: DATA SUMMARIES FROM INTEGRATION RUNS .............. 114

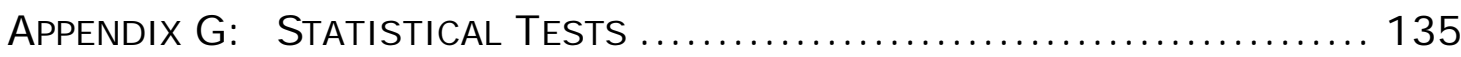




\section{LIST OF TABLES AND FI GURES}

Table 1: Summary of Transit Signal Priority Deployment Results ..... 31

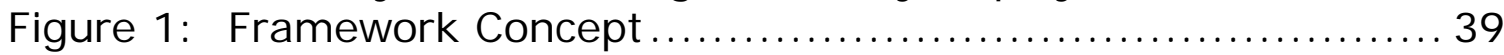

Table 2: Evaluation Measures ...................................... 43

Table 3: Maximum Additional Green Times by Intersection ............ 65

Figure 2: Standard Deviation of "Delta" Time at Navy Annex......... 72

Figure 3: Alternative Visualization of Arrival Reliability............... 73

Figure 4: Average Bus Run Times.................................. 76

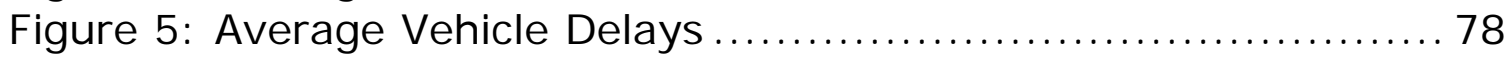

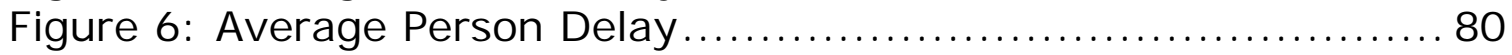




\subsection{NTRODUCTI ON}

Although traffic signal priority strategies for transit have existed for more than two decades, there has been a great deal of interest in new applications in the past few years, and a shift of some attitudes among professionals towards re-examining the use of priority in their jurisdictions. Given the ongoing growth in travel demand, coupled with the limited resources for traditional capacity expansion, increasing focus has been given to improvements that are thought to be more "sustainable". The enhancement of public transportation systems in a way that provides improved mobility and reliability without needing extensive infrastructure investments may contribute to this trend. Traffic signal priority for transit has the potential to help meet this challenge. In part due to the advances in technologies, local jurisdictions have now been able to examine and deploy traffic signal priority for transit vehicles in a variety of different areas using different detection systems and architectures (1).

\section{Problem Statement}

In light of the recent interest in testing and deploying signal priority systems, there is a need for an evaluation framework and plan in order to determine the impacts associated with various traffic signal priority strategies as applied to transit. This evaluation framework and plan 
can provide a systematic basis for local stakeholders to examine the likely impacts of potential deployments and to assess the degree to which the deployments achieve the desired objectives. In particular, the extent to which traffic signal priority strategies can improve the service reliability of bus operations warrants investigation, as this is a commonly cited objective of signal priority.

\section{Research Goal}

The goal of this research is two-fold:

1) to formulate an evaluation framework and plan for traffic signal priority strategies for transit; and

2) to illustrate the use of the framework and plan in the assessment of transit service reliability impacts.

\section{Report Structure}

This report will document the results of the research. First, a review of the relevant literature will be given, establishing the background in which the research attempts to build upon. The research approach is then discussed, and the evaluation framework and plan is presented. The use of the framework and plan will be illustrated using the Columbia Pike corridor in Arlington, Virginia as an example, and the resulting findings from simulation analyses will be discussed. Finally, 
the report will offer conclusions from the research and suggest future directions for further research in this area. 


\subsection{TERATURE REVI EW}

\section{I ntroduction}

The purpose of the literature review is to identify and synthesize appropriate references to demonstrate and illustrate the presence of knowledge gaps to be addressed by this research. These references will include journal articles, conference papers, published reports, and other readily available sources of information, such as World Wide Web pages. The review will provide background on the objectives of signal priority for transit, differentiating between priority and preemption for emergency vehicles; discuss the various detection technologies used; and summarize the prior experiences in the U.S.

\section{Objectives of Transit Signal Priority}

Stakeholders in a Washington, DC Metropolitan Area Case Study (2) suggested four policy requirements for priority systems. They are presented here in the order in which they were mentioned.

1. The system shall improve schedule adherence.

2. The system shall improve the efficiency with which buses run, reducing operating costs and allowing greater schedule flexibility.

3. A priority system shall be part of a larger ITS system that includes improved rider information and other services. 
4. Priority shall increase the overall efficiency with which the road network is used by contributing to an increasing in bus ridership.

In individual past deployments, the objectives varied somewhat, but typically emphasized improving the quality of transit service and/or the efficiency of operations. In terms of measurements, bus travel time and additional delay to general vehicular traffic were the most common metrics used (3).

By potentially improving schedule adherence, a priority system can improve the quality of transit service and enhance the mode share of transit. In addition to considering travel time and other factors, travel demand models may include service reliability as a modal attribute representing the need to be punctual (4). In addition, service unreliability can have a great impact on ridership, by increasing the uncertainty and anxiety to passengers (5). Noland et al (6) found that costs associated with uncertainty resulted primarily from costs of early or late arrival. From the perspective of the transit operations planner, the emphasis is often placed on running times between timepoints, as recovery time is built into each trip. However, if a trip falls behind schedule by a significant amount, bunching with the following bus may occur, or subsequent trips may be impacted due to inadequate recovery time at the end of the run. Within a trip, segments that regularly run either ahead of or behind schedule may 
be identified with the use of ride checks to collect actual running times by segment. The average schedule variance, consisting of the average number of minutes ahead or behind schedule for the trips checked (7), may be used to identify scheduled running times that need adjustment, and allowing timetables to be changed accordingly.

\section{Priority vs. Preemption}

The Washington, DC Study (2) also identified system objectives for emergency vehicle preemption. Again, these objectives are presented here in the order in which they were often mentioned by interviewees. 1. The system shall significantly reduce response time to emergencies. 2. The system shall significantly improve the safety and health of emergency personnel by reducing accidents, relieving stress or both.

3. The system shall reduce accidents between non-emergency vehicles related to responding emergency units at intersections where it is installed.

Generally, preemption focuses on safety, while priority attempts to improve transit service quality and efficiency. The granting of preemption typically has minimal restrictions and acts directly on the controller preempt input, owing to the importance afforded to safety of public emergency workers and response to individuals in need, while use of priority is often subject to various conditions and criteria, mostly to limit the severity of impacts on other traffic. Priority also 
may be considered on a passive basis, using such measures as shortening cycle times, and optimizing signals for bus travel speeds (8), though the focus here is on active strategies. The controller strategies used for active priority are often thought of as green extensions which extend the priority phase if it is already green, and early greens or red truncations, which either skip or shorten conflicting phases when the priority phase is red. TCRP Project A-16 includes detailed discussion of signal controller operations for priority, offering a technical explanation of implementation approaches as well as guidance toward more advanced priority strategies (9). As can be seen, the objectives and controller strategies for priority and preemption are quite different, though the system architecture in implementation may have similarities. In particular, the detection technologies used for preemption and priority are similar.

\section{Detection Technologies}

This section reviews the various detection technologies that have been used in traffic signal preemption and / or priority applications in terms of their functionality, strengths, and limitations (1). Since some technologies (e.g. light, sound, etc.) have been utilized by multiple vendors in a different fashion, different vendor implementations will be reviewed individually. 


\section{Light - 3M Opticom}

\section{Functionality}

3M Opticom components consist of infrared strobe emitters, infrared detectors directionally mounted at intersections, and an interface to the signal controller (10). The emitters are mounted on the front or top of vehicles that are to be given priority treatment and wired into the vehicle's electrical system. When activated by switch or automatic mechanism, the emitter sends a cone of infrared and visible strobe light in the forward direction. If desired, the visible component of the strobe may be filtered out by mounting an optical filter on the emitter (11). Within the strobe's flashing pattern and frequency is a coded message consisting of the vehicle identification number that had been assigned to the emitter. At each intersection approach for which priority is desired, detectors are mounted facing approaching traffic, usually on the mast arm or span wire that supports the signal heads. Opticom supports two or four channels, providing detection capability on two or four approaches respectively. The detectors are connected by wire to the Opticom phase selector card installed in the signal controller cabinet. The phase selector (and card rack for some controllers) provides the interface between the detectors and the preemption inputs of the signal controller. This interface provides authentication and authorization of priority phases using predefined 
logic and acts through standard controller functions (9). In addition, the phase selector supports user classification and operating priorities for vehicle types overriding other vehicle types. Optionally, a confirmation light mounted on the approach can be installed and connected so that priority vehicles may visually confirm that they have obtained the priority right-of-way. Opticom is able to communicate with both centralized and closed loop systems (12). Strengths One of Opticom's most significant strengths is the popularity it has achieved among fire and rescue departments in the U.S. While it has undergone refinement, the technology has been used for many years and is readily available (11). Individual vehicle logging functionality is provided, as long as Opticom equipment is used. Limited compatibility with the Tomar Optronix Strobecom system, which also uses strobebased technology, is available but logging does not work across vendors (11). Since the visible spectrum of the strobe may be filtered, the emitters are usable with both emergency vehicles as well as nonemergency vehicles such as buses and snowplows. The ability for emergency vehicles to override non-emergency vehicles is provided through separate high and low priority levels. Generally, since the emitter can be switched by automated mechanisms, Opticom may be 
suitable for vehicle-level control authority, as in a "smart bus" application (13).

Limitations

As all light based technologies are, Opticom is dependent on a line-ofsight clearance between emitter and detector for detection to be successful. The ability to achieve this clearance may be hindered by curved geometrics, weather-related visibility problems, and obstructing vehicles or objects such as tree foliage (12). Due to the wide cone profile of the strobe light, there is the potential for interference with adjacent or neighboring intersections, resulting from light reflection off of surfaces or roadway geometrics. As mentioned earlier, the vehicle logging capability does not function when a nonOpticom emitter is used, and even with matched equipment, the only information transfer capability is a 4-digit vehicle number. This number also acts as security for the system, as individual vehicle numbers can be set to be active or inactive. However, the difficulty in duplicating the correct pattern and frequency for a vehicle number is unclear. Range of the detectors can be adjusted, but the vehicle location can only be determined by presence in the static predefined range. Similarly, the emitter can only be in a binary on or off state. 
Light - Optronix / Tomar Strobecom

Functionality

As with Opticom, the Strobecom system consists of strobe emitters on vehicles, detectors at intersections, and an interface device in the controller cabinet. Emitters provide a cone of infrared and optionally filtered visible light, coded with a vehicle identification number.

Detectors are placed at the intersection typically near the signal heads, with one detector per desired approach, and are wired to the Optronix interface card in the controller cabinet via serial communications. The interface card provides authentication and authorization for the priority phases, and is preprogrammed to respond to first-come first serve within two bands, with the emergency band overriding the transit band, and up to sixteen priority levels within each band. Upon detection of an emitter, the potential response actions include local preemption, report of detection to central controller and await response, or logging of vehicle passage (12). A confirmation light for right-of-way can be installed optionally. Maintenance routines include cleaning detector lenses, inspecting emitters, and testing operation (12).

Strengths

Limited compatibility with Opticom is an advantage as long as vehicle logging is not required. Similar to Opticom, the Strobecom system 
may be used for different vehicle classes including appropriate override logic, and can log vehicle activations by Tomar emitters. Vehicle-level control may be suitable since emitters can be switched only in an on and off fashion.

Limitations

Strobecom is affected by the same light-based issues described under Opticom, including geometrics, weather/visibility, and obstructions. Though limited compatibility with Opticom is useful, mixed vendor systems cannot provide logging functionality. Also, there is low potential for information transfer since the vehicle identification is the only data transmitted by emitters, and the detection capability and emitter activation states are binary in nature.

Light - Novax Bus Plus

Functionality

The Novax Bus Plus system uses infrared light technology in a "sidefire" configuration. Vehicles are equipped with an infrared transceiver ("VTM") directed in the curbside direction, which transmits a coded signal. On the curbside of the intersection approach (checkin) and at a location past the intersection (check-out), corresponding detection modules ("VDMs") are mounted at the appropriate distance from the intersection. These detection modules authenticates and 
validates the infrared signal from vehicles, and relays the message to a receiver unit ("VIL") installed in the traffic signal controller via lowpower radio. The receiver unit applies user-defined conditional statements to activate / deactivate the appropriate priority inputs on the signal controller (13).

Strengths

Use of short-range radio communications between detector and controller does not require installation of wiring from detector to controller, only AC power. Infrared technology is resistant to radio frequency (RF) interference and electromagnetic interference (EMI) from the bus (14).

Limitations

The receiver in the controller requires an RF antenna in order to receive the relayed message. A suitable mounting location with $A C$ power is also necessary for the sidefire detector at curbside locations.

Sound - Sonic (Unity Wireless) Sonem 2000

Functionality

Sonem 2000 includes a directional microphone array mounted at the intersection, a controller card in the signal controller, and an optional visual confirmation light. The microphone array detects sirens in yelp, wail, or hi-lo with adjustable frequency, period, and range (15). 
Devices can also be mounted on vehicles to permit detection of nonemergency vehicles (11), as well as perform vehicle identification (12). Upon detection, the controller card notifies the signal controller of the priority request by direction, and logs the date, start and stop time, type of siren, and direction of travel (15).

Strengths

In order to be detected, emergency vehicles do not need to have any additional equipment mounted. This also facilitates interjurisdictional emergency actions since emergency vehicles from other areas may utilize the system. The confirmation light also indicates when another vehicle has preemption control. Use in non-emergency situations may be less likely when an audible siren is necessary for activation. Also, the sound detection capability does not depend on line-of sight or visibility.

Limitations

The system only has a binary sensitivity of vehicle presence on an approach, with no data transfer capability. There does not appear to be the ability to restrict vehicles that are equipped with the appropriate siren type. Anecdotal evidence indicates that sound based systems may be susceptible to false activation by alarms, such as building alarms, and potential drift in siren output from original specifications. 
Sound - EPS II

Functionality

The EPS II system consists of a digital sound wave recognition system connected to a phase selector unit that interfaces with the signal controller. Detectors are mounted to distinguish direction and wave profile of sirens, and configured to detect in the desired range. Electronic sirens may be used as the activation device or a special siren emitter can be used to exclude other sirens. Usage is logged by time, date, duration, and direction for each preemption, while individual vehicle use can be tracked with use of on-vehicle equipment (12).

Strengths

No modifications are needed for emergency vehicles to use the system, if individual vehicle logging is not required. EPS II has the capability to be activated by both emergency vehicles and nonemergency vehicles equipped with an inaudible sound generator (11). Like other sound-based detection systems, EPS II does not depend on line-of sight or visibility for detection.

Limitations

The system only has a binary sensitivity of vehicle presence on an approach, without data transfer capability. There is no ability to 
restrict vehicles that are equipped with the appropriate siren type without using additional on-vehicle equipment. Individual vehicle logging requires additional equipment on vehicles. Anecdotal evidence indicates that sound based systems may be susceptible to false activation by alarms, such as building alarms, and potential drift in siren output from original specifications.

Loop Detector - IDC LoopComm

Functionality

The IDC LoopComm system consists of low frequency transponders mounted on vehicles, which are detected by standard pavement loops connected to a special amplifier. The transponders are coded with a vehicle identification number that can be read by the amplifier (13). Strengths

LoopComm does not depend on line of sight/visibility. Transponders may be mounted on both emergency and non-emergency vehicles. Limitations

LoopComm depends on appropriately placed and functional pavement loop detectors. Presence and identification of the vehicle is the only data provided on detection. There is only one state for the transponder when powered on; emergency or other status cannot be transmitted. 
Push-button (Hardwired / Firehouse)

Functionality

Typical hardwire systems include a push-button activation device in the firehouse, connected to the adjacent intersection signal controller. When the button is activated, the signal controller begins the programmed preemption sequence.

Strengths

The hardwire mechanism is simple and reliable, works in all weather conditions, and does not require equipment on-board vehicles.

Limitations

Detection is only provided after human activation of the push-button, and is therefore applicable only to vehicles having access, usually emergency vehicles leaving the firehouse. Activation may not be timely due to the need to get from firehouse to intersection. Remote activation of other intersections not connected directly is not possible, though remote activation of a push-button has been accomplished using devices like garage door opener remotes. Activation of the push-button is not controlled, and is not logged by person or vehicle. 
Radio - TOTE

Functionality

TOTE consists of RF tag readers installed curbside in advance of intersections, and Amtech AVI 185 read/write tags on priority vehicles. Output from the tag reader is provided using RS-232 communication to either the controller or other devices (13).

Strengths

Tags may be placed on both emergency and non-emergency vehicles. Tag readers are installed in advance of the intersection, and hence visibility issues are not significant.

Limitations

TOTE only provides detection and does not provide authentication and phase selector functionality; an interface device needs to take TOTE output and interface with signal controller inputs. Tags may not provide dynamic information on status, such as schedule or emergency status, without needing additional equipment on-board. All tag readers installed at curbside require a suitable mounting location, power, and communications capability. 
Radio - Econolite EMTRAC

Functionality

EMTRAC includes an intersection-mounted antenna and receiver to receive radio transmissions from a bus-mounted spread spectrum transmitter. Up to three levels of priority can be assigned to the transmitters. Preemption activity is logged by vehicle identification number, priority level, preemption direction, time, date, and duration of preemption (12).

Strengths

Transmitters may be mounted on both emergency and non-emergency vehicles. Vehicles are logged on an individual basis along with preemption information.

Limitations

Non-directional nature requires vehicle to provide approach direction; anecdotal reports indicate a potential for system malfunction due to compass failures (12).

Radio / GPS-AVL - Priority One Functionality

Priority One provides preemption at the local controller by using radio (either spread spectrum or narrow band) transmitters placed on vehicles and radio receivers at intersections linked to a preemption 
module interfacing with the signal controller (11). The GPS-AVL component determines vehicle position, direction, speed, and time of day to determine appropriate preemption conditions. Preemption activity is logged including vehicle ID and approach (12). Strengths Use of the AVL system can permit determination of intersections in advance to be preempted, even around turns (11). Preemption can be terminated if the vehicle leaves the intersection approach, or is determined as stopped for too long, or has the door open, etc. (12) Limitations GPS system is susceptible to accuracy issues especially in urban environments. Due to the polling frequency of the AVL system, accuracy for closely spaced intersections may not be adequate (11). Priority activation depends on the AVL system being operational.

Orbtrac 300

Functionality

Since Orbtrac 300 consists of a larger system, comparison with the detection technologies previously discussed is difficult. However, limited information is provided here in order to show how preemption and priority might be managed at a higher level. Orbtrac 300 is a complete bus operations management system that includes GPS 
tracking and priority capability. Priority requests may be generated by an on-bus processor, or by a transit management center, which relays requests to a traffic management center (13).

Strengths

Orbtrac can utilize information on bus occupancy and schedule adherence to selectively request priority. Priority requests are not affected by visibility and weather conditions.

Limitations

For priority, the infrastructure for tracking bus operations needs to be in place. Also, the capability to control local signals from a central management center is necessary. Emergency management may operate separately from transit management, limiting the applicability of Orbtrac for preemption.

\section{U.S. Experiences}

This section reviews deployments of emergency vehicle preemption and priority for transit vehicles $(1,16)$. This review is not intended to be comprehensive but examined both local applications and deployments in other regions. Information was gathered using a combination of published and unpublished literature as well as conversations with personnel. 


\section{Results / Lessons Learned - Emergency Vehicle Preemption}

Northern Virginia Field Observations by VDOT (12)

Tysons Corner

The Tysons Corner fire station has a push-button activated hardwired preemption system controlling the intersection at Route 7 and Spring Hill Road. When preemption was activated by means of the pushbutton, coordination was disrupted while the vehicle left the station. Due to the distance from the firehouse to the intersection, additional preempt time was configured to allow sufficient time for the vehicle to reach the intersection. Recovery to time base coordination took 7 minutes; during this period mainline traffic faced significant congestion during peak hours.

\section{McLean}

The McLean fire station uses a light-based preemption system for the adjacent signal at Chain Bridge Road. Preemption disrupted the corridor coordination, causing a delay related to the time the strobe stayed in the detection zone. Recovery to time base coordination took 3 minutes, 40 seconds. 
Sterling

The Sterling fire station uses a sound-based preemption system (Sonic) at the intersection of Sterling Blvd. This intersection is an isolated signal that operates in fully-actuated (free) control mode 24 hours a day. The duration of delay from preemption was primarily determined by the time the emergency vehicle's siren was present and activated in the detection zone. The minimum delay time observed was 32-37 seconds for the next phase to appear. Since the intersection does not operate in coordination, there is no transition time associated with preemption

Phoenix test of Econolite TS-2 Recovery (11) Phoenix tested the time needed for an Econolite TS-2 controller to recover after preemption activation. The results indicated that the time spent in recovery depended on the point in the cycle where preemption was released. Recovery time was observed to range from 34 seconds to 274 seconds for a 90 second cycle length. The average recovery time for $70 \%$ of Phoenix signals was estimated to be 154 seconds, while the remaining $30 \%$ of signals would need 200 seconds. 
Denver Opticom Study $(11,17)$

Results from a study conducted in Denver using the Opticom system indicated that response times for emergency vehicles were reduced by $14-23 \%$ after the deployment of the preemption system. In addition, the reductions were greater on runs that contained more intersections.

Addison, TX (11)

Addison, TX has claimed a 50\% decrease in response time from preemption.

Houston, TX Opticom (18)

A study of Opticom preemption in Houston indicated an average improvement in travel time from station to incident ranged from 16$23 \%$. In addition, drivers reported a reduction in stress levels associated with driving as a result of the preemption functionality.

St. Paul, MN Opticom (19)

The City of St. Paul found that accident frequency after deployment of Opticom preemption decreased by $70 \%$. Of the 23 accidents, 19 were found to occur when the emergency vehicle had the right of way (green light). 
Washington, DC Opticom (20)

In the vicinity of local hospitals, the Georgia Avenue corridor was equipped with the Opticom system as a test of preemption for ambulances. Side street queues were found to be increased at five of six intersections analyzed, but recovery to normal timing was achieved within three cycles. Study of ambulance operating speeds with preemption showed a statistically significant improvement; in nominal terms, improvements of $4 \mathrm{mph}$ during off-peak periods and $1 \mathrm{mph}$ during peak periods were found.

Fairfax, VA Opticom, Strobecom (21)

Six intersections were equipped with light-based preemption units for fire and rescue vehicles as a pilot project; three were equipped with Opticom, while the other three utilized Strobecom. Use of preemption was found to be seamless in both cases, with positive opinions from emergency vehicle operators. Traffic personnel noted that since they have a relatively short peak period, the disruption from preemption might be less significant. 


\section{Deployments / Results / Lessons Learned - Transit Priority}

Charlotte, NC Opticom $(13,22)$

Charlotte equipped express buses along one radial corridor with Opticom; results showed a reduction in average travel time of 4 minutes. Anecdotal evidence indicated less wear and tear on vehicles, lower local emissions, and reduced driver stress. There were no major unacceptable delays found on cross streets.

Portland, OR TOTE \& LoopComm Tests $(9,23)$

Portland tested both TOTE and LoopComm detection systems along with 170 Type controllers with Wapiti IKS firmware. The test provided green extensions and early green for priority vehicles up to 10 seconds during off-peak periods and 20 seconds during peak periods. Priority time was created by reallocating phase time from other phases, thus maintaining coordination. Results were inconclusive, but a general reduction in bus passenger travel time was noted.

Bremerton, WA Opticom $(9,24)$

Bremerton, WA uses Opticom for both emergency vehicle preemption as well as transit priority. Transit priority was able to reduce travel time for buses on 4 different routes by an average of $10 \%$ with more 
benefit on routes with more intersections. Stopped delay per vehicle at 8 intersections was measured to be slight and not statistically significant. Coordination transition logic allowed return to coordination within $30 \mathrm{sec}$ by allowing phases to be skipped. This was achieved by making modifications to the Traconex 390 controllers to allow preemptor to return to first open phase that satisfies the signal coordination criteria. The phase was determined by the status of vehicle/pedestrian calls, phase or pedestrian omits. The firmware was also enhanced to allow low priority calls to time pedestrian / vehicle minimums completely, limit priority service time with a maximum timer, and provide for a one-cycle normal return where transit priority would be disabled. As a result of their experiences, the city desires the ability to set the number of cycles between permitting priority requests, the ability to designate non-skippable phases, and the ability to use alternative splits under priority rather than normal minimums.

Chicago Cermak Road (9)

Chicago tested a loop detector-based detection system and found it to be simple, reliable, and cost-effective, while performing well. Bus run times in the range of 13-17 minutes was reduced by $2-3$ minutes while the impact to traffic was minimal. Improvement in route travel times was significant. Results also indicated that the priority logic in 
coordinated mode only provided priority to $30 \%$ of buses due to the fact that $70 \%$ of buses arrived during the normal phase.

Louisiana Ave, MN Opticom Test (9)

Opticom was tested at a diamond interchange for through traffic signals; different detectors were used for left turn and through lanes. Econolite ASC-8000 ASC/2 controllers were used in the test. Three levels of priority were tested: low, which gave an extended green while remaining in coordination; medium, which gave a longer extended green and staying in coordination; and high, which provided preemption and left coordination. The high priority reduced bus travel time by $38 \%$, while the medium and low priority did not reduce bus travel time. Medium and low priority did not increase auto-stopped time, but high priority increased it by $4.4 \mathrm{sec}(23 \%)$. This was judged to be acceptable, while noting that increases were probably due to data variations. The only comments received from the public were regarding phase skipping, which resulted from the return to coordination after preemption.

Miami Orange Streaker $(9,25)$

Miami tested a bus preemption system and other priority measures in 1973 along $16 \mathrm{~km}$ of an express bus route, the Orange Streaker. In 
the effectiveness in reducing bus delay and travel time, the most effective treatment was found to be bus lanes, followed by preemption, and then progression. Preemption was found to not be as effective as progression in maintaining schedule adherence. Traffic impacts were found to be minimal, and influenced more by signal control parameters (fully actuated vs. coordinated actuated and pretimed vs. coordinated-actuated) than the preemption.

Montgomery County, MD ATMS System, TMC staff human intervention Another type of priority for buses has been implemented, through the use of global positioning system (GPS) tracking from a centralized Advanced Traffic Management System (ATMS). In addition, when transit management center staff encounter problems with a delayed bus due to an incident, they can contact the traffic management staff in the same office to adjust traffic signal timings in an attempt to facilitate the bus getting back on schedule. It should be noted that Montgomery County provides emergency vehicle preemption only for exiting the firehouse driveway, through manual, push-button activation of the local preempt. There are no system or arterial preemption devices. 
Maryland State Highway Administration (Anne Arundel County, MD) (26)

On Ritchie Highway, express buses are given priority using a combination of Opticom as the detection technology and Econolite ASC/ 2 controllers with bus priority logic. The types of priority involved include green extension, queue jump (special bus-only signal display for early green from near-side stop), and left turn phase recall (lagging left arrow if bus detected). Bus travel time reductions of $13-18 \%$ were observed after implementation of the priority system. Travel time for other vehicles was observed to decrease by $9 \%$ in one mainline direction and increase by $4-5 \%$ in the other. Similar priority using only the green extension is also provided in the Southern Maryland area.

Eindhoven, Netherlands (27)

Though much progress has been made in transit priority outside the U.S., the institutional structure and policies are often quite different, such that direct comparison of projects can sometimes be challenging. However, one example is cited here to illustrate a key attribute of a more sophisticated implementation, conditional priority. In the Eindhoven implementation, buses were given priority only if they were running late, in an attempt to provide operational control for buses to 
maintain schedule adherence. Measures considered included vehicle delay, bus delay, and bus schedule deviations. As compared with no priority, the conditional priority had little impact on vehicle delay while improving schedule adherence. Bus delay reductions for conditional priority were found to lie between absolute and no priority.

Works In Progress

In addition, several cities are currently in the process of investigating or deploying transit signal priority and have reported preliminary results. These results have been included in Table 1 , which summarizes reported results from the transit signal priority deployments previously discussed.

Table 1: Summary of Transit Signal Priority Deployment Results

\begin{tabular}{|l|l|l|}
\hline Deployment & Measure & Result \\
\hline \multirow{2}{*}{ (Express Buses) } & & 4 minute decrease \\
\cline { 2 - 3 } & Cross Street Delays & Not unacceptable \\
\hline \multirow{2}{*}{$\begin{array}{l}\text { LoopComm Tests } \\
\text { Bremerton, WA }\end{array}$} & Bus Travel Time & Reduction noted \\
\hline & Bus Travel Time & $10 \%$ decrease \\
\cline { 2 - 3 } & Stopped Delay/vehicle & Insignificant \\
\hline
\end{tabular}




\begin{tabular}{|c|c|c|}
\hline Chicago, IL Cermak & Bus Travel Time & $\begin{array}{l}\text { 2-3 minute decrease } \\
\text { on } 13-17 \text { run }\end{array}$ \\
\hline \multirow[t]{2}{*}{$\begin{array}{l}\text { MN Louisana Ave } \\
\text { Opticom Hi-Priority }\end{array}$} & Bus Travel Time & $38 \%$ decrease \\
\hline & Auto Stopped Delay & $23 \%$ increase \\
\hline \multirow[t]{2}{*}{$\begin{array}{l}\text { MN Louisiana Ave } \\
\text { Opticom Med/Lo- } \\
\text { Priority }\end{array}$} & Bus Travel Time & No change \\
\hline & Auto Stopped Delay & No change \\
\hline \multirow[t]{3}{*}{ MD SHA Anne Arundel } & Bus Travel Time & $13-18 \%$ reduction \\
\hline & $\begin{array}{l}\text { Auto Travel Time - } \\
\text { Same Direction }\end{array}$ & 9\% decrease \\
\hline & $\begin{array}{l}\text { Auto Travel Time - } \\
\text { Opposing Direction }\end{array}$ & $4-5 \%$ increase \\
\hline $\begin{array}{l}\text { Los Angeles, CA Metro } \\
\text { Rapid (attributable } \\
\text { component) (28)* }\end{array}$ & Bus Travel Time & $8-10 \%$ decrease \\
\hline \multirow[t]{3}{*}{$\begin{array}{l}\text { Seattle, WA Rainier } \\
(29)^{*}\end{array}$} & Priority Bus Delay & $34 \%$ decrease \\
\hline & Bus Intersection Stops & $24 \%$ decrease \\
\hline & Bus Travel Time & $8 \%$ decrease \\
\hline
\end{tabular}




\begin{tabular}{|l|l|l|}
\hline $\begin{array}{l}\text { Portland, OR Pilot } \\
\text { Routes (30)* }\end{array}$ & Bus Travel Time & $10 \%$ decrease \\
& & \\
\cline { 2 - 3 } & On Time Performance & $8-10 \%$ improvement \\
\hline
\end{tabular}

* Works currently in progress (initial results)

\section{Transit Priority Evaluation using Simulation}

Beyond the evaluations conducted on field deployments and operational tests, several efforts have been made to evaluate transit signal priority using simulation and other analytic approaches. One of the earliest efforts, by Benevelli et al (31) in 1983, reflected the technology available at the time. The study attempted to weigh the benefits and costs of signal priority with the use of the UTCS-BPS simulation model; in addition to capital and operating costs for the priority equipment, the user costs considered included travel time delay and fuel consumption. While the results indicated that bus priority was not economically justified for the network tested, the authors noted several important factors influencing the results, such as the simplistic signal priority control algorithms in the simulation, which could not return to coordination.

As the state of technology and simulation tools improved, additional efforts were made to evaluate the potential for transit signal priority using simulation. In 1996, Khasnabis et al (32) used the NETSIM simulation model to evaluate a hypothetical bus corridor with 
priority. However, since NETSIM did not provide the capability for signal priority, the researchers visually tracked the buses using the graphical display tool, and determined whether the bus would be granted priority accordingly. The delay output measures from NETSIM were then adjusted for assumed vehicle occupancy and the resulting person-minutes of delay was used as the evaluation measure. The test corridor evaluated indicated a decrease in delay along the main (priority) direction while the cross streets had an increase in delay. Bus travel time with priority decreased by a range of 0.3 to 13.5 percent as compared to the base.

Garrow and Machemehl (33) attempted to use NETSIM simulation to establish what conditions tend to be favorable and unfavorable for transit priority. Unconditional priority was simulated in a similar fashion as Khasnabis et al (32), under various scenarios. Delay on a vehicle basis serves as the primary evaluation measure in this analysis, while selected scenarios also examine bus and auto travel times, and delay weighted by vehicle occupancy. The results from this study suggested that degree of saturation plays a key role in the delay impacts when transit vehicles are given priority.

A more comprehensive evaluation process using simulation was designed by the King County Department of Transportation (34) in order to satisfy the needs of local stakeholders. This process utilized 
limited field tests in addition to simulation in order to provide a more solid foundation of evidence before proceeding with transit signal priority. In both the field tests and simulation, the same set of measures of effectiveness were selected so as to facilitate comparison. The measures selected included: intersection control delay, minor movement delay, minor movement cycle failures, bus travel times, bus schedule reliability, intersection bus delay, average person delay, vehicle emissions, and accidents.

\section{Summary}

In summary, signal priority for transit attempts to improve the quality of service and/or efficiency of transit operation while considering potential detrimental effects on other vehicular traffic. While schedule adherence is a common element of quality of service, it has not often been measured in prior experience. More frequently, the travel time savings for buses, representing another quality of service element as well as efficiency improvement, have been used as the general metric for benefit to transit riders. In terms of technologies, priority and preemption can often use the same subsystem for interactions between the vehicle and the preemption/priority activation mechanism. However, the detection technologies should be considered within a higher-level view of the overall system design (1), 
keeping in mind that priority for transit and preemption for emergency vehicles have quite different objectives. Past deployment experiences with signal priority for transit have generally been positive, with minimal delay for other traffic, and improvements in travel time for transit buses. However, given the varying situations that exist in the deployments, caution should be exercised in generalizing the results. In particular, variables such as the level of saturation, coordination transition algorithms, and priority criteria, are not the same across the various deployments. These considerations play an important role in the implementation of signal priority and the nature of benefits and impacts. 


\subsection{RESEARCH APPROACH}

This chapter will present an evaluation framework and plan that may be used in the assessment of alternative traffic signal priority strategies for bus transit. First, the formulated evaluation framework will be presented. Subsequently, the framework will be used to develop an evaluation plan for use on the Columbia Pike corridor in Arlington, Virginia. This in turn will lead into the next chapter, which will illustrate the use of this plan in conjunction with simulation analyses.

The evaluation framework establishes the appropriate context in which traffic signal priority strategies for transit will be examined. As in the evaluation of Advanced Public Transportation Systems (APTS), and other Intelligent Transportation Systems (ITS) deployments, the framework will be used to test alternatives in order to assess performance. The evaluation framework provides an important foundation for determining whether a project or an individual strategy meets the intended objectives. Without a framework, there is a risk of attempting to justify the worthwhileness of a project without systematic reasoning. Almost all potential projects have some merits to them. However, when considering whether a project should be developed or deployed, the planning process should consider to what 
extent the stated objectives would be met and what negative impacts would be realized, relative to other alternatives.

The framework (see Figure 1) centers around the evaluation plan, which considers objectives of stakeholders and the environment surrounding traffic signal priority in order to isolate positive and negative effects of traffic signal priority under various conditions. In order to reduce the susceptibility of choosing a strategy and determining reasons for its use rather than the opposite, the objectives and environment are considered "given" or "fixed" in the framework. Stakeholders' input may be gathered and analyzed to record the issues, needs, and objectives of traffic signal priority for transit before the consideration of the design or performance of various strategies. Similarly, the local operating environment plays an important role in the suitability of any priority strategy in meeting stakeholder objectives. For example, interoperability requirements at a jurisdictional or regional level can greatly affect which strategies could even be considered. However, it should be noted that this is not the only way of relating issues associated with transit signal priority. For example, TCRP Project A-16 (9) considers transit priority logic, agency operating policy, and the operational scenario all as mutually interconnected components of a priority strategy. 
The various traffic signal priority strategies are an "input" to the evaluation process, while the "output" consists of the performance of each strategy. The central element of the framework, the evaluation plan, specifies how the performance of each strategy in terms of meeting stated objectives in the specific environment would be quantified. After conducting the evaluation, guidelines for application of varying priority strategies can then be established based on performance under varying conditions.

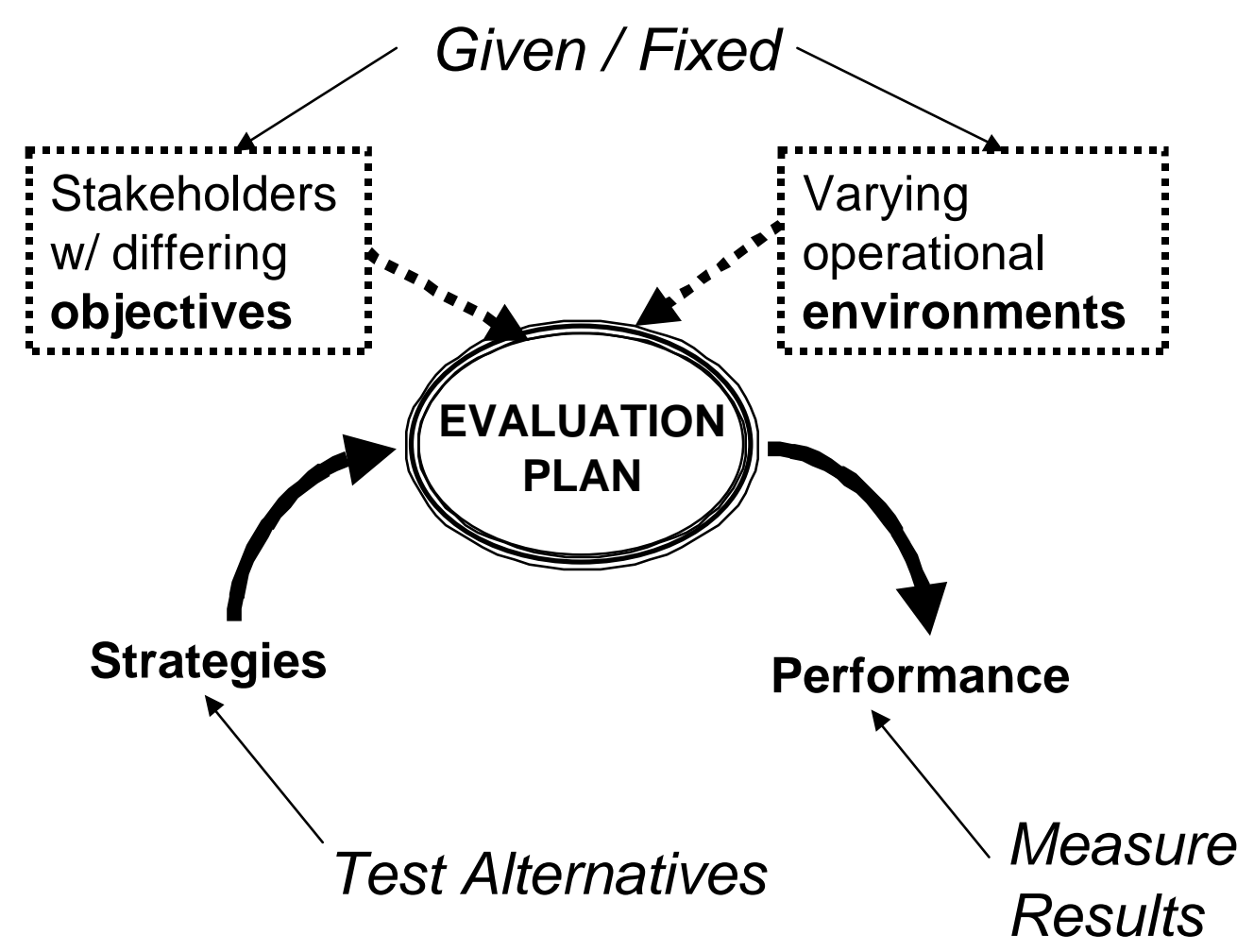

Figure 1: Framework Concept 
In the case of the Columbia Pike corridor, a key objective targeted by stakeholders concerns the improvement of bus schedule adherence without substantial negative impacts on other traffic. While the underlying aim deals with provision of a higher quality of service for transit in the subject corridor, schedule adherence can impact riders in varying ways. Adding consideration of the local operating environment can clarify the specific manner in which the objectives would be achieved.

Columbia Pike is a radial arterial that connects inner suburban neighborhoods with the Pentagon, a major employment center, and freeway access to Washington, DC. Within the study area, a 4-mile segment in Arlington, frequent local bus service and peak limited-stop service is provided by the Metrobus division of the Washington Metropolitan Area Transit Authority (WMATA). Primarily, the services connect various neighborhoods with the Columbia Pike corridor and the Pentagon. Significantly, at the Pentagon, a major intermodal transfer center provides connections to buses and Metrorail rapid transit trains traveling into Washington as well as toward destinations in Northern Virginia.

How do these characteristics affect the objective of improved schedule adherence without substantial adverse impacts on other traffic? For example, bus service in the corridor is very frequent 
during peak periods, with headways in the range of 5 minutes, and less frequent in non-peak periods, typically with 15-minute headways. When headways are below 10 minutes, most riders will choose to arrive randomly at a stop. On the other hand, as headways get longer, riders would tend to attempt to meet a bus at the scheduled time. Hence, the notion of schedule adherence or more generally, service reliability, can have different implications depending on variables such as whether one was considering service in the peak or off-peak period. From this simple distinction, several dimensions of service reliability may be envisioned. The effectiveness of timing of transfers at the Pentagon can reflect the reliability in the arriving service. In the off-peak situation, a traditional attempt may be made to get buses to arrive at the bus stop on schedule, i.e. no earlier than the scheduled time and no later than a certain threshold. During the frequent peak service, schedule adherence may be thought of in the same fashion, or alternatively, a headway-based scheduling approach may be taken. In this case, distinguishing between early and late buses from the passenger perspective may be difficult, making deviations from schedules less relevant. Passengers waiting at a stop might consider the spacing or headway between buses to represent schedule adherence, so that buses arriving at the advertised headway would be considered to adhere to the schedule. Finally, service 
reliability in the peak may be thought of in terms of consistency in travel time. If a rider's travel time is inconsistent from day to day, the service may be considered to have poor reliability, and vice versa. This particular view of service reliability will be examined further in more detail in the illustration of the evaluation plan.

As can been seen, there may be many different dimensions to a single objective. Selection of an appropriate perspective and corresponding measures can be facilitated by a systematic evaluation plan. The following section will further examine the evaluation plan and how it can be tailored to the objectives and environment.

\section{Evaluation Plan}

As discussed previously, the evaluation plan embodies the evaluation objective, in this case the measurement of performance impacts resulting from various traffic signal priority strategies. Appropriate measures of effectiveness, both quantitative and qualitative, can be established for each system objective to be assessed in the evaluation. For example, measurement of service reliability may be accomplished through the use of on-time performance (OTP), which gauges the frequency of differences between actual and scheduled arrivals at timepoints beyond certain thresholds. Another measure of service reliability might be the perceived waiting time by riders at bus stops, 
which may be examined through the riders' subjective opinions of long waits, or perhaps may be related to the actual maximum headway achieved in operation. This research has conceptualized and developed measures of effectiveness corresponding to differing objectives of transit signal priority, as per the methodology defined in the evaluation framework. Table 2 illustrates the measures of effectiveness and the connections to the underlying objectives. Cities desiring to evaluate a transit signal priority deployment can use the framework to establish objectives, the local environmental conditions, and strategies selected. Based on this information, the appropriate evaluation measures can then be selected from Table 2.

Table 2: Evaluation Measures

\begin{tabular}{|c|c|c|}
\hline Objective & Measure & Measurement \\
\hline \multirow[t]{3}{*}{$\begin{array}{l}\text { 1.0 Bus Service } \\
\text { Reliability (transit } \\
\text { schedule } \\
\text { adherence) }\end{array}$} & $\begin{array}{l}\text { 1.1 On Time } \\
\text { Performance (OTP) }\end{array}$ & $\begin{array}{l}\% \text { of arrivals in on-time } \\
\text { window at timepoint(s) }\end{array}$ \\
\hline & 1.2 Time Reliability & $\begin{array}{l}\text { Standard deviation of } \\
\text { elapsed time between } \\
\text { timepoints or endpoints }\end{array}$ \\
\hline & 1.3 Perceived OTP & $\begin{array}{l}\text { Survey measure of rider } \\
\text { opinion }\end{array}$ \\
\hline
\end{tabular}




\begin{tabular}{|c|c|c|}
\hline & 1.4 Spacing & $\begin{array}{l}\text { Maximum headway } \\
\text { measured at timepoint(s) }\end{array}$ \\
\hline & 1.5 Arrival Reliability & $\begin{array}{l}\text { Standard deviation of } \\
\text { delta (actual time vs. } \\
\text { scheduled) at } \\
\text { timepoint(s) }\end{array}$ \\
\hline \multirow[t]{4}{*}{$\begin{array}{l}\text { 2.0 Bus Efficiency } \\
\text { (transit travel } \\
\text { time savings) }\end{array}$} & 2.1 Run Time (RT) & $\begin{array}{l}\text { Elapsed time(mean) } \\
\text { between start and end } \\
\text { points }\end{array}$ \\
\hline & 2.2 95\%-ile RT & $\begin{array}{l}\text { 95\%-ile elapsed time } \\
\text { between start and end } \\
\text { points }\end{array}$ \\
\hline & 2.3 Trip Time & $\begin{array}{l}\text { Weighted passenger time } \\
\text { on board (in-vehicle) }\end{array}$ \\
\hline & $\begin{array}{l}\text { 2.4 Perceived Travel } \\
\text { Time }\end{array}$ & $\begin{array}{l}\text { Survey of change in } \\
\text { riders' opinions before \& } \\
\text { after }\end{array}$ \\
\hline $\begin{array}{l}\text { 3.0 Other Traffic- } \\
\text { Related Impacts }\end{array}$ & 3.1 Overall Delay & $\begin{array}{l}\text { Delay by [corridor or } \\
\text { intersection], [person or } \\
\text { vehicle] }\end{array}$ \\
\hline
\end{tabular}




\begin{tabular}{|l|l|}
\hline 3.2 \# of stops & $\begin{array}{l}\text { Stops by [corridor or } \\
\text { intersection], [person or } \\
\text { vehicle] }\end{array}$ \\
\hline Time & $\begin{array}{l}\text { \%-ile or average } \\
\text { operating speed }\end{array}$ \\
\hline 3.4 Cross Street Delay & Maximum, 95\%-ile, or \\
average delay
\end{tabular}

The plan can also include a design of simulations and field tests to be used in the collection of measures of effectiveness for each alternative strategy to be tested. These simulations and field tests will consider the level of buy-in anticipated, the tradeoffs between precision and level of effort and resources required, and the applicability to dynamic situations, including various operational environments and system objectives. 
Some examples of data collection techniques as well as analysis methods appropriate for the system objective will now be briefly described, but additional detail on the measures selected for the case study will be presented in the discussion of the case.

\subsection{Bus Service Reliability (transit schedule adherence)}

1.1 On Time Performance (\% of arrivals in on-time window at timepoint): This measure is often suitable for a general estimation of service reliability. Many transit agencies have an established definition of "on-time", such as from 0 minutes early to 10 minutes late. This measure can therefore provide consistency with established reporting mechanisms. Data for this measurement may be collected by recording arrival times at selected timepoints and comparing with scheduled times for a predefined sample of buses. A simple ratio representing On Time Performance may then be calculated as the number of buses arriving in the "on-time" window divided by the total number of samples.

1.2 Time Reliability (Standard deviation of elapsed time between timepoints or endpoints): This measure is suitable for the assessment of service reliability of a particular route or route segment. This may be used for the purposes of scheduling, to ensure that sufficient recovery time, the out-of-service time planned at the terminal points, 
is available. If enough recovery time is not planned into the schedule, the ability of a bus to continue service either on a return trip or another route can be negatively impacted. In addition to recovery time considerations, this measure can isolate the routes or segment(s) of routes that have inconsistent running times. These areas may be targeted for alternative improvements ranging from operational control measures such as holding to provision of advanced traveler information systems. This measure may be calculated by gathering the elapsed time between designated timepoints for a sufficient sampling of trips, and calculating the standard deviation of the samples.

\subsection{Perceived OTP (Survey measure of rider opinion): This} measure provides a tool to assess whether riders feel that reliability is a concern, and to what degree it is viewed to be a problem. Since service reliability is never $100 \%$ perfect, it is often desirable to assess whether a given level of reliability, though imperfect, is viewed by riders as adequate or as a key service issue requiring priority attention. Given the limited resources available to a transit agency, prioritizing the efforts to improve service can be important in making the most productive use of resources. Keeping in mind that rider perceptions of "schedule adherence" or "reliable service" can be 
influenced by other factors such as travel time, survey measures can nonetheless provide valuable direction to planners on specific routes requiring attention. Surveys measuring this opinion may ask questions such as "Do you feel that the buses usually arrive on time?" and ask riders to rate their opinion on a range such as (strongly agree, agree, neither agree nor disagree, disagree, strongly disagree). This range may have numeric values assigned and an average may be calculated, or each category may be viewed separately as a proportion of the total.

1.4 Spacing (Maximum headway measured at timepoints): This measure is suitable for measuring service reliability in service with relatively frequent headways. Operational control problems related to bus bunching may cause the apparent headway to be much longer than the scheduled headway. If two buses become bunched, the scheduled headway between them has been lost, and effectively transferred to the bus preceding and following the pair. For a passenger arriving at a stop, the expected waiting time increases accordingly, as the second bus in a pair does not provide any reduction in waiting time over the first bus alone. The maximum headway measured at a timepoint would capture the worst-case waiting time for a passenger arriving at the stop, and may be compared with the 
passenger's expected waiting time based on the schedule, one-half the scheduled headway. This measurement may be collected by noting the arrival times of buses at a given timepoint, and selecting the two arrival times with the longest period of time in between.

1.5 Arrival Reliability (Standard deviation of delta / actual time vs. scheduled at timepoint): This measure is suitable for assessing service reliability at key locations. While this measure is similar to 1.2 Time Reliability, this measure considers the scheduled time specifically. In the case of a trip or service requiring a connection, the variability in the arrival time at the connection point plays an important role in the overall level of service. For a passenger, high variability in the arrival time translates into an untimed transfer, with the passenger facing the corresponding expected waiting time for the second service. In the case of a timed transfer, the expected waiting time (and travel time) for the passenger is lesser, since the services are designed to meet, and can continue after the later service arrives at the transfer point. From the perspective of the transit operator, the ability to create a successful timed transfer, with a minimum of waiting, depends on consistent arrival times. Since each service will wait until the later one arrives, both services will need to consider a longer expected waiting time in their schedules. This measurement 
may be calculated by computing the standard deviation of the "delta", defined here as the difference between the actual arrival time and scheduled arrival time, at the timepoint of interest.

\subsection{Bus Efficiency (transit travel time savings)}

2.1 Run Time (Mean elapsed time between start and end points): This measure is suitable for scheduling purposes, as well as providing information on passenger travel times. The average running time provides the primary information for determining the buses and operating hours required for a given trip and route. If the run time can be reduced, there may be the potential for reducing the operating hours necessary for providing the service. However, since there are other factors, such as maintaining clock-based headways, actual operating savings may or may not occur. Generally, savings of a "bus" are easier to achieve on more frequent, short-headway service. For example, a route with a 10 minute scheduled headway and a 120 minute cycle (complete round trip) time needs 12 buses to operate; if the cycle time could be reduced to 110 minutes, only 11 buses would be required, yielding the cost savings associated with one bus. From the perspective of passengers, run time reductions provide for scheduled and in-vehicle travel time savings which provide benefits depending on the magnitude of savings. 
$2.295 \%$-ile RT $\left(95^{\text {th }}\right.$ percentile elapsed time between start and end points): This measure is similar to 2.1 Run Time, but attempts to integrate some aspects of service reliability. Often, planning decisions are not made based on the average travel time, but on the expected likely maximum travel time. This is based on the need to arrive at a destination on time; if the average travel time were used, one might be late half the time. The use of a percentile ( $95^{\text {th }}$ in this case) allows some flexibility for extreme cases, and the specific percentile may be selected based on the characteristics of the need and the meaningfulness of the measure. In order to calculate this measurement, a sample of travel times between endpoints would be collected and the value corresponding to the $95^{\text {th }}$ percentile would be selected. It is significant to note that this may require a fair number of samples to provide a more precise estimate.

2.3 Trip Time (Weighted passenger time on board / in-vehicle): This measure is suitable for establishing aggregate benefits from travel time savings, if any. By considering the bus occupancy over time, the net benefit to riders in terms of travel time savings over a base case could be computed for a benefit analysis. This measurement can be difficult to calculate, especially in a field test, since the time and number of passengers boarding and alighting needs to be gathered. 
With the use of automatic passenger counters (APCs) or simulation models that include sufficient monitoring of bus operations, this may be possible. In other cases, an approximation may be adequate; for example, the average occupancies may be estimated over certain segments of a route (e.g. between major timepoints) and the segment travel times may be added, weighing each by the corresponding occupancy on the segment.

2.4 Perceived Travel Time (Survey of change in riders' opinions before $\&$ after): This measure can provide an assessment of whether signal priority has created a noticeable difference for riders. In cases where the signal priority system is promoted, there should be caution given to potential biases. However, if riders are not aware of the system, a before and after survey measuring perceived travel time can provide useful information. A potential survey question addressing this measurement might be, "My travel time on this route is good," followed by answers such as (strongly agree, agree, neither agree nor disagree, disagree, strongly disagree). Since there are many factors that play a role in this perception, the results should be considered carefully. 


\subsection{Other Traffic-Related I mpacts}

3.1 Overall Delay (Delay by corridor or intersection, person or vehicle): This measure can provide information on the degree to which other vehicles are being delayed by a signal priority system. On a corridor basis, the delay to vehicles would provide an aggregate basis for potential disbenefits, while an intersection-level analysis would provide information that may suggest certain intersections that should not be included in a priority system or that should be given special consideration. On a person basis, this measurement provides information that can be useful in determining whether the system is benefiting all individuals in the aggregate, considering the higher occupancy of buses. As in the case of Measure 2.3 Trip Time, variable occupancies may be approximated and uses as weighting factors in delay studies or simulation models.

3.2 \# of Stops (Stops by corridor or intersection, person or vehicle): This measure is similar to Measure 3.1 Delay, but considers the number of stops made by vehicles rather than delay experienced. The occupancies of vehicles may again be used to weight the vehicle stops accordingly to get an average representing the average number of stops per individual. 
3.3 Mainline Travel Time (percentile, or average operating speed): This measure provides an assessment of the overall performance of the main (priority) arterial. Since a priority system is likely to create different impacts on the priority corridor versus the cross streets, it can be useful to examine the impacts separately. This measurement can be calculated over a selected segment of the corridor by averaging a sample of travel times and taking the reciprocal to yield average operating speed. A percentile may also be used to examine how the drivers experiencing the (near) worst-case situations are faring.

3.4 Cross Street Delay (Maximum, $95^{\text {th }}$ percentile, or average delay): This measure considers the impacts of a signal priority system on the drivers on the cross streets. Various signal priority strategies may reduce green times on the side streets or even skip the cross street phases. By examining whether and how much the (near) maximum delay experienced on a cross street has increased with priority, the potential for dissatisfied drivers can be assessed. By using an average measure, the overall impacts of the system can be weighted in comparison with benefits and arterial performance. This measurement may be calculated by taking a sample of delays for a cross street (or streets) and examining the maximum, percentile, 
and/or average.

3.5 Fuel Consumption / Emissions (Model output for corridor, average per vehicle): This measure is suitable for assessing environmental impacts from the provision of signal priority. Since priority has the ability to increase and decrease speeds, delay, and stops, there are likely to be changes in fuel consumption and emissions. While bus fuel consumption may potentially be measured in a field test, more precise estimates of impacts depend on simulation models that can aggregate environmental impacts over the corridor.

3.6 Overall System Efficiency (Throughput achieved vehicles per hour, persons per hour): This measure attempts to consider the overall impacts on traffic and person flow. On a network basis, this may be assessed with the use of simulation models, weighting occupancies accordingly if desired. However, one needs to consider the potential for route diversion to impact this measure if delay changes are significant.

3.7 Intersection Safety (Red light running, accident frequency): This measure attempts to gauge some of the safety impacts of implementing priority. With potential increases in cross street delay, 
there may be an increase in frustration of drivers forced to wait longer at red lights. This may translate into an increase in the number of drivers who run red lights. Since accident frequencies are generally low, it may be difficult to assess the safety impacts using accidents, but red light running and other driver behaviors may be related to the potential for accidents. Simulation models would provide only limited assistance in this measure (e.g. vehicles do not run red lights in simulations); before-and-after field studies would likely provide a better basis for measurements.

As an example, if local stakeholders desire to implement traffic signal priority for transit for the purpose of decreasing bus "bunching" on a service with short headways, Measure 1.4, Spacing, would be an appropriate measure since bunching tends to enlarge the gap between bus "bunches" arriving at a given location. The corresponding measurement in this case would be the maximum headway between buses, measured at key points. In a simulation or field test, the bus arrival times at the key timepoints would be noted and the maximum headway in the analysis period would be computed. After gathering sufficient samples with the priority strategy active and inactive for the desired statistical confidence intervals, a comparison may then be 
made to determine whether the priority strategy was associated with any improvement.

\section{Application to Service Reliability (Theory \& Hypotheses)}

Building upon the previous discussions of service reliability, the framework and plan are applied in this research to the evaluation of bus service reliability impacts resulting from various traffic signal priority strategies. A theory is posited which establishes bus transit reliability as a function of four major factors; this theory attempts to apply the insights of Markowitz (35) in Modern Portfolio Theory to analysis and optimization of transit reliability. Furthermore, the composition of running times are in part developed from analyses on running times and reliability, while attempting to incorporate claims and results from traffic signal priority studies and deployments. The first factor concerns dwell time associated with the bus' need to service passengers stops, and includes passenger demand and stop locations, vehicle characteristics, and the boarding / alighting process. The second factor pertains to signal delay, which is affected by signal locations, signal operations and signal timing plans. Congestion and traffic-related delay make up the third factor, and is dependent on traffic volumes, road capacity / characteristics, weather, and bus 
dynamics. Finally, the fourth factor considers the "controllable" measures, such as the bus schedule / assigned slack time, timepoints / driver actions, and the priority criteria / strategy. By adjusting the fourth factor, a specific priority strategy attempts to impact the other factors in a way such that the overall running time is favorably affected. Signal priority for transit targets most directly the reduction of the second factor, though due to the interrelationships between factors, the other factors can also be influenced.

\section{Columbia Pike Model}

The evaluation plan will be applied using field and simulation data from the Columbia Pike corridor (See Appendix B for map). This research builds upon prior work by Dion et al (36) and Zhang (37), including the substantial effort that had been expended in the construction of the base simulation network. While a summary is provided here, additional detail may be found in those references. This base network was constructed in the INTEGRATION simulation package, which provides strength in modeling of individual vehicles on a second by second basis, as well as a signal priority feature that is selectable by vehicle class and intersection. Since the operation of priority depends on the location and travel of the buses, precise location and tracking is necessary for analysis. INTEGRATION was used in conjunction with the QueensOD model, which provided the 
means to calibrate the INTEGRATION model. INTEGRATION uses a zonal origin-destination matrix; QueensOD utilized the observed data from field traffic counts at intersections and traffic detectors to provide INTEGRATION with the required zonal flows. The geometric data, fixed signal timings, and bus stop locations were provided by the Arlington County Department of Public Works, while speed data was collected using a GPS-equipped vehicle. While the corridor currently uses the SCOOT signal system, the fixed timings provided were recently optimized plans intended for backup operations. Given the particular conditional priority strategy developed and tested in this research, it was necessary to use the simple fixed timing plans as they provided repeatability over multiple runs, whereas SCOOT may alter the timings in successive runs. Transit data was based on a combination of published schedules and field data collection of occupancy, travel time, and dwell times. It is important to note that INTEGRATION provides limited modeling capabilities for transit operations, and therefore, simplifying assumptions, such as buses servicing each stop with a uniform dwell time, were necessary.

The corridor itself includes numerous cross streets, of which 21 are signalized. As mentioned previously, bus service is frequent with one mainline trunk route and a few crossing or overlapping routes; this research will focus on the performance of the mainline trunk 
route, Route 16 , at a corridor level. There was an ongoing effort to gather base data so that it could be used for both the simulation and field data portion of the evaluation data. Such base data included traffic related information such as speed, delay, and stops, as well as transit information such as travel time composition (composed of the four factor variables: dwell, signal delay, traffic delay, and control measures) and occupancy. After signal priority is deployed in the corridor, it is anticipated that "after" data collection will occur in a similar fashion. Statistical analyses, in the form of paired two-sample t-tests for means, will attempt to determine whether priority control measures are related to reliability. Since 30 sample runs will be conducted, the central limit theorem suggests that the averages will approximate a normal distribution. The priority strategy to be examined will be limited to extended green and early green phases, with the thresholds and conditions for activation that exist in INTEGRATION (see Appendix D).

In the illustration of the evaluation plan, a specific situation will be examined, namely the AM peak period for buses traveling eastbound on Columbia Pike. The measures of effectiveness to be used were selected from Table 2, and were chosen to represent passengers who board eastbound buses destined for the Pentagon as either a final destination or transfer point. Given that many of the 
trips are work trips, the bus service reliability measure was selected to be arrival reliability, since workers are generally trying to arrive to work on time, usually the same time each day. With the large number of people transferring at the Pentagon bus/rail station, the significance of arrival time is magnified, since missing a transfer often translates into the addition of a relatively long wait time for the next bus, or to a lesser extent, the next train. In general, these passengers would be able to adjust to somewhat longer or shorter travel times, as long as they are consistent. However, to the extent to which travel times vary greatly, passengers are likely to add additional planned travel time by leaving early enough to arrive on-time most of the time. In terms of bus efficiency, the measure to be used is the averaged Run Time, noting that while the $95^{\text {th }}$ percentile Run Time would yield an enhanced estimate of planned travel time, one measure of reliability is already being considered and also, a good estimate of the $95^{\text {th }}$ percentile may require many samples. Finally, the impact on other traffic will be evaluated based on impacts on overall delay in the corridor, both on a person and vehicle basis. Since stakeholders are cautious so as not to create substantial adverse impacts on other traffic, measurements of change in average delay are important to examine. 
The selection of these measures under the given conditions on the Columbia Pike corridor give rise to the following hypotheses which were examined, using INTEGRATION:

Hypothesis \# 1. The provision of priority to eastbound buses that are late will be associated with higher bus service reliability.

Hypothesis \# 2. The provision of priority to eastbound buses that are late will be associated with higher bus efficiency.

Hypothesis \# 3. The provision of priority to eastbound buses that are late will be associated with other traffic-related impacts such as increased overall delay. 


\subsection{RESULTS}

As previously stated, the application of the evaluation framework and plan will be illustrated through its use in evaluating potential transit signal priority applications on Columbia Pike. This chapter describes the results achieved in the assessment of a scenario of a "catch up" priority strategy for eastbound buses in the AM peak period, using the INTEGRATION simulation tool. In the "catch up" priority strategy, a single checkpoint is used to establish whether a particular bus is behind schedule by more than a certain threshold. If so, the bus is given priority for the remaining portion of the corridor, in order to "catch up" to its schedule. Since INTEGRATION does not currently have direct support for real-time conditional priority, this "catch up" strategy was selected as a compromise that provides conditional priority yet entails a reasonable level of complexity in implementation. At the same time, the strategy has a practical basis in operations by attempting to address the problem of late-running buses through the use of conditional priority.

The checkpoint selected for this analysis is the intersection of Columbia Pike and George Mason Drive. This location was chosen primarily to balance the data requirements for the simulation. The 
longer the length of the test segment, the more distinguishable the priority results should be. However, as the checkpoint is placed farther upstream, fewer buses will traverse the segment, due to the branching of interlined routes off of Columbia Pike. This leads to a reduction in the number of data samples. From a practical standpoint, some limitation on the extent of priority deployment is likely given cost considerations; as such, the segments that are more frequently traversed by buses would probably be deployed prior to other segments. The endpoint of the segment was selected based on the availability of a scheduled timepoint near the end of the corridor. The timepoint at Columbia Pike at the Navy Annex was chosen. Overall, this segment covers 2.3 miles of the 4-mile test corridor.

The threshold for determining whether a bus is sufficiently behind schedule to warrant the "catch up" priority was estimated based on the priority logic in the INTEGRATION simulation model and the characteristics of the priority segment. However, such as strategy should not make the bus get ahead of schedule as a result of receiving priority treatment. Therefore, the threshold is set to a value approximating the total maximum additional green time for a bus receiving priority. In this way, a bus would need to be sufficiently behind schedule at the threshold so as not to arrive at the destination 
early even if receiving the maximum benefit from priority. The priority logic provides for a green extension or early green recall up to a maximum green time constrained by amber time ( 3 seconds/phase) and a 5 second minimum green time per phase. Based on the phase splits on the 10 signals on the segment, a total maximum additional green time of 221 seconds could theoretically be achieved by a bus arriving at precise times (see Table 3). However, the probability of this occurring is extremely small; a more balanced estimated maximum benefit was assigned two-thirds of this value, rounded to a value of 150 seconds. This value was used as the threshold for priority, so buses which arrive more than 150 seconds later than the scheduled time at Columbia Pike and George Mason Drive are given priority for the remainder of the corridor.

Table 3: Maximum Additional Green Times by Intersection

\begin{tabular}{|l|c|c|}
\hline Cross Street & $\begin{array}{c}\text { Cross Street Green } \\
\text { Split (s) }\end{array}$ & $\begin{array}{c}\text { Max extension / } \\
\text { truncation (s) }\end{array}$ \\
\hline George Mason & 39 & 31 \\
\hline Quincy & 25 & 17 \\
\hline Monroe & 25 & 17 \\
\hline Glebe & 45 & 37 \\
\hline Highland & 23 & 15 \\
\hline Walter Reed & 32 & 24 \\
\hline Barton & 27 & 19 \\
\hline Wayne & 25 & 17 \\
\hline Courthouse & 35 & 27 \\
\hline Quinn & 25 & 17 \\
\hline Sum of Maximum & & 221 \\
Additional Green Time & & \\
\hline
\end{tabular}




\section{Simulation Process}

The simulation process used in this research builds upon prior work by Dion, Rakha and Zhang (36). Their INTEGRATION model network of the Columbia Pike corridor was used as a base network upon which testing was conducted. Since INTEGRATION currently does not provide real-time priority, a method was developed for using the existing class-based priority mechanism. Due to limitations in the vehicle classes available, cross street buses were recoded as local buses so that an additional vehicle class would be available for priority buses. This "priority class" was configured as eligible for priority on signals from George Mason Dr. to the Navy Annex. In order to activate priority for a particular bus, the bus would be reclassified into the "priority class" vehicle type prior to the run. However, in order to determine which buses were eligible for priority based on the lateness threshold, it was necessary to first run the simulation without priority and analyze the bus operations. The arrival times of buses at George Mason Dr. were compared with the scheduled times, yielding the lateness to be compared with the threshold. Hence, each simulation run needed to be run at least twice for each random number seed.

Postprocessing of the output from the simulation was conducted external to INTEGRATION, using the Microsoft Excel spreadsheet 
package. INTEGRATION can provide time and other information when designated vehicles complete an individual network link. This data was imported into Excel and filtered to find the eastbound buses of interest. Then, the simulation times for each bus were extracted for George Mason Dr. and Navy Annex. These times were compared with the scheduled timepoints at these locations, and by subtraction, the arrival time "delta" (representing lateness) was calculated. In the non-priority (first) run, the lateness at the threshold location (George Mason Dr.) was used to determine which buses would receive priority. In addition, the endpoint lateness was also captured in order to provide a basis for comparison with the priority case. After recoding the input files to reflect the priority buses, by reclassifying the vehicle class to the priority class, the simulation process was repeated. In this priority (second) case, the calculation of arrival time delta was made at the endpoint (Navy Annex). By computing the standard deviation of these lateness values, the selected measure of bus service reliability was generated. In order to capture run time for use in measuring bus efficiency, the same simulation times at George Mason Dr. and Navy Annex were used, with the difference representing the run time between the endpoints. Finally, the simulation summary file with aggregate traffic measures including delay was saved and postprocessed to extract overall delay by vehicle class. 


\section{Relationship with hypotheses}

The application of the "catch up" priority strategy attempts to illustrate the presence of a relationship between the priority condition, being behind schedule by at least a certain amount, and bus service reliability. In particular, this analysis attempts to establish a relationship between the priority strategy and the signal delay experienced by buses. By selecting buses for priority treatment using the lateness criteria, overall bus service reliability may be increased, as the first hypothesis states. In addition, by reducing the signal delay, the bus efficiency would also be increased, as stated in the second hypothesis. Finally, the third hypothesis suggests that the priority given will have other traffic-related impacts due to the changes in signal timing resulting from priority.

\section{Bus Service Reliability - Arrival Reliability}

Based upon the capabilities of INTEGRATION and the priority strategy being tested, the measure selected for bus service reliability is arrival reliability (Measure 1.5 from Table 2). In the test scenario, buses begin at varying origin points since there are several interlined routes. Arrival reliability may be quantified by the standard deviation of the 
arrival time delta or lateness (the difference between actual and scheduled arrival time) at the endpoint, Columbia Pike at the Navy Annex. If buses arrive very close to the scheduled arrival time, the standard deviation would be low, and arrival reliability would be high. Conversely, if buses arrive much earlier and later than the scheduled time, arrival reliability would be low. However, further clarification of an exception to this statement is warranted. If buses arrive consistently late or early by a certain amount, the arrival reliability could be high, even if the degree of earliness or lateness is significant. The reasoning in this case is that the service may be reliable, but the schedule may not reflect arrival times accurately.

\section{I ndividual Trip Level Analysis}

By applying the measure of arrival reliability at the trip level, individual scheduled runs may be analyzed to examine the impact of priority on a specific trip, and hence, the riders who regularly ride that trip. The run time from George Mason Dr. to the Navy Annex was examined for a particular scheduled trip, scheduled to depart at 1350 seconds into the simulation (see Appendix F). Based on 30 runs, the arrival reliability of this trip, measured by the standard deviation of the "delta" at the Navy Annex, was 340.8 seconds in the base case, and

325.7 seconds with priority active, representing a $4 \%$ decrease. This 
increase in arrival reliability was found to be statistically significant using the paired two-sample t test for means with a $p$ value of 0.039 (see Appendix G).

\section{Analysis of Reliability over a Period of Time}

Schedule reliability may be examined across the peak period, rather than looking at individual scheduled runs. By using the measure of arrival reliability, quantified by the standard deviation of the difference between arrival time and scheduled time, one can get a picture of the bus service reliability over a time period. As the standard deviation decreases, the arrival time becomes more consistent. Though there

may be an offset versus a printed schedule, this may be remedied in a consistent service by adjusting the timetable, or otherwise regular riders would become accustomed to the offset. Ideally, the offset, represented by the mean deviation from schedule, would approach zero as the standard deviation narrows, but may be a tradeoff in preventing buses from getting ahead of schedule.

\section{Bus Service Reliability - Hypothesis \# 1}

In the case of the test segment on Columbia Pike from George Mason Drive to Navy Annex, the arrival reliability (Measure 1.5 from Table 2) represented by the standard deviation of arrival time "delta", or difference between actual and scheduled time, was calculated at Navy 
Annex for eastbound buses. The resulting values for the 30 pairs of simulation runs without and with priority are shown in Figure 2 . In 23 of the 30 cases, the provision of priority resulted in a lower standard deviation, representing greater bus service reliability. Overall there was an average decrease of $3.2 \%$ in the standard deviation of arrival time delta, from 209 to 202.4 seconds. Using the paired two-sample t test for means, this difference was found to be statistically significant with a $p$ value of 0.003 . This indicates that the arrival reliability is higher with conditional priority than with no priority, affirming Hypothesis \#1, which states that the provision of priority will be associated with higher bus service reliability. 


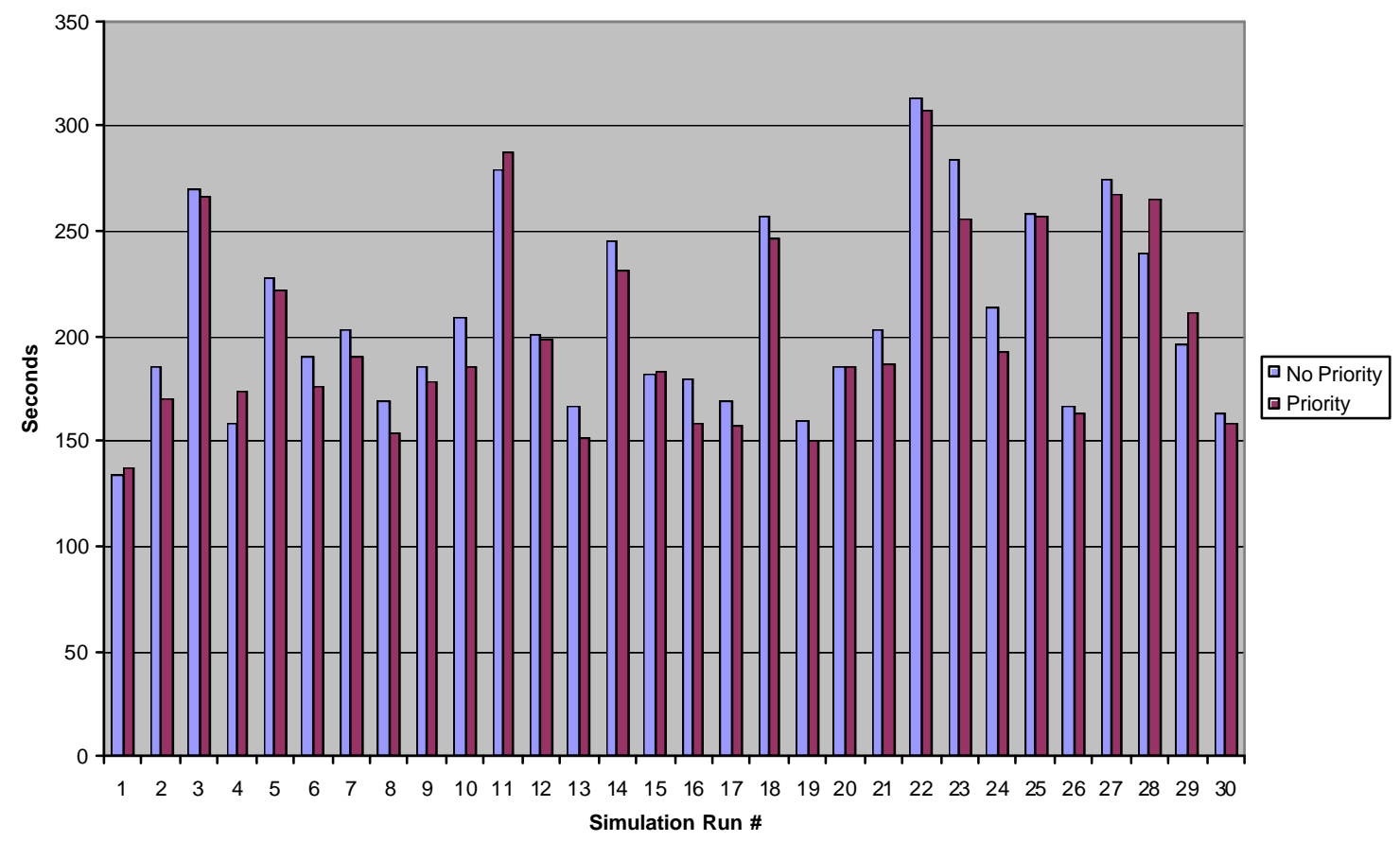

Figure 2: Standard Deviation of “Delta" Time at Navy Annex

Aggregating the data from the 30 runs depicted in Figure 2, the effect of priority on arrival reliability (Measure 1.5 from Table 2) can also be visualized in a smoothed frequency chart of arrival time delta, as shown in Figure 3. The arrival reliability relates graphically to the "narrowness" and height of the curve, which corresponds to the same measure used previously, the standard deviation of arrival time delta. I deally, the curve would be represented by an impulse function, located at the exact scheduled time, i.e. 0 minutes behind schedule. In reality, the most desirable distributions have a steep cutoff at 0 minutes, meaning few early buses, a tall peak immediately after, representing arrivals on time and immediately after, and again a steep 
cutoff downward near as possible to the 0 point, representing few buses that are significantly behind schedule. Improved arrival reliability would result in a lower standard deviation of arrival time delta, and a narrower and taller, and hence more desirable, frequency distribution chart. The "catch up" priority treatment for late buses appears to narrow the distribution of arrival time delta by a small amount, consistent with the prior results in terms of standard deviation.

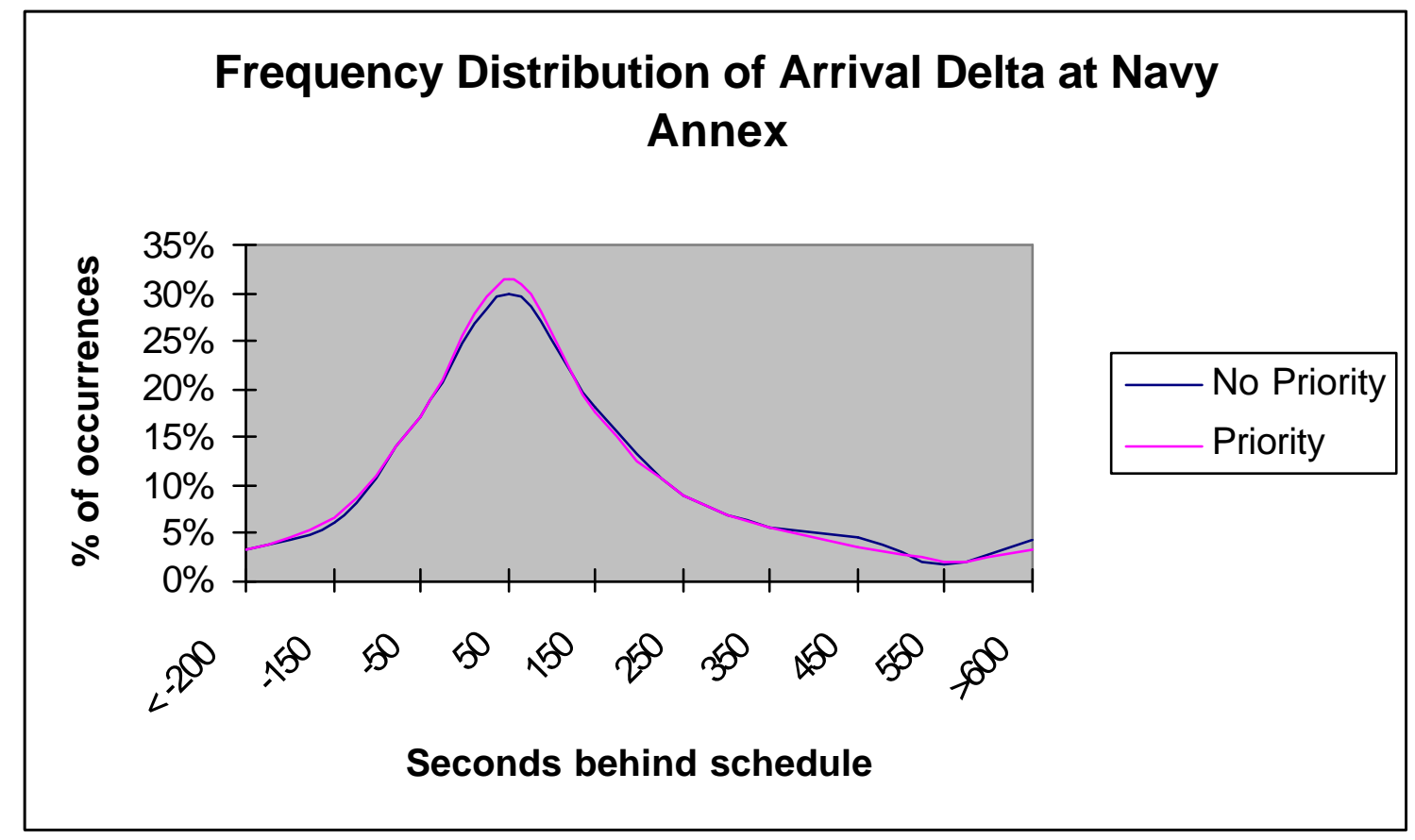

Figure 3: Alternative Visualization of Arrival Reliability 


\section{A Comparison with Autos (Time Reliability)}

As a reference for comparison of variability in travel times, a sampling of probe vehicles, consisting of normal autos, was specified for the 30 base simulation runs in INTEGRATION. The arrival times for these vehicles were captured at the two timepoints at George Mason Dr. and the Navy Annex, just as bus arrival times were captured. However, since autos do not have a schedule, Time Reliability (Measure 1.2 from Table 2) was used for analysis. Travel times were calculated based on these arrival times, and the standard deviations of these travel times for each run were computed. Averaging the data for 30 runs (see Appendix F), the average standard deviation for a run was found to be 41.9 seconds. Comparing to the corresponding value for buses in the base case (see Appendix F), 157.7 seconds, the results indicate substantially less variability in travel time for autos as compared to buses. This is consistent with the prior discussion of the four factors impacting bus reliability. Autos and buses would generally have similar exposure to the factors of signal delay (in the base case) and traffic-related delay. However, buses are exposed to the significant factor of dwell time, which is likely to be highly variable due to passenger demand and loading variations. For example, a limited 
sample of field data from Columbia Pike indicated a coefficient of variation for dwell times of 0.7 (36).

\section{Bus Efficiency - Average Run Time}

In terms of bus efficiency from an operational perspective, the $95^{\text {th }}$ percentile running time (Measure 2.2 from Table 2) can provide a good indication of potential performance in terms of bus schedules. If a particular run may be completed in a shorter time on a consistent basis, there exists the potential for operational savings. However, one reliability measure is already being considered; also, in order to get a good estimate of the $95^{\text {th }}$ percentile running time, it is desirable to complete a large number of simulation runs since each run only provides one observation for any particular bus trip, and the potential for a fewer number of samples to skew the result is substantial.

\section{Bus Efficiency - Hypothesis \#2}

Meanwhile, the average running time (Measure 2.1 from Table 2 ), can be used for scheduling by considering it along with applicable recovery/layover time. For passengers, changes in mean running time without priority and with priority, should provide evidence of potential direct travel time benefits. Figure 4 shows the average bus run times for the test segment for the 30 simulation run pairs. In 20 of the 30 cases, the average run time was lower in the case with priority. 
Overall, a $0.9 \%$ decrease in travel times was observed on average over the segment when "catch up" priority was granted, from 552.6 to 547.8 seconds. Using the paired two-sample t test for means, this difference was found to be statistically significant with a $\mathrm{p}$ value of 0.015. This indicates that the average bus run time is lower with conditional priority than with no priority, affirming Hypothesis \#2, which states that the provision of priority will be associated with higher bus efficiency.

Average Bus Run Time (G. Mason Dr. - Navy Annex)

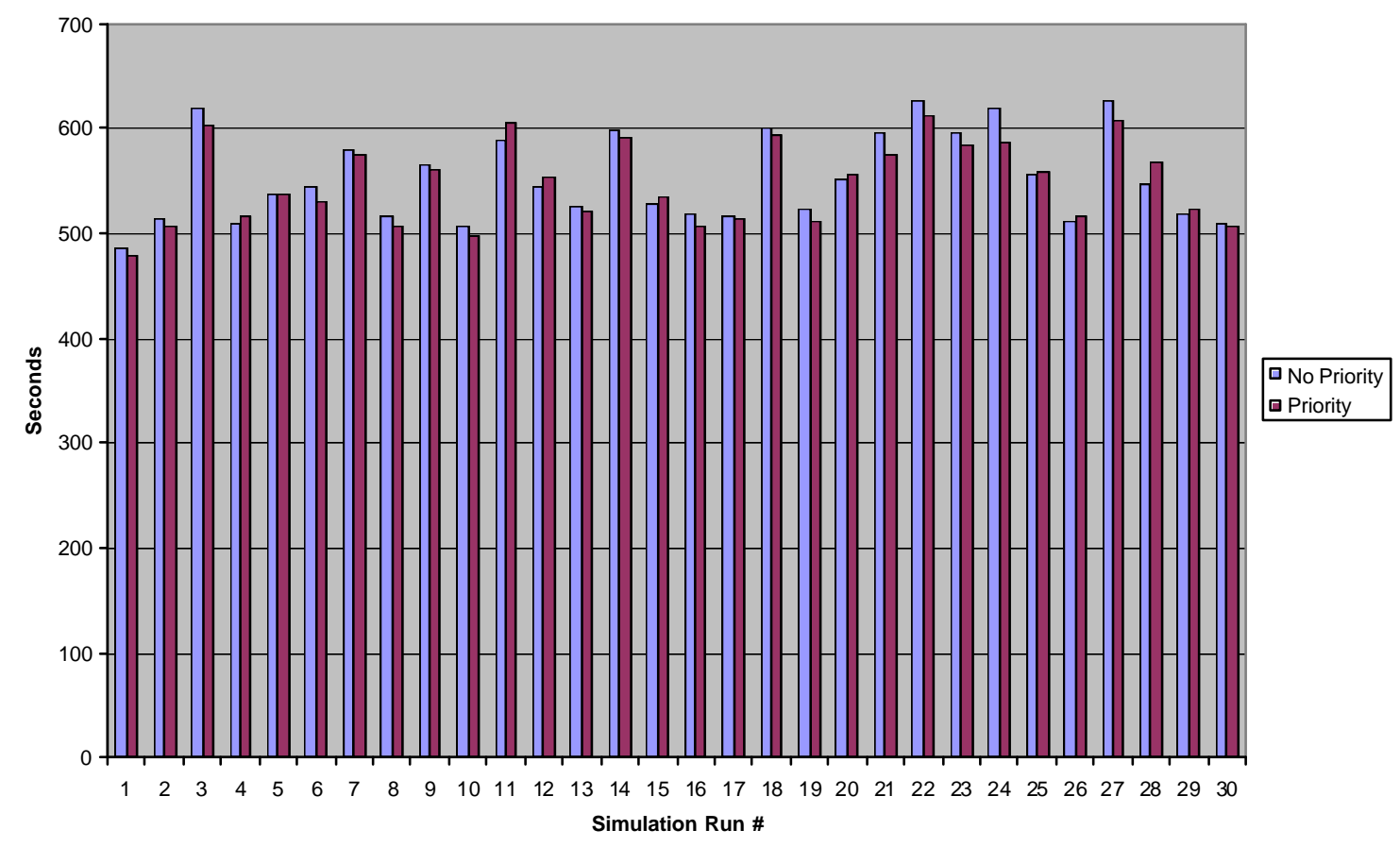

Figure 4: Average Bus Run Times 


\section{Other Traffic-Related I mpacts - Overall Delay (person, vehicle)}

Other traffic-related impacts resulting from the use of transit signal priority play a critical role in the evaluation process. Some important stakeholder groups tend to be more cognizant of potential negative impacts on the general motoring public than potential benefits to transit users and operators. The ability to quantify these potential impacts using simulation is a key part of the evaluation plan.

\section{Other Traffic-Related I mpacts - Hypothesis \# 3}

The INTEGRATION simulation model contains built-in measurement tools to assess changes in delay, emissions, and other similar impacts. In this case of evaluating transit signal priority, two measures relating to Overall Delay (Measure 3.1 from Table 2) were selected to reflect the other traffic-related impacts. Overall vehicle delay on the corridor captures the aggregate delays experienced by all vehicles. Given the same underlying conditions, the simulation runs without and with priority may be compared to estimate average changes in delay per vehicle. Figure 5 shows the results from the 30 simulation run pairs. In 21 of the 30 cases, the average delay per vehicle was higher when priority was given. Overall, there is an average increase in vehicle delay of $1.0 \%$ with priority, from 86.5 seconds to 87.4 seconds per vehicle. Using the paired two-sample t 
test for means, this difference was found to be statistically significant with a $p$ value of 0.003 . This indicates that the overall delay on a vehicle basis is higher with conditional priority than with no priority, affirming Hypothesis \#3, which states that the provision of priority will be associated with other traffic-related impacts such as increased overall delay.

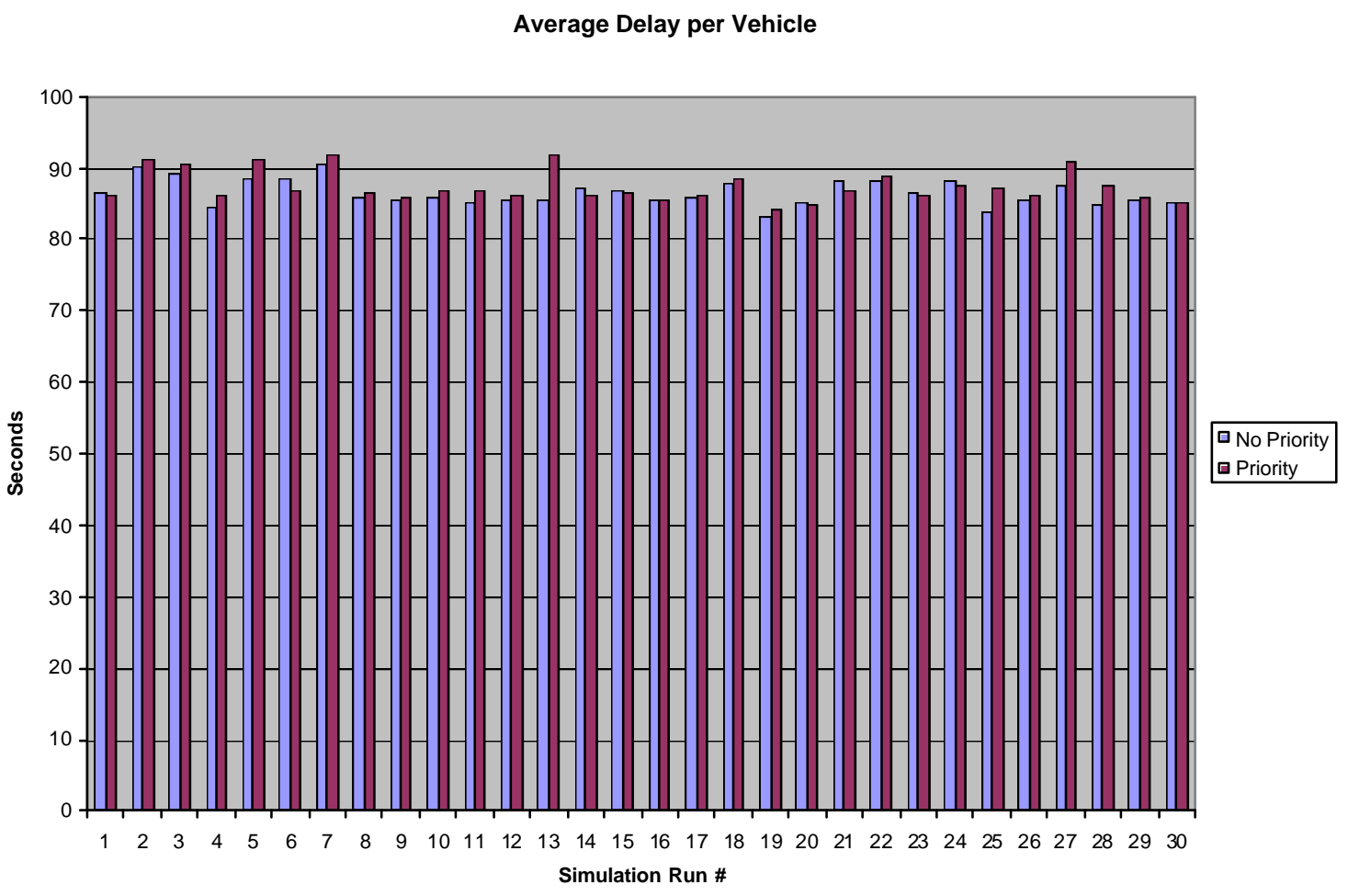

Figure 5: Average Vehicle Delays

Another way to analyze the impacts that transit signal priority has on other traffic is to examine the average change in delay experienced by each individual person traveling in the corridor. Since buses typically carry a much higher passenger load than other vehicles, the delay 
impact on buses is magnified relative to other vehicles. Based on field data, the average occupancy for buses was assigned a value of 23 passengers, while other traffic was given an average occupancy of 1.1. Figure 6 shows the results after weighting the delay amounts by number of passengers. Overall, the net average increase in person delay over the corridor is $0.6 \%$ when priority is granted, from 104.4 to 105.1 seconds per person. Using the paired two-sample t test for means, this difference was found to be statistically significant with a $p$ value of 0.021 . This indicates that the overall delay on a person basis is higher with conditional priority than with no priority, affirming Hypothesis \#3, which states that the provision of priority will be associated with other traffic-related impacts such as increased overall delay. 


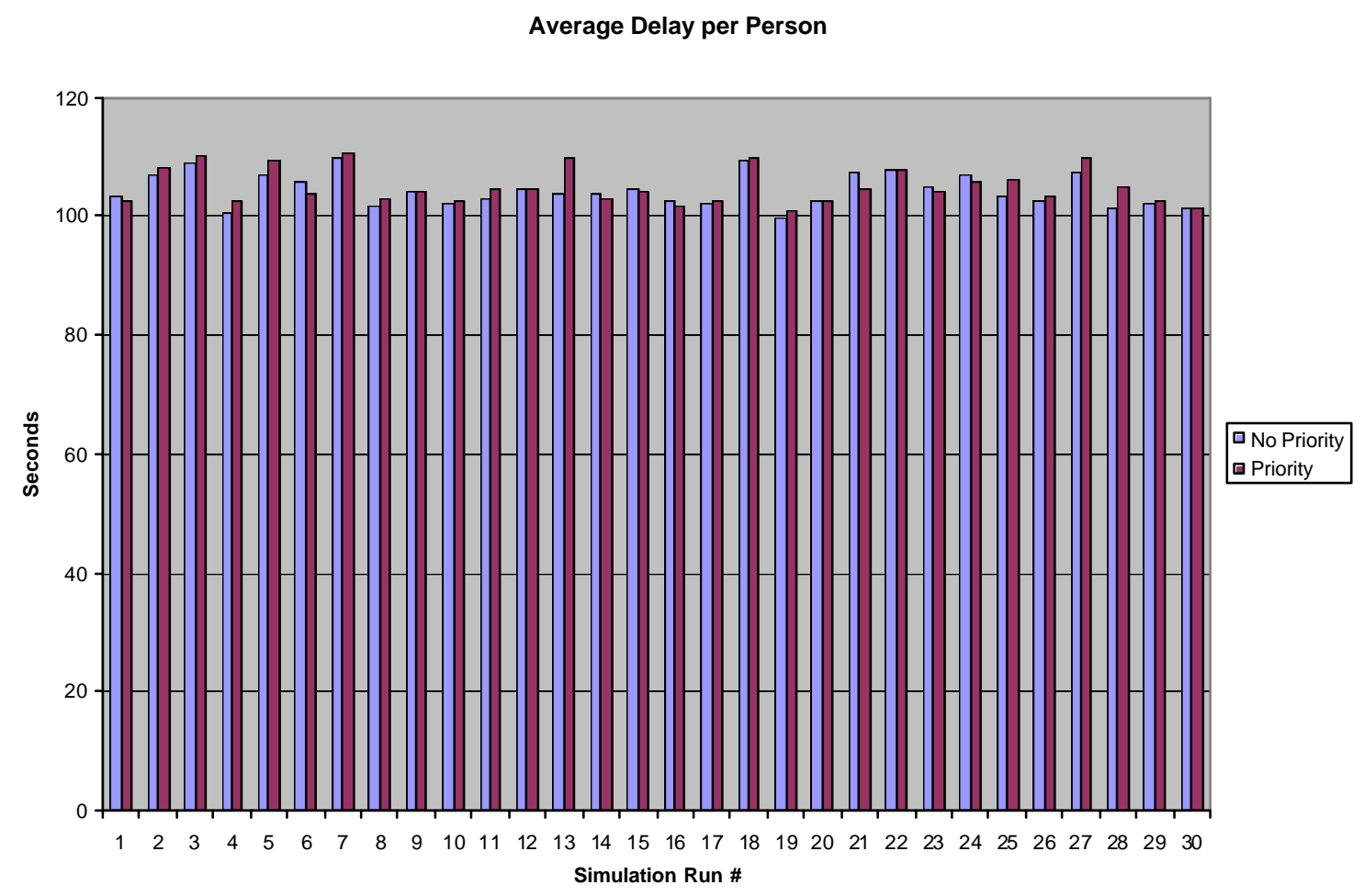

Figure 6: Average Person Delay 


\subsection{SUMMARY / CONCLUSI ONS / RECOMMENDATI ONS}

\section{Summary}

This research resulted in the development of an evaluation framework and plan that assesses the impacts of signal priority strategies for transit buses. Three major categories of impacts were considered:

- Effects on Bus Service Reliability

- Effects on Bus Efficiency

- Other Traffic-Related Impacts

Within these categories, a variety of indicators were proposed, each measuring a different aspect of impact. Depending on the particular environment and objectives, the most appropriate measures of effectiveness could be chosen from the proposed measures.

The application of the framework and plan was illustrated through its application on the Columbia Pike corridor in Arlington, Virginia, using the INTEGRATION simulation package. A specific strategy was considered in this analysis, namely a "catch up" provision for eastbound buses in the AM peak period. This provision had the intended goal of lessening the lateness of buses at the destination by offering conditional priority to buses that were late at a certain checkpoint. The priority status was continued for late buses until the 
end of the corridor. The priority given to buses consisted of extending the green indication on the main street (Columbia Pike) up to a certain limit, or providing an early green indication, again up to a limit.

The INTEGRATION simulation software was used to model the movement of vehicles and provide priority through an external computer-assisted conditional priority method developed in this research. The method involves using the simulation to determine which buses would be late at the checkpoint, and assigning the late buses to a different vehicle class which would be then be given priority in a new simulation run. Results were tabulated and analyzed with the use of the Microsoft Excel spreadsheet package.

\section{Conclusions}

Under the given conditions, the results indicated a statistically significant change in each of the selected impact measures when conditional priority was granted to the eastbound AM peak buses:

- A 3.2\% improvement the bus service reliability, as measured by arrival reliability in the form of standard deviation of arrival time delta was found.

- In terms of bus efficiency, a $0.9 \%$ decrease in run time, also statistically significant, was observed when transit buses were given conditional priority. 
- An average $1.0 \%$ increase in vehicle delay, or a $0.6 \%$ increase in terms of person delay, was found for all vehicles and persons traveling on the corridor.

These impacts are consistent with prior expectations as well as results from transit signal priority field deployments (see Table 1), keeping in mind that only buses late by more than 150 seconds were given priority. In this situation, transit signal priority granted on a conditional basis is associated with improvements in bus service reliability and bus efficiency. Since the late buses should have a reduced travel time as a result of priority, they should arrive at the endpoint closer to the scheduled time. The provision of extended green and early green to priority buses also tends to reduce travel time for those buses and therefore the average for all buses. While the absolute magnitude of the travel time savings $(0.9 \%)$ is small, it is important to note that the primary objective of the "catch-up" strategy is not to make transit travel time faster, but more reliable. At the same time, when conditional priority is granted, an increase in delay to other travelers is found, though the average magnitude is small. Since the signal timing plan attempts to optimize the efficiency of overall vehicular traffic, changes to the signal timings resulting from priority would tend to move the timings away from the optimal state, thereby increasing vehicle delay. Given the higher occupancy of the buses that 
benefit from priority, the observed lesser impact on person delay is expected.

\section{Significance of Research}

This research has contributed to the body of knowledge relating to transit signal priority evaluation. There are often conflicting goals and objectives from multiple stakeholders when transit signal priority strategies are being considered. The framework presented here provides a basis for stakeholders to use objective measures and data to evaluate various proposed signal priority strategies. Depending on the local issues, concerns, and needs, the appropriate level of importance can be assigned to the selected evaluation criteria. Agencies evaluating deployments or planning evaluations of traffic signal priority for transit can utilize the evaluation framework and plan, selecting measures that are suitable for the particular situation.

This research has also built upon the analysis of Dion, Rakha, and Zhang (36), which examined the use of unconditional priority on the Columbia Pike corridor. Buses in selected classifications (e.g. local buses, express buses, cross street buses, and combinations) were given priority at all intersections without regard to lateness, occupancy, or other bus dependent factors; however, the priority functionality in INTEGRATION contains internal conditions such as 
minimum green times and a limit of one activation per cycle. On the same corridor during the same time period, but with unconditional priority for regular buses along Columbia Pike, the prior study found a $6 \%$ decrease in travel time for buses, an $8 \%$ increase in overall person-delay. A comparison with the results of this research must be considered carefully given the substantially different degree of priority; however, the results indicate that a "lesser" (i.e., conditional) priority strategy yielded a smaller decrease in bus travel time, and a smaller increase in overall person-delay.

The technique developed in this research to institute conditional priority using a computer-assisted technique external to INTEGRATION may be extended to examine other cases along the "spectrum" between no priority and full unconditional priority in order to gain a better understanding of the relationship. The small nominal impacts found in this research suggest that the priority strategy selected, "catch-up", under the given conditions, falls close to the no priority part of the spectrum. Nevertheless, using the INTEGRATION simulation package, research demonstrated the ability to show measurable and statistically significant impacts, lending support to the evaluation framework and plan. These impacts were found to be comparable and consistent with prior results from other research. In addition, the impact on service reliability was shown to be greatest of 
the impacts measured, results in line with the primary objective of the strategy.

\section{Recommendations for Future Research}

While this research has developed a foundation for the evaluation of transit signal priority strategies, future efforts can build upon this research. The capabilities of INTEGRATION may be extended to allow conditional priority to be granted internally in realtime rather than on an external basis. This would also permit priority to be granted based on lateness at each intersection, rather than priority for a corridor segment as was performed in this research. If the lateness of buses at each intersection were evaluated, the threshold for priority could be lowered from the 150 seconds late in this research to a lower value corresponding to intersection-level benefits. Such priority could illustrate the similarities and differences with a "keep on schedule" approach rather than the "catch up" approach. Research could also examine the relationship between various lateness threshold values and the impacts of priority. In this research, the lateness threshold was set high so as not to cause buses to get ahead of schedule. With only a small number of buses per run receiving priority, the impacts were relatively minor. It is likely that as 
more buses are given priority (as in a "keep on schedule" approach), the impacts would be greater.

While this research has illustrated the application of several of the evaluation measures developed, further work may examine the measures not directly tested here using this corridor or other networks. Such research may test other alternative priority strategies, unconditional or conditional on various other criteria, such as the degree of saturation at the intersections (33), that may alter the nature and magnitude of impacts. For example, in order to minimize adverse impacts on traffic delays while still providing benefits to buses, cross streets that are near saturation may potentially be excluded from priority, while intersections below saturation may have priority activated. In addition, future studies may examine the application of the measures as part of a field study rather than using a simulation model. Lessons learned from such additional studies may be used to refine the evaluation measures.

Also, further exploration of the relationship between the factors affecting bus service reliability would provide a better understanding of the role transit signal priority plays relative to other measures. Using INTEGRATION for this exploration would also require extending the capabilities of INTEGRATION since the components of bus travel time are in some cases unrelated. For example, dwell time is related to 
passenger loads and demand as well as achieved headways. Since priority can affect the time at which a bus arrives at a stop, the dwell time can in turn be affected. As was illustrated in the comparison of Time Reliability between autos and buses, the dwell time factor plays a significant role in variability, and capturing such interactions in INTEGRATION would be a significant area of further research.

In addition, the role of passenger loads and demand may also be examined in the context of overall impacts on person delay. As mentioned previously, the overall delay increases are lesser on a person delay basis as compared to a vehicle delay basis. Future work can investigate the contribution of higher passenger loads to potential reductions in negative person delay impacts and even potential improvements on a person delay basis. 


\section{REFERENCES}

1. Collura, J., Chang, J., Willhaus, E.W., and Gifford, J.L., Traffic Signal Preemption and Priority: Technologies, Past Deployments, and System Requirements, Conference Proceedings of the ITS America Eleventh Annual Meeting and Exposition, Miami Beach, Florida, J une 2001.

2. Gifford, J., Pelletiere, D., and Collura, J., An Analysis of the Issues, Concerns, Needs, and Requirements Associated with Traffic Signal Preemption and Priority in the Washington, D.C. Region, Presented at the 2001 TRB Annual Meeting.

3. O'Brien, W., Design and Implementation of Transit Priority at Signalized Intersections, Canadian Urban Transit Association, Report STRP 15, November 2000.

4. Domencich, T.A., and McFadden, D., Urban Travel Demand: A Behaviorial Analysis, New York: American Elsevier Publishing Company, 1975.

5. Transit Cooperative Research Program, Traveler Response to Transportation System Changes: I nterim Handbook, TCRP Web Document 12 (Project B-12), March 2000.

6. Noland, R.B., Small, K.A., Koskenoja, P.M., and Chu, X., Simulating Travel Reliability, University of California Transportation Center Working Paper UCTC No. 372, November 1997.

7. Transit Cooperative Research Program, Transit Scheduling: Basic and Advanced Manuals, TCRP Report 30, 1998.

8. Sunkari, S.R., Beasley, P.S., Urbanik, T. II, and Fambro, D.B., Model to Evaluate the Impacts of Bus Priority on Signalized Intersections, Transportation Research Record 1494, 1995

9. Gardner Systems, Improved Traffic Signal Priority for Transit, TCRP Project A-16, Interim Report, December 1998.

10. 3M Corporation, Opticom informational material 
11. BRW, An Evaluation of Emergency Vehicle Preemption Systems, August 1997.

12. Virginia Department of Transportation Northern Virginia District Traffic Field Operations, Traffic Signal Preemption Study, 1997.

13. PB Farradyne, Inc., Bus Signal Priority Pilot Project Literature Survey Technical Memorandum, October 1999.

14. Novax Industries Corporation, Bus Plus WWW page, http://www.novax.com/pdf/sda03810.pdf.

15. Unity Wireless Systems Corporation, Sonem 2000 WWW page, http://www.sonic-systems.com/Brochure. pdf.

16. Collura, J., Chang, J., and Gifford, J.L., Traffic Signal Priority Strategies for Transit: A Review of Selected Experiences in the United States, Proceedings of the $7^{\text {th }}$ World Congress on Intelligent Transport Systems, Torino, I taly, November 2000.

17. City of Denver, Time Study of Effectiveness of the Opticom Traffic Control System, October 5, 1978.

18. Traffic Engineers, Inc., Emergency Response Management System Study, April 1991.

19. St. Paul Department of Fire and Safety Services, Accident Rate Reduction Information, August 1977.

20. David Volkert \& Associates, Emergency Vehicle Preemption System for 22 Locations, Post Implementation Study Report, October 1997.

21. Verzosa, A., and Burney, J., City of Fairfax Transportation Department, Personal Interview, May 9, 2000.

22. 3M Corporation, Charlotte, North Carolina: Innovation Whisks Express Bus Riders To/From Work With Time to Spare, 1993.

23. Kloos, W.C., Danaher, A.R., and Hunter-Zaworski, K.M., Bus Priority at Traffic Signals in Portland: The Powell Boulevard Pilot Project, 1994 ITE Compendium of Technical Papers.

24. 3M Corporation, Bremerton, Washington: Room to Move Provides Room to Grow, 1993. 
25. Michalopoulos, P.G., Bus Priority System Studies, Traffic Engineering, Vol. 46, No. 7, July 1976.

26. Maryland State Highway Administration, Office of Traffic \& Safety, MD 2 Bus Pre-emption System, Anne Arundel County, October 1993.

27. Furth, P.G., and Muller, T.H.J., Conditional Bus Priority at Signalized Intersections, Transportation Research Record 1731, pp. 23-30.

28. Hu, K., Skehan, S., and Gephart, R., Implementing a Smart Transit Priority System for Metro Rapid Bus in Los Angeles, Paper presented at the $80^{\text {th }}$ Annual Meeting of the Transportation Research Board, January 2001.

29. Kemper, B., Transit Signal Priority (TSP), presentation at Transit Signal Priority Workshop, January 13, 2002 at $81^{\text {st }}$ Annual Meeting of the Transportation Research Board.

30. Kloos, B., Bus Priority in Portland - Lessons Learned, presentation at Transit Signal Priority Workshop, January 13, 2002 at $81^{\text {st }}$ Annual Meeting of the Transportation Research Board.

31. Benevelli, D.A., Radwan, A.E., and Hurley, J.W. Jr., Evaluation of a Bus Preemption Strategy by Use of Computer Simulation, Transportation Research Record 906, pp. 60-67.

32. Khasnabis, S., Karnati, R.R., and Rudra Raju, R.K., A NETSIM based Approach to Evaluate Bus Preemption Strategies, Transportation Research Record 1554, 1996.

33. Garrow, M., and Machemehl, R., Development and Evaluation of Transit Signal Priority Strategies, Report SWUTC/97/47284000068-1, 1997.

34. Dale, J.J., Bauer, T., Atherley, R.J., Madsen, L., A Transit Signal Priority I mpact Assessment Methodology - Greater Reliance on Simulation, $78^{\text {th }}$ Annual Meeting of the Transportation Research Board, 1999.

35. Markowitz H., Portfolio Selection: Efficient Diversification of Investments, 1959. 
36. Dion, F., Rakha, H., and Zhang, Y., Evaluation of Transit Signal Priority Benefits Along a Fixed-Time Signalized Arterial, Paper presented at the $81^{\text {st }}$ Annual Meeting of the Transportation Research Board, January 2002.

37. Zhang, Y., An Evaluation of Transit Signal Priority and SCOOT Adaptive Signal Control, M.S. Thesis, Virginia Polytechnic Institute and State University, May 2001.

38. M. Van Aerde and Associates, INTEGRATION Release 2.30 for Windows, User's Guides, M. Van Aerde and Associates, Kingston, Ontario, Canada, 2000. 


\section{APPENDIX A: Bibliography (Additional Background Material)}

\section{General}

Dion, F., Review of Transit Priority Projects and Practice, Unpublished, 1999

Fox, K., Chen, H., Montgomery, F., Smith, M., Jones, S., Selected Vehicle Priority in the UTMC Environment (Literature Review), http: //www. its.leeds.ac.uk/projects/spruce/utmclrev.html, 1998

FTA, Advanced Public Transportation Systems: The State of the Art Update '96, DOT-VNTSC-FTA-95-13, 1996

FTA, Advanced Public Transportation Systems: The State of the Art Update '98, DOT-VNTSC-FTA-97-9, 1998

FTA, APTS Deployment in the U.S. [prelim draft], Draft Document, 1996

Kelman, L., Bus Priority Operations in Traffic Signal Systems (memo/attachments), Memo to TRB Signal Systems Committee, 1993

McCreery, D.B., Signal Priority System Designs and Conformity with the National ITS Architecture [draft], Unpublished draft, 1999

McCreery, D.B., Willhaus, E., Bigdeli, F., Regional Signal Priority Treatment Study, Class Project Slides, 1999

Northern Virginia Transportation Coordinating Council, NOVA 2020 Plan Draft Part 2, Identifying 2020 Plan Strategies, http: //www.nova2020.org/techdocs/docsects/2ndpart.htm, 1999

Proper, A.T., ITS Benefits: 1999 Update, FHWA Report FHWA-OP-99012, 1999

TRRL, Bus Priority: Proceedings of a Symposium held at TRRL, 1972, TRRL Laboratory Report 570, 1973

\section{Implementation / Mechanisms}

Bretherton, D., Hounsell, N., Radia, B., Public Transport Priority in SCOOT, Proceedings of the 3rd Annual World Congress on Intelligent Transport Systems, Vol. 1, 1996

Econolite, Econolite Transit Priority, Specifications and Related Materials, 1998 
Econolite, Maryland Bus Priority Control System, Econolite Application Note 1001 http://www.econolite.com/an1001.htm, 1999

FTA, ISO/TC 204 WG 8 - Transit / Emergency [info sheet], Information Sheet, 1996

Jacobs, A., Bus Preemption Strategies [message board posting], ATMS Forum

http://www.itsonline.com/atmsforum/messages/202.html, 1999

Nor, M., Strand, K., A Public.. - Aalborg's Bus Priority System

Explained, Traffic Technology International, 1998

UTMS Japan, Public Transportation Priority Systems, ITS Developed by Japanese Police, 1998

Yagar, S., and Han, B., A Procedure for Real-Time Signal Control That Considers Transit Interference and Priority, Transportation Research B, 1994

\section{Evaluation}

Casey, R., Collura, J., Advanced Public Transportation Systems: Evaluation Guidelines, FTA-MA-26-0007-94-2, 1994

Chang, G., Vasudevan, M., Modeling and Evaluation of Adaptive BusPreemption Control With and Without AVL Systems, Transportation Research A, 1996

Chang, G-L: Su, C-C:Vasudevan, M, Bus-Preemption Under Adaptive Signal Control Environments, Transportation Research Record 1494, 1995

Cisco, BA:Khasnabis, S, Techniques To Assess Delay and Queue Length Consequences of Bus Preemption, Transportation Research Record 1494, 1995

Garrow, M., Machemehl, R., Development and Evaluation of Transit Signal Priority Strategies, Journal of Public Transportation V2, N2, 1999

Khasnabis, S., Cisco, B.A., A Comparative Analysis of Two Methods to Assess Operational Traffic Consequences of Bus Preemption, ITS America A.M. 1995, 1995

Shalaby, A.S., Simulating the Performance Impacts of Bus Lanes and Supporting Measures, Journal of Transportation Engineering, 1999 
Wilbur Smith Associates/MORPC, Assessment of Transit Priority Benefits in Congested Corridors, MORPC/COTA Strategic Transit Plan, 1999

Yedlin, M., and Lieberman, E.B., Analytic and Simulation Studies of Factors that Influence Bus-Signal-Priority Strategies, Transportation Research Record 798, 1981

\section{Case Studies}

Al-Sahili, K., and Taylor, W.C., Evaluation of Bus Priority Signal Strategies in Ann Arbor, Michigan, Transportation Research Record 1554, 1996

Bruun, Eric C., and Schiller, Preston L., A New Vision for America's Passenger Rail, Excerpted from Urban Transport International, at http://www.istea.org/progress/jaug97/impr.htm, 1997

Finger, W., Express Bus Priority in Charlotte [infosheet], Information Sheet, undated

FTA, Advanced Public Transportation Systems Deployment in the United States, Update, January 1999, DOT-VNTSC-FTA-99-1, 1999

Greenough, J.C., Noehammer, R.A., ITS Technology Solving Bus Priority Needs - "The Better Way Gets Better" [draft], draft paper, 1999

J acobson, KL, Brinckerhoff, P., Hendrickson, CT, Transit Signal Priority Treatments in the Puget Sound Region, Proceedings / Pacific Rim TransTech Conference, July 25-28, 1993, Washington State Convention Center, Seattle, Washington, USA. TA1005 P33 1993, 1993

King County Department of Transportation, Puget Sound's Regional Automatic Vehicle Identification (AVI) Demonstration Project, Unpublished, 1998

Kloos, W.C., Danaher, A.R., Hunter-Zaworski, K.M., Bus Priority at Traffic Signals in Portland: The Powell Boulevard Pilot Project, 1994 ITE Compendium of Technical Papers, 1994

Kloos, W.C., Danaher, A.R., Hunter-Zaworski, K.M., Bus Priority at Traffic Signals in Portland: The Powell Boulevard Pilot Project, ITS America A.M. 1995, 1995

MacGowan, C.J., Bus Priority and Bus Preemption in the Urban Traffic Control System, ITE $45^{\text {th }}$ Annual Meeting, Compendium of Technical Papers, 1975 
McCreery, D.B., Willhaus, E., Bigdeli, F., Regional Traffic Signal Priority Treatment Study for the Metropolitan Washington Region, Class Project Report, 1999

Signal Priority Discussion List, Transit Signal Priority Evaluation Begins in Seattle, Transportation Communications Newsletter (via listserv), 2000

Williams, T., Haselkorn, M., Alalusi, K., Impact of Second Priority Signal Preemption on Kitsap Transit and Bremerton Travelers, Transportation Northwest Report TNW-93-06, 1993

Wolanin, E., Information on Montgomery County Transit Priority in ATMS, Miscellaneous Excerpts, 2000

\section{Bus Operations}

Abkowitz, M., and Englestein, I., Methods for Maintaining Transit Service Regularity, Transportation Research Record 961, 1984

Abkowitz, M.D., and Lepofsky, M., Implementing Headway-Based Reliability Control on Transit Routes, Journal of Transportation Engineering, 1990

Andersson, P.A., et al, Analysis and Simulation of an Urban Bus Route, Transportation Research A, 1979

Barnett, A., On Controlling Randomness in Transit Operation, Transportation Science, 1974

Bly, P.H., Webster, F.V., Contra-Flow Bus Lanes: Economic Justification Using a Theoretical Model, TRRL Digest LR 918, 1979

Ceder, A., Practical Methodology for Determining Dynamic Changes in Bus Travel Time, Transportation Research Record 798, 1981

DC DOT, A Plan for the Improvement of Bus Travel in the District of Columbia Part I - Radial Corridors, DC DOT, 1976

DC DOT, Bus Priority in the 14th-15th St., NW Corridors, DC DOT, 1976

DC DOT, DC DOT Statement at the Public Hearing on " Proposed Revision of Express Bus Lane Strategy of the Air Implementation Plan of DC", DC DOT, 1976

Friedrich, M., Modeling Public Transport - A European Approach, TRB 1999 A.M. Preprint, 1999 
Henderson, G., Kwong, P., and Adkins, H., Regularity Indices for Evaluating Transit Performance, Transportation Research Record 1297, 1991

Hendrickson, C.T., Travel Time and Volume Relationships in Scheduled Fixed-Route Public Transportation, Transportation Research A, 1981

Levinson, H.S., Analyzing Transit Travel Time Performance, Transportation Research Record 915, 1983

Moses Santhakumar, S., and Hariharan, P., Transportation Systems Management Options to Improve Urban Bus Route Performance Using Computer Simulation, Transportation Research Record 1338, 1992

Ng, C-P., and Brah, S.A., A Running time Model for Bus Operations in Singapore, Road \& Transport Research, 1998

Senevirante, P.N., Analysis of On-Time Performance of Bus Services using Simulation, Journal of Transportation Engineering, 1990

TRB, Traffic Control and Regulation at Transit Stops, Synthesis of Transit Practice 11, 1987

TU Delft, TRITAPT: Trip Time Analysis in Public Transport [brochure], Brochure, undated

Turnquist, M., A Model for Investigating the Effects of Service Frequency and Reliability on Bus Passenger Waiting Times, Transportation Research Record 663, 1978

Victor, D.J., and Santhakumar, S.M., Simulation Study of Bus Transit, Journal of Transportation Engineering, 1986

\section{Traffic Operations}

Column, Taking the Tram, ITS International, 1999

Dion, F., Existing Real-Time, Traffic-Responsive Signal Control

Systems, Appendix A, Ph.D. Dissertation, University of Waterloo, 1998

FHWA, Priority Control of Traffic Signals section 4B-22, MUTCD, 1988

Khasnabis, S., and Rudraraju, R.K., Optimum Bus Headways for Preemption: A Simulation Approach, Transportation Research Record 1603, 1997

Lin, G-S, Liang, P., Schonfeld, P., Larson, R., Adaptive Control of Transit Operations, FTA Report MD-26-7002, 1995

Thomas, G.B., The Relationship Between Detector Locations and Travel Characteristics on Arterial Streets, ITE Journal, 1999 


\section{Appendix B: Map of Columbia Pike Corridor in Arlington, Virginia}

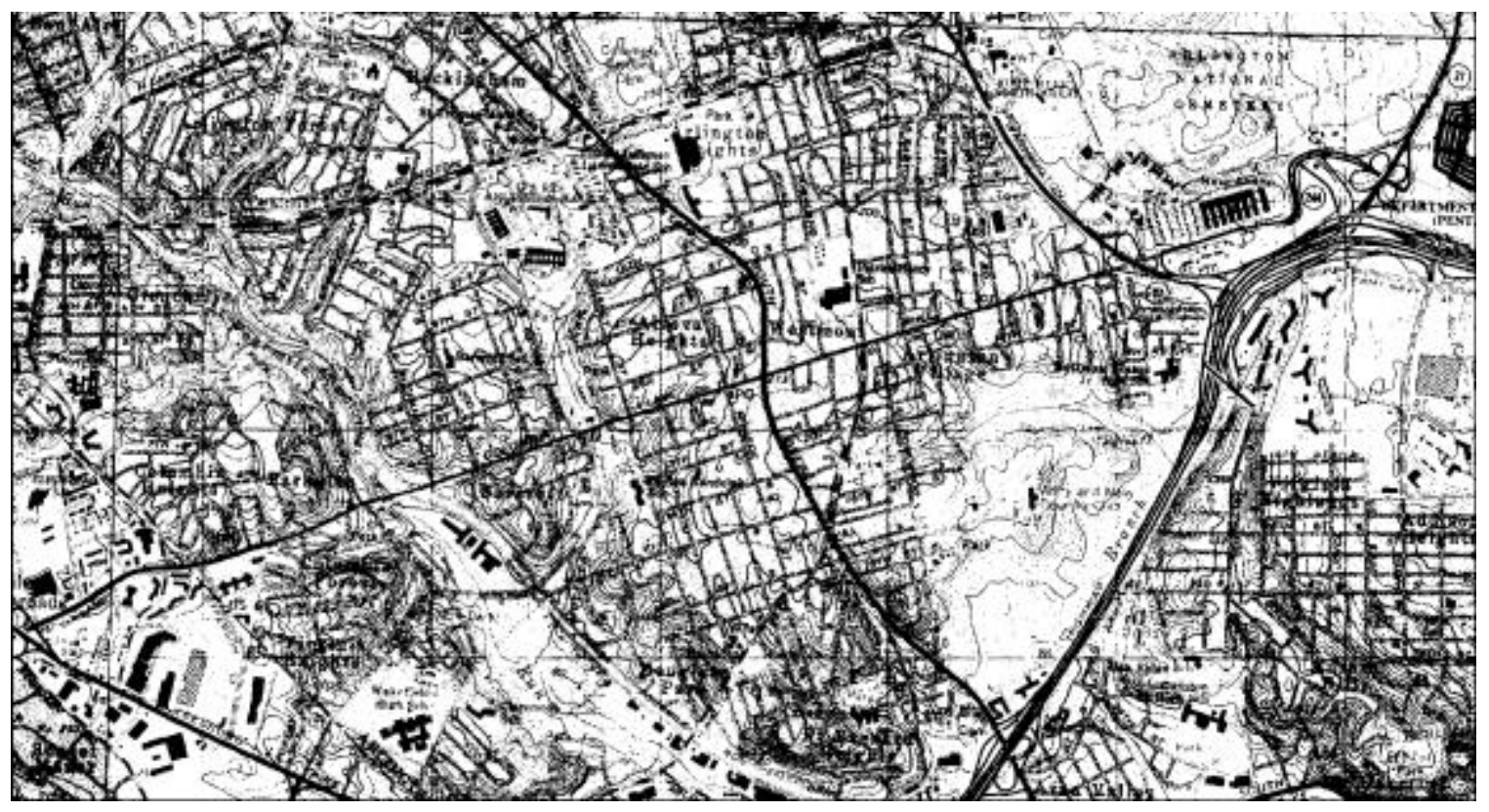

Source: 1983 USGS Topographic Map, from www.terraserver.microsoft.com 


\section{Appendix C: Screen Views of Columbia Pike Network in I NTEGRATI ON}

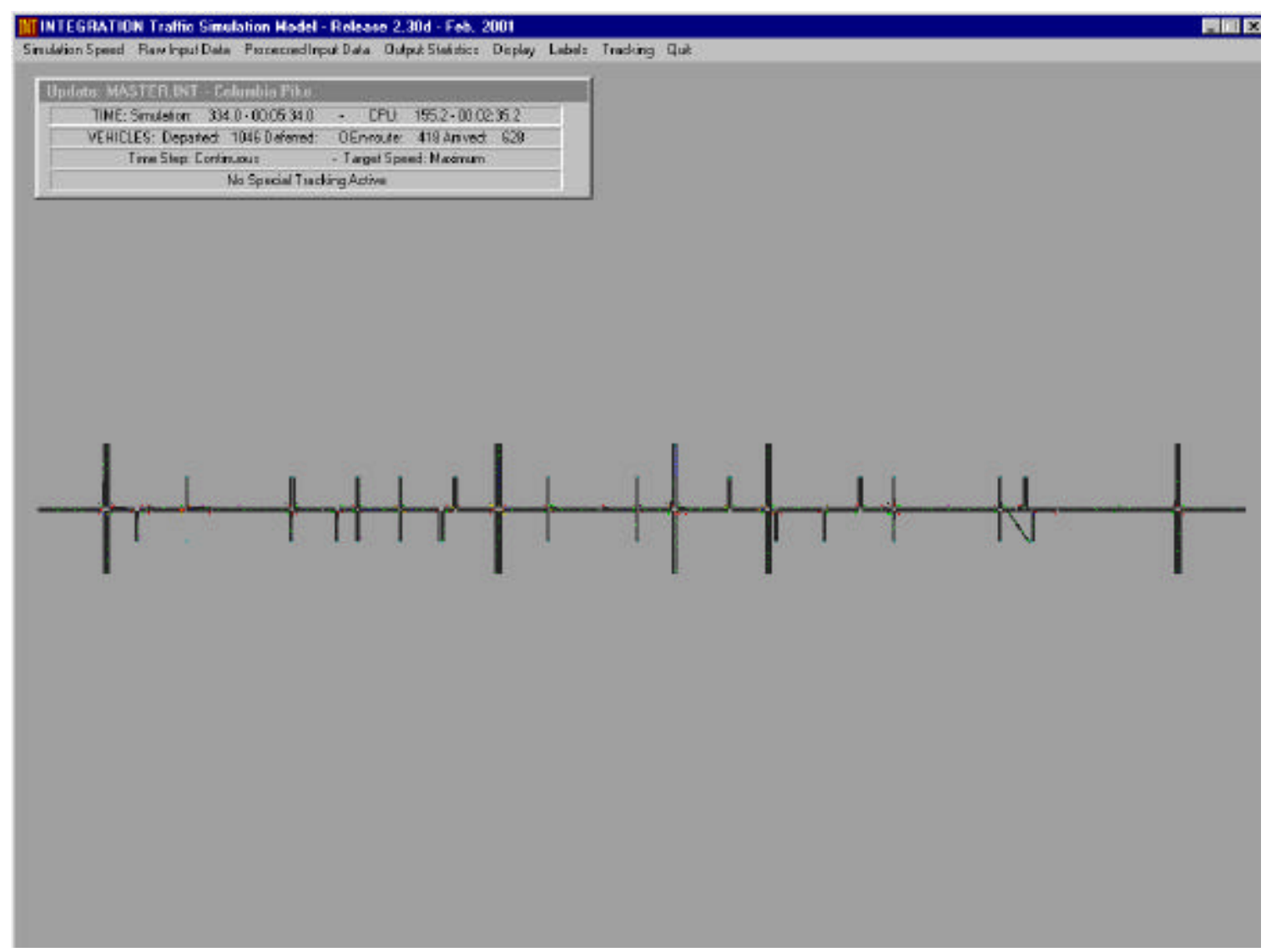

View of Entire Columbia Pike Network (Carlin Springs Dr. to J oyce St.) 


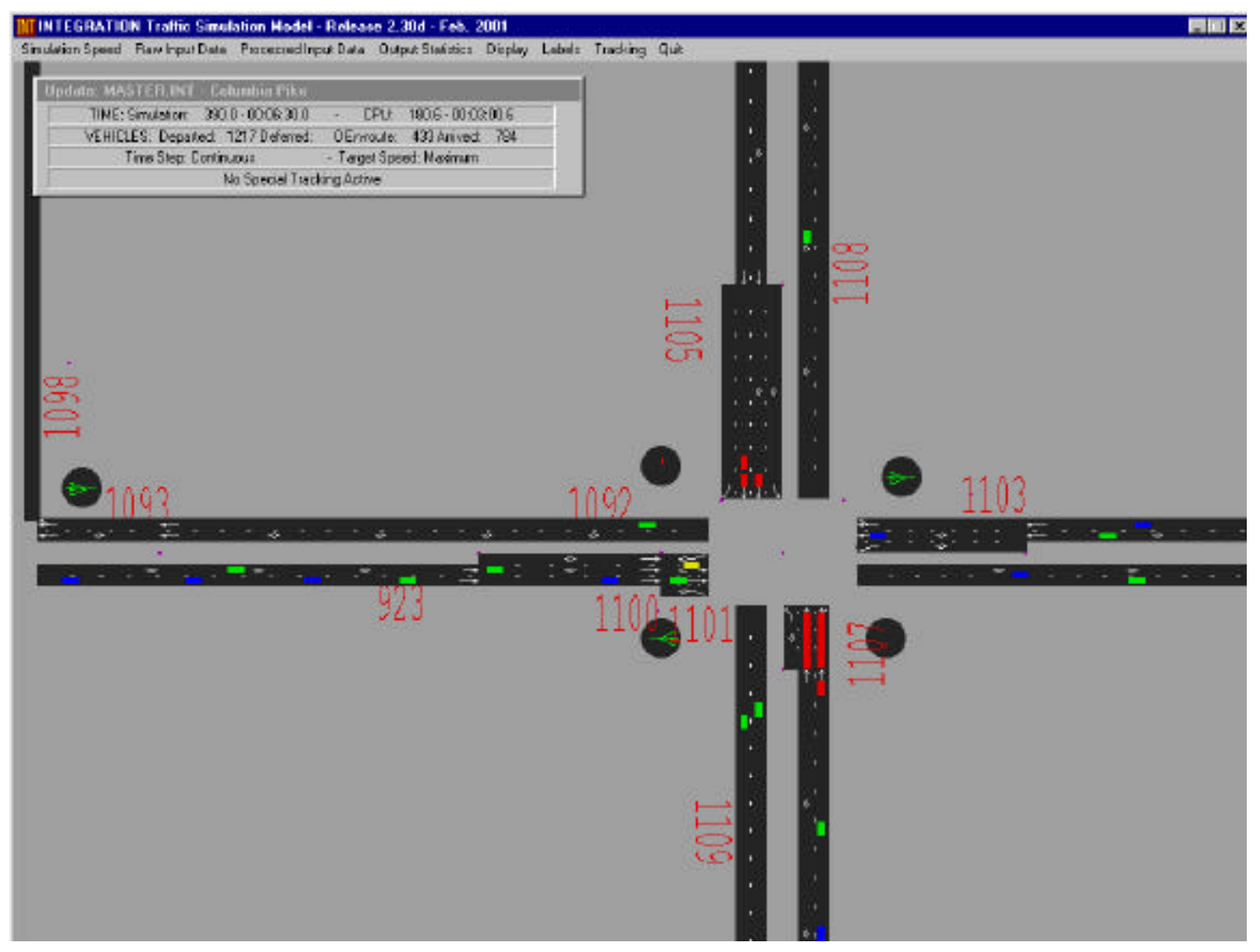

View of Starting Timepoint (end of Link 1101) at George Mason Dr. 


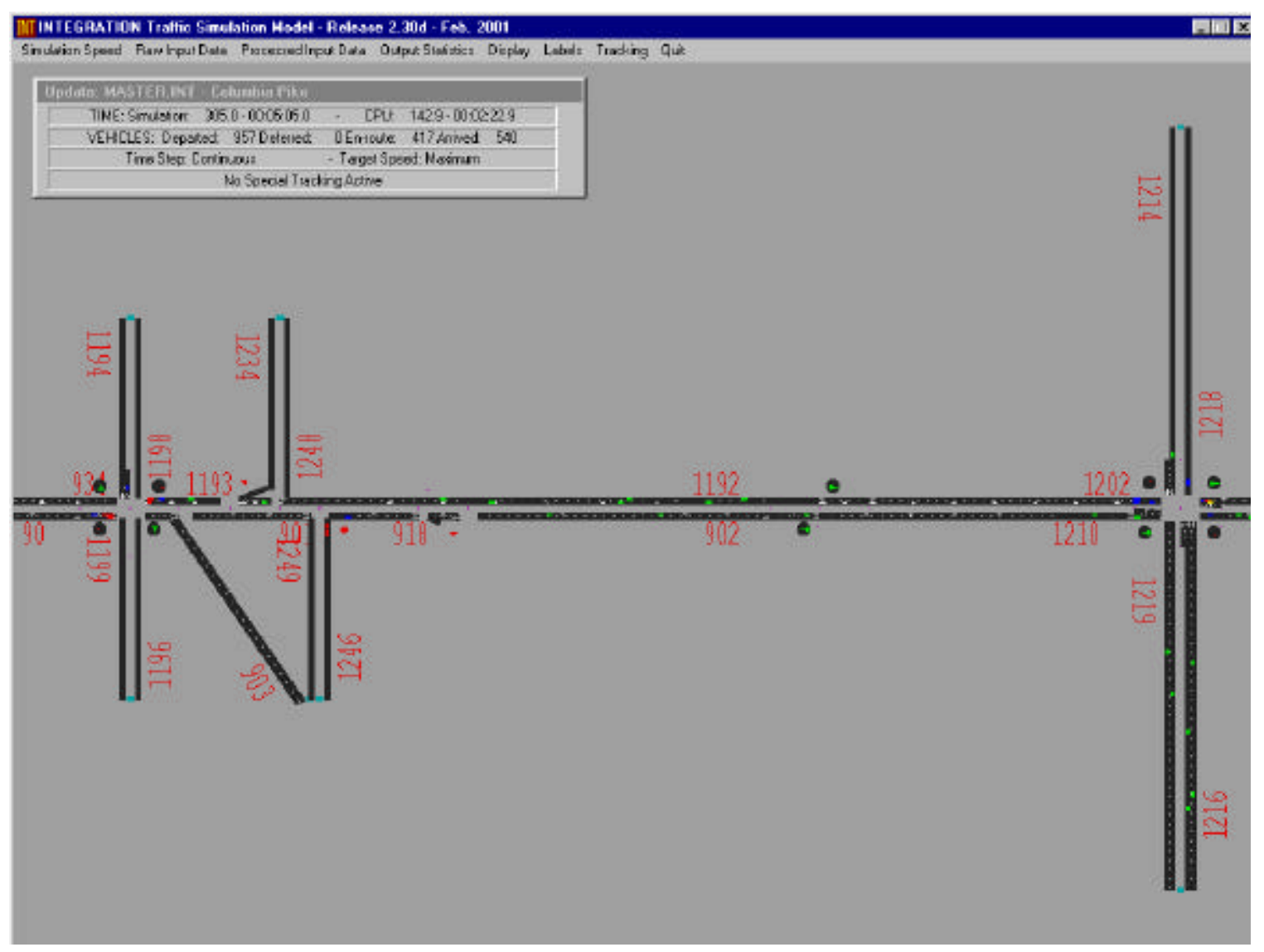

View of Ending Timepoint (end of Link 902) at Navy Annex 


\section{Appendix D: Description of I NTEGRATI ON Modeling Approach}

(from INTEGRATION User's Guide Release 2.30 for Windows- Volume I, Section 2.3-Microscopic Modeling Approach) (38)

INTEGRATION is a fully microscopic simulation model, as it tracks both the lateral and longitudinal movements of individual vehicles at a resolution of up to one deci-second.

This microscopic approach permits the analysis of many dynamic traffic phenomena, such as shock waves, gap acceptance, and weaving. These attributes are usually very difficult, or infeasible, to capture under nonsteady state conditions using a macroscopic rate-based model, but become emergent behavior with the INTEGRATION model. For example, in a dynamic network, average gap acceptance curves typically cannot be utilized at permissive left turns if the opposing flow rate varies from cycle to cycle and/or within a particular cycle. These curves also cannot be used if the size of the acceptable gap varies as a function of the length of time for which a vehicle has been waiting to find an acceptable gap. Similarly, most microscopic models cannot model platoon progression between adjacent traffic signals that have cycle lengths that are not multiples of each other.

The INTEGRATION model can consider virtually continuous time varying traffic demands, routings, link capacities and traffic controls without the need to pre-define explicit time-slice duration between these processes. This implies that the model is not restricted to hold departure rates, signal timings, incident severity, or even traffic routings, at a constant setting for any particular common period of time. Consequently, instead of treating each of the above model attributes as a sequence of steadystate conditions, as needs to be done in most rate-based models, all of these attributes can be changed on virtually a continuous basis over time.

The microscopic approach also permits considerable flexibility in terms of representing spatial variations in traffic conditions. For example, while most rate-based models consider traffic conditions to be uniform along a given link, INTEGRATION permits the density of traffic to vary continuously along the link. In particular, such dynamic density variation permits, along an arterial link, the representation of platoons departing from traffic signals and the associated propagation of shock waves in an upstream or downstream direction, or both. 
Finally, it is important to note that the model is primarily microscopic. However, these microscopic rules have been carefully calibrated in order to capture concurrently most of the target macroscopic traffic features that traffic engineers are most familiar with. Examples of these features are link speed-flow relationships, multi-path equilibrium traffic assignment, and uniform, random or over-saturation delay, as well as weaving and ramp capacities. The main challenge in the design of INTEGRATION has been to ensure that these important macroscopic features automatically remain emergent behavior arising from the more fundamental microscopic model rules that are needed to represent the system dynamics using a single integrated approach.

INTEGRATI ON Signal Priority Summary (Summarized from (36) - see reference for complete details)

- Buses detected 100 m upstream from intersection

- If priority already provided in current cycle, no change to timing made

- If bus arrives early in green and should reach intersection, no change made

- If bus arrives near end of green, extend green in $5 \mathrm{~s}$ intervals until bus served or max green is reached (cycle length - amber times - $5 \mathrm{~s}$ min green for each phase)

- If bus arrives on red, truncate red phase after minimum green has been served, and provide required amber interval

- If conflicting priority vehicles detected, no change made 


\section{Appendix E: Selected Excerpts from I NTEGRATI ON I nput/ Output Files}

FI LE03AM.DAT (Signal Timings - Note Priority given to class 3 vehicles indicated by <NODE $>$.00100)

\begin{tabular}{|c|c|c|c|c|c|c|c|c|c|c|}
\hline FILE 3 & - & \multicolumn{2}{|c|}{ Columbia } & Pike & - & \multicolumn{2}{|c|}{ Signal } & \multicolumn{2}{|c|}{ Timings } & $(\mathrm{AM})$ \\
\hline 21 & 9000 & & & & & & & & & \\
\hline \multicolumn{11}{|l|}{1} \\
\hline 101.00000 & 130 & 40 & 180 & 0 & 5 & 48 & 3 & 17 & 3 & 28 \\
\hline 3 & 15 & 3 & 7 & 3 & 0 & & & & & \\
\hline 102.00000 & 100 & 40 & 180 & 39 & 2 & 63 & 3 & 31 & 3 & 0 \\
\hline 103.00000 & 100 & 40 & 180 & 56 & 3 & 61 & 3 & 23 & 3 & 7 \\
\hline 3 & 0 & & & & & & & & & \\
\hline 104.00000 & 100 & 40 & 180 & 84 & 2 & 63 & 3 & 31 & 3 & 0 \\
\hline 105.00000 & 100 & 40 & 180 & 2 & 2 & 74 & 3 & 20 & 3 & 0 \\
\hline 106.00000 & 100 & 40 & 180 & 11 & 2 & 73 & 3 & 21 & 3 & 0 \\
\hline 107.00000 & 100 & 40 & 180 & 22 & 2 & 72 & 3 & 22 & 3 & 0 \\
\hline 108.00000 & 100 & 40 & 180 & 36 & 2 & 70 & 3 & 24 & 3 & 0 \\
\hline 109.00000 & 100 & 40 & 180 & 32 & 2 & 73 & 3 & 21 & 3 & 0 \\
\hline 110.00100 & 100 & 40 & 180 & 53 & 3 & 37 & 3 & 36 & 3 & 21 \\
\hline 0 & 0 & & & & & & & & & \\
\hline 111.00100 & 100 & 40 & 180 & 70 & 2 & 72 & 3 & 22 & 3 & 0 \\
\hline 112.00100 & 100 & 40 & 180 & 4 & 2 & 72 & 3 & 22 & 3 & 0 \\
\hline 113.00100 & 100 & 40 & 180 & 15 & 2 & 52 & 3 & 42 & 3 & 0 \\
\hline 114.00100 & 100 & 40 & 180 & 15 & 2 & 74 & 3 & 20 & 3 & 0 \\
\hline 115.00100 & 100 & 40 & 180 & 27 & 3 & 53 & 3 & 29 & 3 & 12 \\
\hline 0 & 0 & & & & & & & & & \\
\hline 116.00100 & 100 & 40 & 180 & 53 & 2 & 70 & 3 & 24 & 3 & 0 \\
\hline 117.00100 & 100 & 40 & 180 & 65 & 2 & 72 & 3 & 22 & 3 & 0 \\
\hline 118.00100 & 100 & 40 & 180 & 75 & 2 & 62 & 3 & 32 & 3 & 0 \\
\hline 119.00100 & 100 & 40 & 180 & 8 & 2 & 72 & 3 & 22 & 3 & 0 \\
\hline 120.00000 & 100 & 40 & 180 & 75 & 2 & 69 & 3 & 25 & 3 & 0 \\
\hline
\end{tabular}


121.00000 0
100 0
$180 \quad 0$

3

54

3

30

3

10

\section{5}


FILE04AM.DAT - EXCERPT (OD Flows, showing scheduled bus departures; BASE CASE (No Priority) does not have Class 3 vehicles)

\begin{tabular}{|c|c|c|c|c|c|c|c|c|c|c|}
\hline \multirow{2}{*}{11098} & 25 & 26 & 60 & 0 & \multicolumn{2}{|c|}{1005.075} & 1065.075 & 0 & -1 & 0 \\
\hline & 0 & 0 & 1 & 2 & & & & & & \\
\hline \multirow[t]{2}{*}{11099} & 25 & 26 & 60 & 0 & \multirow{2}{*}{\multicolumn{2}{|c|}{2805.075}} & 2865.075 & 0 & -1 & 0 \\
\hline & 0 & 0 & 1 & 2 & & & & & & \\
\hline \multirow[t]{2}{*}{11100} & 25 & 26 & 60 & 0 & \multirow{2}{*}{\multicolumn{2}{|c|}{4605.075}} & 4665.075 & 0 & -1 & \\
\hline & 0 & 0 & 1 & 2 & & & & & & \\
\hline \multirow[t]{2}{*}{11101} & 25 & 26 & 60 & 0 & \multirow{2}{*}{\multicolumn{2}{|c|}{6405.075}} & 6465.075 & 0 & -1 & \\
\hline & 0 & 0 & 1 & 2 & & & & & & \\
\hline \multirow[t]{2}{*}{11102} & 1 & 36 & 60 & 0 & \multirow{2}{*}{\multicolumn{2}{|c|}{1607.207}} & 1667.207 & 0 & -1 & \\
\hline & 0 & 0 & 1 & 2 & & & & & & \\
\hline \multirow[t]{2}{*}{11103} & 1 & 36 & 60 & 0 & \multirow{2}{*}{\multicolumn{2}{|c|}{5387.207}} & 5447.207 & 0 & -1 & \\
\hline & 0 & 0 & 1 & 2 & & & & & & \\
\hline \multirow[t]{2}{*}{11104} & 5 & 36 & 60 & 0 & \multirow{2}{*}{7860} & 7920 & -1 & 0 & 0 & \\
\hline & 1 & 2 & & & & & & & & \\
\hline \multirow[t]{2}{*}{11105} & 1 & 36 & 60 & 0 & \multirow{2}{*}{\multicolumn{2}{|c|}{3407.207}} & 3467.207 & 0 & -1 & \\
\hline & 0 & 0 & 1 & 2 & & & & & & \\
\hline \multirow[t]{2}{*}{11106} & 1 & 36 & 60 & 0 & \multirow{2}{*}{\multicolumn{2}{|c|}{7187.207}} & 7247.207 & 0 & -1 & \\
\hline & 0 & 0 & 1 & 2 & & & & & & \\
\hline \multirow[t]{2}{*}{11107} & 1 & 36 & 60 & 0 & 107 & 068 & 167.2068 & 0 & 0 & \\
\hline & -1 & 0 & 1 & 2 & & & & & & \\
\hline 11108 & 1 & 36 & 60 & 0 & 707 & 068 & 767.2068 & 0 & 0 & \\
\hline & -1 & 0 & 1 & 2 & & & & & & \\
\hline 11109 & 1 & 36 & 60 & 0 & 1307 & 207 & 1367.207 & 0 & 0 & \\
\hline & -1 & 0 & 1 & 2 & & & & & & \\
\hline 11110 & 1 & 36 & 60 & 0 & 1907 & 207 & 1967.207 & 0 & 0 & \\
\hline & -1 & 0 & 1 & 2 & & & & & & \\
\hline 11111 & 1 & 36 & 60 & 0 & 2507 & 207 & 2567.207 & 0 & 0 & \\
\hline & -1 & 0 & 1 & 2 & & & & & & \\
\hline 11112 & 1 & 36 & 60 & 0 & 3287 & 207 & 3347.207 & 0 & 0 & \\
\hline & -1 & 0 & 1 & 2 & & & & & & \\
\hline 11113 & 1 & 36 & 60 & 0 & 3707 & 207 & 3767.207 & 0 & 0 & \\
\hline & -1 & 0 & 1 & 2 & & & & & & \\
\hline 11114 & 1 & 36 & 60 & 0 & 4427 & 207 & 4487.207 & 0 & 0 & \\
\hline & -1 & 0 & 1 & 2 & & & & & & \\
\hline 11115 & 1 & 36 & 60 & 0 & 5207 & 207 & 5267.207 & 0 & 0 & \\
\hline & -1 & 0 & 1 & 2 & & & & & & \\
\hline 11116 & 1 & 36 & 60 & 0 & 5807 & 207 & 5867.207 & 0 & 0 & \\
\hline & -1 & 0 & 1 & 2 & & & & & & \\
\hline 11117 & 7 & 36 & 60 & 0 & 766. & 695 & 826.6695 & 0 & -1 & \\
\hline & 0 & 0 & 1 & 2 & & & & & & \\
\hline 11118 & 7 & 36 & 60 & 0 & 2446 & & 2506.67 & 0 & -1 & \\
\hline & 0 & 0 & 1 & 2 & & & & & & \\
\hline 11119 & 7 & 36 & 60 & 0 & 4486 & & 4546.67 & 0 & -1 & \\
\hline & 0 & 0 & 1 & 2 & & & & & & \\
\hline 11120 & 7 & 36 & 60 & 0 & 6346 & & 6406.67 & 0 & -1 & \\
\hline & 0 & 0 & 1 & 2 & & & & & & \\
\hline 11121 & 4 & 36 & 60 & 0 & 1320 & 1380 & -1 & 0 & 0 & \\
\hline & 1 & 2 & & & & & & & & \\
\hline 11122 & 4 & 36 & 60 & 0 & 3000 & 3060 & -1 & 0 & 0 & \\
\hline & 1 & 2 & & & & & & & & \\
\hline
\end{tabular}




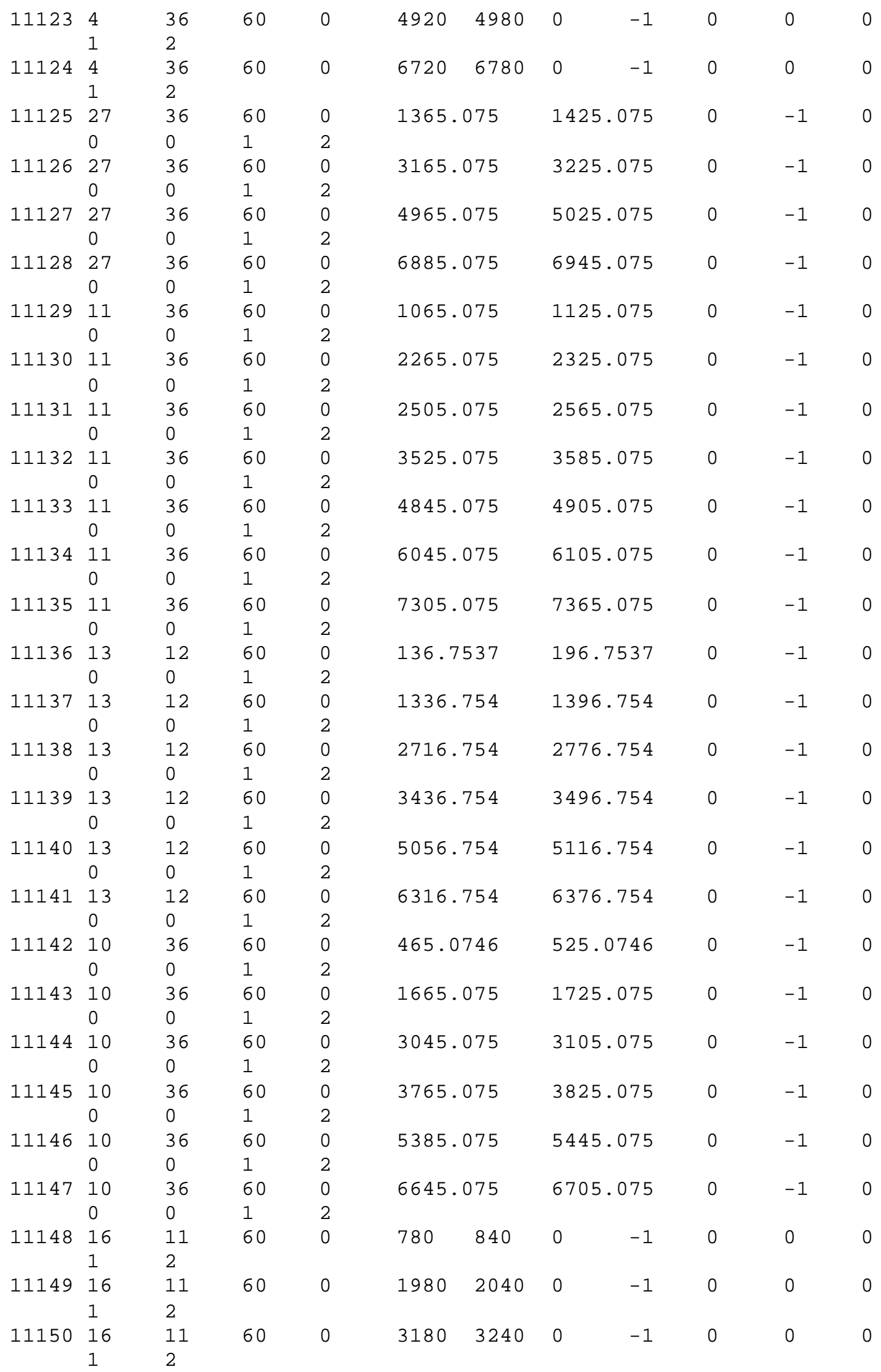




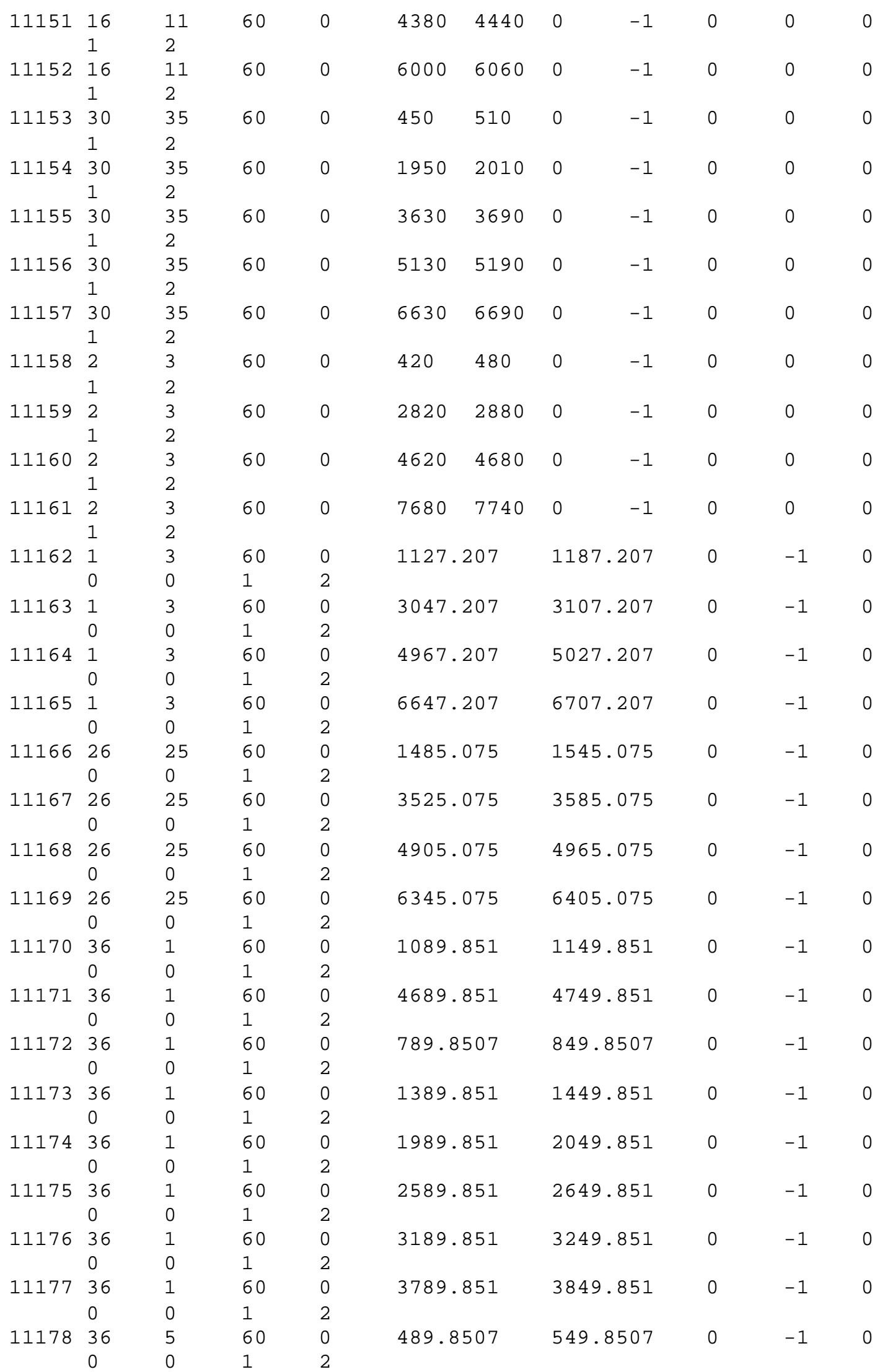




\begin{tabular}{|c|c|c|c|c|c|c|c|c|c|c|}
\hline \multirow{2}{*}{11179} & 36 & 5 & 60 & 0 & \multirow{2}{*}{\multicolumn{2}{|c|}{2289.851}} & \multirow[t]{2}{*}{2349.851} & \multirow[t]{2}{*}{0} & \multirow[t]{2}{*}{-1} & \multirow[t]{2}{*}{0} \\
\hline & 0 & 0 & 1 & 2 & & & & & & \\
\hline \multirow[t]{2}{*}{11180} & 36 & 5 & 60 & 0 & \multirow{2}{*}{\multicolumn{2}{|c|}{4089.851}} & 4149.851 & 0 & -1 & 0 \\
\hline & 0 & 0 & 1 & 2 & & & & & & \\
\hline \multirow[t]{2}{*}{11181} & 36 & 5 & 60 & 0 & \multirow{2}{*}{\multicolumn{2}{|c|}{7389.851}} & 7449.851 & 0 & -1 & 0 \\
\hline & 0 & 0 & 1 & 2 & & & & & & \\
\hline \multirow[t]{2}{*}{11182} & 36 & 1 & 60 & 0 & \multirow{2}{*}{\multicolumn{2}{|c|}{2889.851}} & 2949.851 & 0 & -1 & 0 \\
\hline & 0 & 0 & 1 & 2 & & & & & & \\
\hline \multirow[t]{2}{*}{11183} & 36 & 1 & 60 & 0 & \multirow{2}{*}{\multicolumn{2}{|c|}{6489.851}} & 6549.851 & 0 & -1 & 0 \\
\hline & 0 & 0 & 1 & 2 & & & & & & \\
\hline \multirow[t]{2}{*}{11184} & 36 & 4 & 60 & 0 & \multirow{2}{*}{\multicolumn{2}{|c|}{1689.851}} & 1749.851 & 0 & -1 & 0 \\
\hline & 0 & 0 & 1 & 2 & & & & & & \\
\hline 11185 & 36 & 4 & 60 & 0 & 3489 & 851 & 3549.851 & 0 & -1 & 0 \\
\hline & 0 & 0 & 1 & 2 & & & & & & \\
\hline 11186 & 36 & 4 & 60 & 0 & 5589 & 851 & 5649.851 & 0 & -1 & 0 \\
\hline & 0 & 0 & 1 & 2 & & & & & & \\
\hline 11187 & 11 & 16 & 60 & 0 & 945. & 746 & 1005.075 & 0 & -1 & 0 \\
\hline & 0 & 0 & 1 & 2 & & & & & & \\
\hline 11188 & 11 & 16 & 60 & 0 & 2145 & 075 & 2205.075 & 0 & -1 & 0 \\
\hline & 0 & 0 & 1 & 2 & & & & & & \\
\hline 11189 & 11 & 16 & 60 & 0 & 3345 & 075 & 3405.075 & 0 & -1 & 0 \\
\hline & 0 & 0 & 1 & 2 & & & & & & \\
\hline 11190 & 11 & 16 & 60 & 0 & 4605 & 075 & 4665.075 & 0 & -1 & 0 \\
\hline & 0 & 0 & 1 & 2 & & & & & & \\
\hline 11191 & 11 & 16 & 60 & 0 & 5805 & 075 & 5865.075 & 0 & -1 & 0 \\
\hline & 0 & 0 & 1 & 2 & & & & & & \\
\hline 11192 & 11 & 16 & 60 & 0 & 7005 & 075 & 7065.075 & 0 & -1 & 0 \\
\hline & 0 & 0 & 1 & 2 & & & & & & \\
\hline 11193 & 35 & 30 & 60 & 0 & 369. & 507 & 429.8507 & 0 & -1 & 0 \\
\hline & 0 & 0 & 1 & 2 & & & & & & \\
\hline 11194 & 35 & 30 & 60 & 0 & 1869 & 851 & 1929.851 & 0 & -1 & 0 \\
\hline & 0 & 0 & 1 & 2 & & & & & & \\
\hline 11195 & 35 & 30 & 60 & 0 & 3369 & 851 & 3429.851 & 0 & -1 & 0 \\
\hline & 0 & 0 & 1 & 2 & & & & & & \\
\hline 11196 & 35 & 30 & 60 & 0 & 4869 & 851 & 4929.851 & 0 & -1 & 0 \\
\hline & 0 & 0 & 1 & 2 & & & & & & \\
\hline 11197 & 35 & 30 & 60 & 0 & 6369 & 851 & 6429.851 & 0 & -1 & 0 \\
\hline & 0 & 0 & 1 & 2 & & & & & & \\
\hline 11198 & 35 & 30 & 60 & 0 & 7869 & 851 & 7929.851 & 0 & -1 & 0 \\
\hline & 0 & 0 & 1 & 2 & & & & & & \\
\hline 11199 & 3 & 2 & 60 & 0 & 1230 & 1290 & -1 & 0 & 0 & 0 \\
\hline & 1 & 2 & & & & & & & & \\
\hline 11200 & 3 & 2 & 60 & 0 & 2160 & 2220 & -1 & 0 & 0 & 0 \\
\hline & 1 & 2 & & & & & & & & \\
\hline 11201 & 3 & 2 & 60 & 0 & 4860 & 4920 & -1 & 0 & 0 & 0 \\
\hline & 1 & 2 & & & & & & & & \\
\hline 11202 & 3 & 2 & 60 & 0 & 6060 & 6120 & -1 & 0 & 0 & 0 \\
\hline & 1 & 2 & & & & & & & & \\
\hline 11203 & 3 & 1 & 60 & 0 & 1005 & 075 & 1065.075 & 0 & -1 & 0 \\
\hline & 0 & 0 & 1 & 2 & & & & & & \\
\hline 11204 & 3 & 1 & 60 & 0 & 2805 & 075 & 2865.075 & 0 & -1 & 0 \\
\hline & 0 & 0 & 1 & 2 & & & & & & \\
\hline 11205 & 3 & 1 & 60 & 0 & 4905 & 075 & 4965.075 & 0 & -1 & 0 \\
\hline & 0 & 0 & 1 & 2 & & & & & & \\
\hline 11206 & 3 & 1 & 60 & 0 & 6705 & 075 & 6765.075 & 0 & -1 & 0 \\
\hline & 0 & 0 & 1 & 2 & & & & & & \\
\hline
\end{tabular}


FILE04-30.DAT - EXCERPT FOR PRIORITY RUN \#30 (OD Flows, showing selected scheduled bus departures; has late buses coded as Class 3 vehicles - 11121, 11122, 11143 are late in BASE RUN \#30)

\begin{tabular}{|c|c|c|c|c|c|c|c|c|c|c|}
\hline \multirow{3}{*}{$\begin{array}{l}11120 \\
11121\end{array}$} & 7 & 36 & 60 & 0 & \multicolumn{2}{|c|}{6346.67} & \multirow[t]{2}{*}{6406.67} & \multirow[t]{2}{*}{0} & \multirow[t]{2}{*}{-1} & \multirow[t]{2}{*}{0} \\
\hline & 0 & 0 & \multirow{3}{*}{$\begin{array}{l}1 \\
60\end{array}$} & \multirow{3}{*}{$\begin{array}{l}2 \\
0\end{array}$} & & & & & & \\
\hline & 4 & 36 & & & 1320 & 1380 & 0 & -1 & 0 & 0 \\
\hline & 1 & 2 & & & & & & & & \\
\hline \multirow[t]{2}{*}{11122} & 4 & 36 & \multirow[t]{2}{*}{60} & \multirow[t]{2}{*}{0} & \multirow[t]{2}{*}{3000} & \multirow[t]{2}{*}{3060} & \multirow[t]{2}{*}{0} & \multirow[t]{2}{*}{-1} & \multirow[t]{2}{*}{0} & 0 \\
\hline & 1 & 2 & & & & & & & & \\
\hline \multirow[t]{2}{*}{11123} & 4 & 36 & \multirow[t]{2}{*}{60} & \multirow[t]{2}{*}{0} & 4920 & 4980 & -1 & 0 & 0 & 0 \\
\hline & 1 & 2 & & & & & & & & \\
\hline 11124 & 4 & 36 & 60 & 0 & 6720 & 6780 & -1 & 0 & 0 & 0 \\
\hline & 1 & 2 & & & & & & & & \\
\hline 11125 & 27 & 36 & 60 & 0 & 1365 & 075 & 1425.075 & 0 & -1 & 0 \\
\hline & 0 & 0 & 1 & 2 & & & & & & \\
\hline 11126 & 27 & 36 & 60 & 0 & 3165 & 075 & 3225.075 & 0 & -1 & 0 \\
\hline & 0 & 0 & 1 & 2 & & & & & & \\
\hline 11127 & 27 & 36 & 60 & 0 & 4965 & 075 & 5025.075 & 0 & -1 & 0 \\
\hline & 0 & 0 & 1 & 2 & & & & & & \\
\hline 11128 & 27 & 36 & 60 & 0 & 6885 & 075 & 6945.075 & 0 & -1 & 0 \\
\hline & 0 & 0 & 1 & 2 & & & & & & \\
\hline 11129 & 11 & 36 & 60 & 0 & 1065 & 075 & 1125.075 & 0 & -1 & 0 \\
\hline & 0 & 0 & 1 & 2 & & & & & & \\
\hline 11130 & 11 & 36 & 60 & 0 & 2265 & 075 & 2325.075 & 0 & -1 & 0 \\
\hline & 0 & 0 & 1 & 2 & & & & & & \\
\hline 11131 & 11 & 36 & 60 & 0 & 2505 & 075 & 2565.075 & 0 & -1 & 0 \\
\hline & 0 & 0 & 1 & 2 & & & & & & \\
\hline 11132 & 11 & 36 & 60 & 0 & 3525 & 075 & 3585.075 & 0 & -1 & 0 \\
\hline & 0 & 0 & 1 & 2 & & & & & & \\
\hline 11133 & 11 & 36 & 60 & 0 & 4845 & 075 & 4905.075 & 0 & -1 & 0 \\
\hline & 0 & 0 & 1 & 2 & & & & & & \\
\hline 11134 & 11 & 36 & 60 & 0 & 6045 & 075 & 6105.075 & 0 & -1 & 0 \\
\hline & 0 & 0 & 1 & 2 & & & & & & \\
\hline 11135 & 11 & 36 & 60 & 0 & 7305 & 075 & 7365.075 & 0 & -1 & 0 \\
\hline & 0 & 0 & 1 & 2 & & & & & & \\
\hline 11136 & 13 & 12 & 60 & 0 & 136 & 537 & 196.7537 & 0 & -1 & 0 \\
\hline & 0 & 0 & 1 & 2 & & & & & & \\
\hline 11137 & 13 & 12 & 60 & 0 & 1336 & 754 & 1396.754 & 0 & -1 & 0 \\
\hline & 0 & 0 & 1 & 2 & & & & & & \\
\hline 11138 & 13 & 12 & 60 & 0 & 2716 & 754 & 2776.754 & 0 & -1 & 0 \\
\hline & 0 & 0 & 1 & 2 & & & & & & \\
\hline 11139 & 13 & 12 & 60 & 0 & 3436 & 754 & 3496.754 & 0 & -1 & 0 \\
\hline & 0 & 0 & 1 & 2 & & & & & & \\
\hline 11140 & 13 & 12 & 60 & 0 & 5056 & 754 & 5116.754 & 0 & -1 & 0 \\
\hline & 0 & 0 & 1 & 2 & & & & & & \\
\hline 11141 & 13 & 12 & 60 & 0 & 6316 & 754 & 6376.754 & 0 & -1 & 0 \\
\hline & 0 & 0 & 1 & 2 & & & & & & \\
\hline 11142 & 10 & 36 & 60 & 0 & 465 & 746 & 525.0746 & 0 & -1 & 0 \\
\hline & 0 & 0 & 1 & 2 & & & & & & \\
\hline 11143 & 10 & 36 & 60 & 0 & 1665 & 075 & 1725.075 & 0 & 0 & -1 \\
\hline & 0 & 0 & 1 & 2 & & & & & & \\
\hline 11144 & 10 & 36 & 60 & 0 & 3045 & 075 & 3105.075 & 0 & -1 & 0 \\
\hline & 0 & 0 & 1 & 2 & & & & & & \\
\hline
\end{tabular}




\section{SUMMARY.OUT (Summary Output Measures for each vehicle class, including Delay for one run e.g. \#30 Priority)}

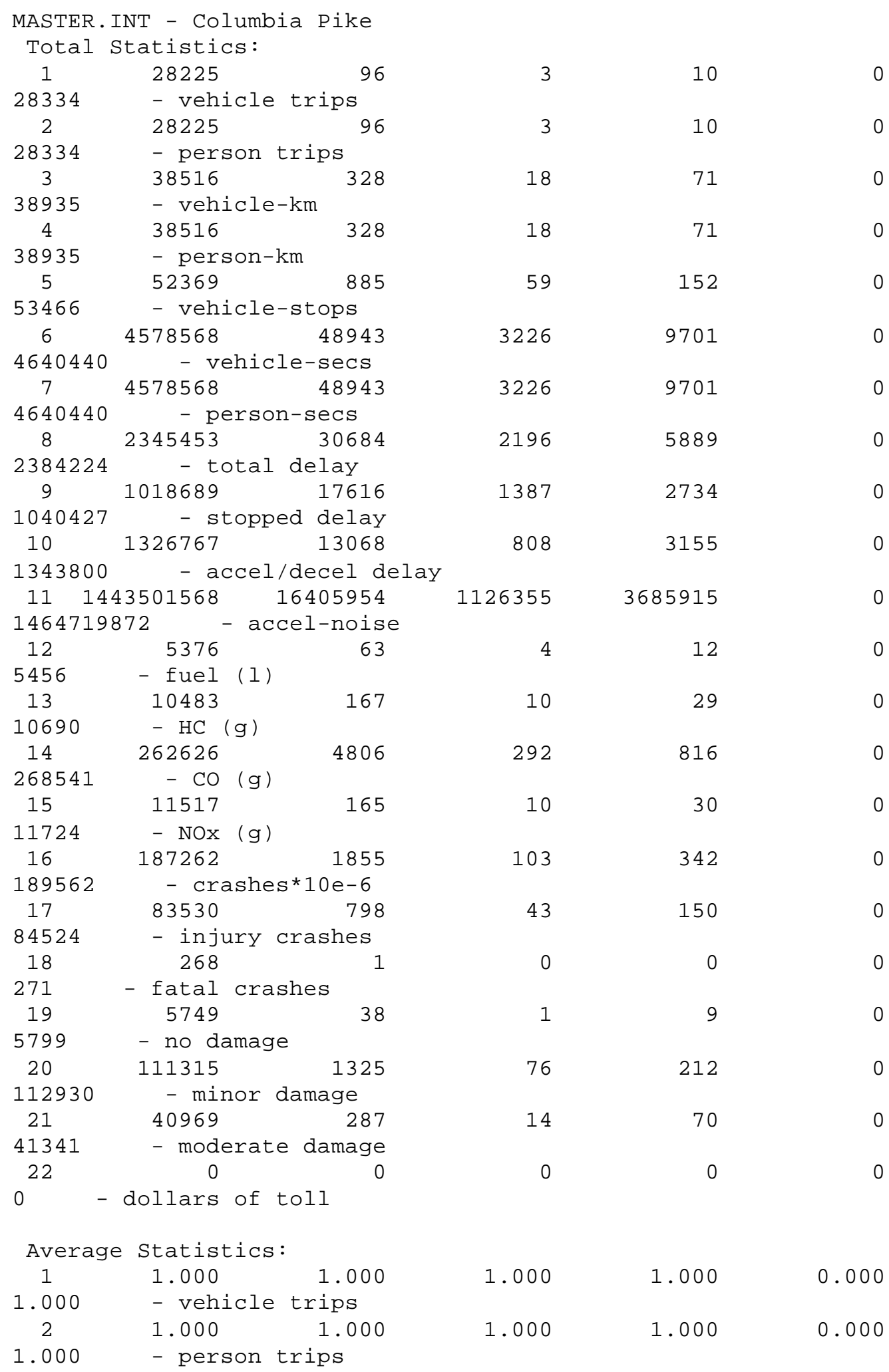




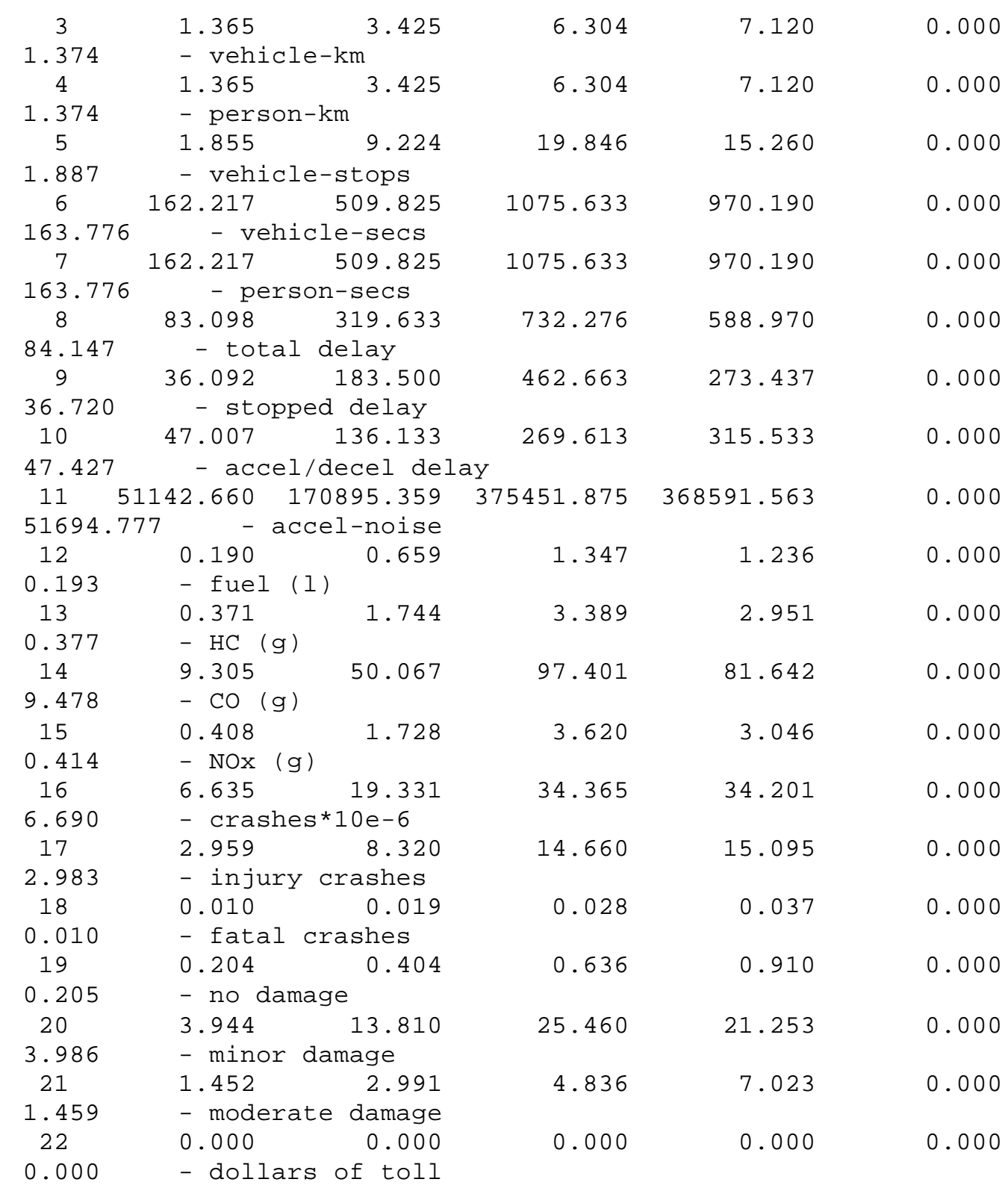




\section{FILE16AM.DAT - EXCERPT PRIORITY RUN \#30 (Shows time of individual bus link traversals)}

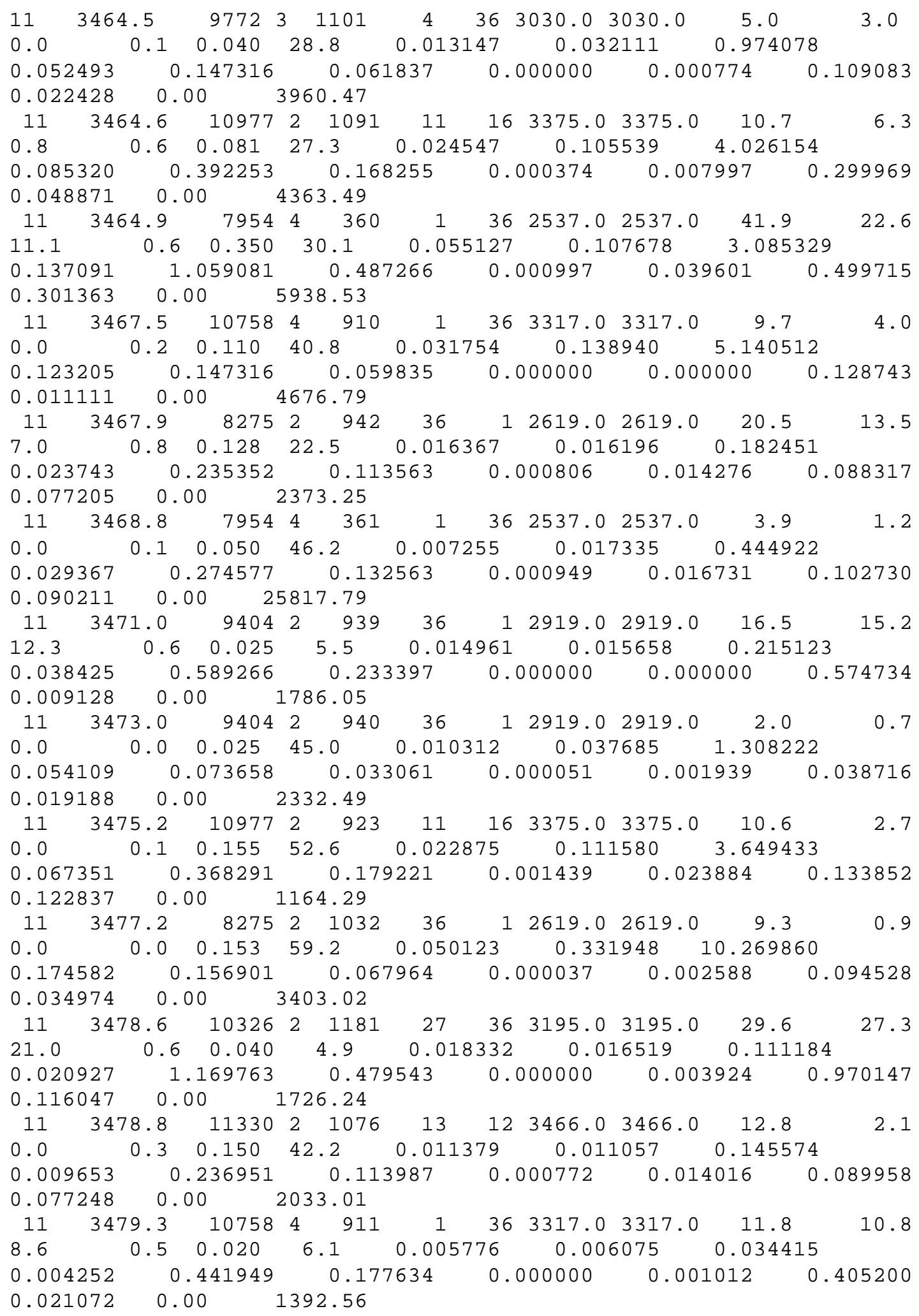




\section{Appendix F: Data Summaries from I NTEGRATI ON Runs}

\section{Main Summary Comparing No Priority (NP) with Priority for 30 runs}

\begin{tabular}{|c|c|c|c|c|c|}
\hline \multirow[b]{2}{*}{ Run \# } & \multicolumn{2}{|c|}{$\begin{array}{l}\text { Avg. Delta } \\
\text { Navy Annex }\end{array}$} & & \multicolumn{2}{|c|}{ St. Dev. Delta } \\
\hline & NP & $\mathrm{P}$ & & NP & $\mathrm{P}$ \\
\hline 1 & 32.91 & 20.38 & & 133.9 & 137.7 \\
\hline 2 & 66.18 & 64.82 & & 185.9 & 170.8 \\
\hline 3 & 235.6 & 210.3 & & 269.9 & 266.2 \\
\hline 5 & 62.84 & 63.79 & & 158.9 & 173.1 \\
\hline 9 & 98.44 & 95.84 & & 227.3 & 221.6 \\
\hline 10 & 111.5 & 97.75 & & 190.8 & 176.2 \\
\hline 11 & 154.2 & 139.9 & & 203 & 190.6 \\
\hline 13 & 75.32 & 65.51 & & 169.3 & 153.3 \\
\hline 14 & 128.2 & 130.9 & & 185.9 & 178.7 \\
\hline 17 & 76.17 & 58.58 & & 209.1 & 185.2 \\
\hline 19 & 150.6 & 167.1 & & 278.7 & 287.7 \\
\hline 20 & 113.2 & 116.3 & & 200.8 & 198.4 \\
\hline 21 & 102.3 & 92.44 & & 166.9 & 152.1 \\
\hline 24 & 164.4 & 152.1 & & 245.8 & 231.6 \\
\hline 25 & 88.74 & 88.01 & & 182.1 & 183.7 \\
\hline 26 & 87.14 & 61.79 & & 179.6 & 158.1 \\
\hline 27 & 77.54 & 72.89 & & 169.3 & 157.8 \\
\hline 28 & 164.9 & 156.9 & & 257.6 & 246.4 \\
\hline 30 & 75.23 & 68.94 & & 160.1 & 150.5 \\
\hline 4 & 114.9 & 123 & & 185.2 & 185.8 \\
\hline 6 & 167.6 & 142.7 & & 203.2 & 186.8 \\
\hline 7 & 208 & 193.4 & & 312.9 & 307.3 \\
\hline 8 & 172 & 158.1 & & 283.5 & 255.6 \\
\hline 12 & 187.2 & 152.2 & & 214 & 192.6 \\
\hline 15 & 136.9 & 125.4 & & 258.2 & 257.4 \\
\hline 16 & 61.93 & 67.44 & & 166.6 & 163.4 \\
\hline 18 & 199.9 & 184.6 & & 274.7 & 267.3 \\
\hline 22 & 96.39 & 118.2 & & 239.2 & 265.7 \\
\hline 23 & 69.24 & 68.14 & & 195.9 & 210.9 \\
\hline 29 & 61.51 & 61.79 & & 163.4 & 158.1 \\
\hline AVG & 118 & 110.6 & $-6.3 \%$ & 209 & 202.4 \\
\hline STDEV & 51.76 & 47.72 & & 45.42 & 46.78 \\
\hline
\end{tabular}

\begin{tabular}{cc}
\multicolumn{3}{c}{ St Dev Run Tim $\epsilon$} \\
GM-Navy Ann. \\
NP & P \\
78.122 & 81.404 \\
148.33 & 129.23 \\
221.11 & 224.72 \\
104.24 & 124.37 \\
163.05 & 163.8 \\
140.29 & 127.69 \\
156.33 & 157.91 \\
126.57 & 114.57 \\
150.75 & 159.69 \\
131.19 & 106.06 \\
209.51 & 231.8 \\
145.88 & 142.74 \\
117.01 & 106.66 \\
185.44 & 195.97 \\
137.71 & 143.98 \\
119.1 & 95.22 \\
114.13 & 104.22 \\
196.42 & 182.62 \\
123.19 & 112.85 \\
162.76 & 157.42 \\
189.27 & 165.15 \\
229.15 & 223.47 \\
201.77 & 182.31 \\
182.62 & 165.87 \\
207.94 & 212.49 \\
132.63 & 136.95 \\
232.01 & 236.2 \\
187.01 & 219.48 \\
131.47 & 150.5 \\
105.37 & 95.22 \\
157.68 & 155.02 \\
40.992 & 45.211 \\
& \\
&
\end{tabular}

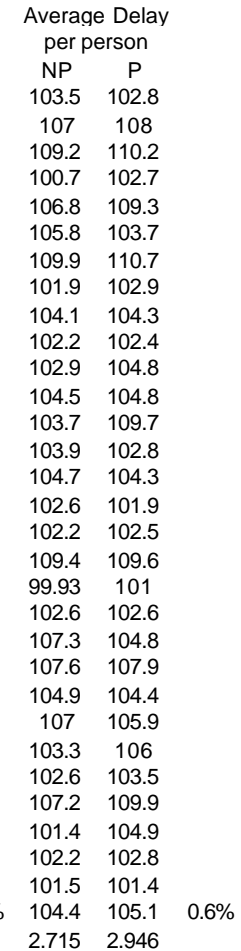




\section{Sample of More Detailed Table: Base Run \#30 Showing Timepoints}

$\begin{array}{rr} & \text { GMASON } \\ 439.2 & 459 \\ 676.7 & 1517 \\ 1083.2 & 2427 \\ 1178.5 & 2245 \\ 1235.4 & 3357 \\ 1735.5 & 4106 \\ 1888.9 & 4066 \\ 1989.6 & 5144 \\ 2069.5 & 4957 \\ 2435.7 & 5981 \\ 2535.6 & 7152 \\ 2733.8 & 7943 \\ 2738.9 & 7741 \\ 2967.2 & 7954 \\ 3235.6 & 9940 \\ 3435.6 & 9772 \\ 3735.1 & 11682 \\ 3739.6 & 10758 \\ 3833.8 & 11210 \\ 3987.6 & 12634 \\ 4235.7 & 12422 \\ 4735.6 & 15381 \\ 4848.6 & 15152 \\ 5035.6 & 16763 \\ 5289.2 & 17029 \\ 5637.8 & 18784 \\ 5735.6 & 18064 \\ 5939.6 & 18794 \\ 6185.8 & 20354 \\ 6271.5 & 21232 \\ 6633.7 & 22385 \\ 6786.2 & 23489 \\ 7087.7 & 23761 \\ 7535.5 & 25832 \\ 7742.4 & 25436 \\ 8159.8 & 27654\end{array}$

\begin{tabular}{rrrr} 
NA & & \multicolumn{2}{c}{ nopriority time } \\
819.8 & 459 & 0 & 380.6 \\
1029.9 & 1517 & 0 & 353.2 \\
1784.4 & 2427 & 0 & 701.2 \\
1824 & 2245 & 0 & 645.5 \\
1841.2 & 3357 & 0 & 605.8 \\
2218.9 & 4106 & 0 & 483.4 \\
2314.5 & 4066 & 0 & 425.6 \\
2807.5 & 5144 & 0 & 817.9 \\
2828.1 & 4957 & 0 & 758.6 \\
2854.7 & 5981 & 0 & 419 \\
3242.3 & 7152 & 0 & 706.7 \\
3266.1 & 7943 & 0 & 532.3 \\
3295.5 & 7741 & 0 & 556.6 \\
3381.3 & 7954 & 0 & 414.1 \\
3695.5 & 9940 & 0 & 459.9 \\
3918.5 & 9772 & 0 & 482.9 \\
4346.8 & 11682 & 0 & 611.7 \\
4131.8 & 10758 & 0 & 392.2 \\
4374 & 11210 & 0 & 540.2 \\
4467 & 12634 & 0 & 479.4 \\
4639.7 & 12422 & 0 & 404 \\
5185.1 & 15381 & 0 & 449.5 \\
5237.5 & 15152 & 0 & 388.9 \\
5527 & 16763 & 0 & 491.4 \\
5786.9 & 17029 & 0 & 497.7 \\
6113 & 18784 & 0 & 475.2 \\
6146.2 & 18064 & 0 & 410.6 \\
6505.2 & 18794 & 0 & 565.6 \\
6583.7 & 20354 & 0 & 397.9 \\
6909.1 & 21232 & 0 & 637.6 \\
7085.5 & 22385 & 0 & 451.8 \\
7583.5 & 23489 & 0 & 797.3 \\
7599.1 & 23761 & 0 & 511.4 \\
8080 & 25832 & 0 & 544.5 \\
8413.1 & 25436 & 0 & 670.7 \\
8571.8 & 27654 & 0 & 412 \\
& & & \\
& & & 524.2472 \\
& & & \\
& & & 123.1917
\end{tabular}

\begin{tabular}{|c|c|c|c|c|c|}
\hline SCHDEP & $\mathrm{SCH}$ GM & SCH NA & & DEV GM & DEV NA \\
\hline 137 & 540 & 900 & & -100.8 & $-80.2 n p$ \\
\hline 495 & 600 & 1200 & & 76.7 & $-170.1 \mathrm{np}$ \\
\hline 796 & 960 & 1500 & & 123.2 & $284.4 \mathrm{np}$ \\
\hline 737 & 1140 & 1500 & & 38.5 & $324 \mathrm{np}$ \\
\hline 1095 & 1200 & 1800 & & 35.4 & $41.2 \mathrm{np}$ \\
\hline 1350 & 1560 & 2100 & 1320 & 175.5 & 118.9 PR \\
\hline 1337 & 1740 & 2100 & & 148.9 & $214.5 \mathrm{np}$ \\
\hline 1695 & 1800 & 2400 & 1665 & 189.6 & 407.5 PR \\
\hline 1637 & 2040 & 2580 & & 29.5 & $248.1 \mathrm{np}$ \\
\hline 1937 & 2340 & 2700 & & 95.7 & $154.7 \mathrm{np}$ \\
\hline 2295 & 2400 & 3000 & & 135.6 & $242.3 \mathrm{np}$ \\
\hline 2535 & 2640 & 3240 & & 93.8 & $26.1 \mathrm{np}$ \\
\hline 2476 & 2640 & 3360 & & 98.9 & $-64.5 \mathrm{np}$ \\
\hline 2537 & 2940 & 3360 & & 27.2 & $21.3 \mathrm{np}$ \\
\hline 3075 & 3180 & 3780 & & 55.6 & $-84.5 \mathrm{np}$ \\
\hline 3030 & 3240 & 3960 & 3000 & 195.6 & $-41.5 P R$ \\
\hline 3555 & 3660 & 4260 & & 75.1 & $86.8 \mathrm{np}$ \\
\hline 3317 & 3720 & 4140 & & 19.6 & $-8.2 \mathrm{np}$ \\
\hline 3437 & 3840 & 4560 & & -6.2 & $-186 \mathrm{np}$ \\
\hline 3795 & 4200 & 4800 & & -212.4 & $-333 n p$ \\
\hline 3737 & 4140 & 4560 & & 95.7 & $79.7 \mathrm{np}$ \\
\hline 4516 & 4680 & 5160 & & 55.6 & $25.1 \mathrm{np}$ \\
\hline 4457 & 4860 & 5220 & & -11.4 & $17.5 \mathrm{np}$ \\
\hline 4875 & 4980 & 5460 & & 55.6 & $67 \mathrm{np}$ \\
\hline 4950 & 5220 & 5760 & & 69.2 & $26.9 \mathrm{np}$ \\
\hline 5415 & 5520 & 6000 & & 117.8 & $113 \mathrm{np}$ \\
\hline 5237 & 5640 & 6000 & & 95.6 & $146.2 \mathrm{np}$ \\
\hline 5417 & 5820 & 6360 & & 119.6 & $145.2 \mathrm{np}$ \\
\hline 5837 & 6240 & 6600 & & -54.2 & $-16.3 \mathrm{np}$ \\
\hline 6075 & 6180 & 6660 & & 91.5 & $249.1 \mathrm{np}$ \\
\hline 6376 & 6540 & 7020 & & 93.7 & $65.5 \mathrm{np}$ \\
\hline 6675 & 6780 & 7260 & & 6.2 & $323.5 \mathrm{np}$ \\
\hline 6750 & 7020 & 7560 & & 67.7 & $39.1 \mathrm{np}$ \\
\hline 7335 & 7440 & 7920 & & 95.5 & $160 \mathrm{np}$ \\
\hline 7217 & 7620 & 8160 & & 122.4 & $253.1 \mathrm{np}$ \\
\hline 7890 & 8220 & 8760 & & -60.2 & $-188.2 \mathrm{np}$ \\
\hline & & & & & 22778 \\
\hline
\end{tabular}




\section{Delay Table for Base Cases}

$\begin{array}{lrrr}\text { t-total, p-per vericle } & \\ 01-\mathrm{t} & 8 & 2409771 & 33208 \\ 01-\mathrm{p} & 8 & 85.523 & 335.444 \\ 02-\mathrm{t} & 8 & 2491256 & 32868 \\ 02-\mathrm{p} & 8 & 89.187 & 345.986 \\ 03-\mathrm{t} & 8 & 2484401 & 38080 \\ 03-\mathrm{p} & 8 & 87.794 & 388.574 \\ 04-\mathrm{t} & 8 & 2368743 & 34061 \\ 04-\mathrm{p} & 8 & 83.944 & 344.053 \\ 05-\mathrm{t} & 8 & 2349802 & 32274 \\ 05-\mathrm{p} & 8 & 83.335 & 326.006 \\ 06-\mathrm{t} & 8 & 2462043 & 36475 \\ 06-\mathrm{p} & 8 & 87.112 & 368.434 \\ 07-\mathrm{t} & 8 & 2455019 & 37006 \\ 07-\mathrm{p} & 8 & 87.011 & 373.8 \\ 08-\mathrm{t} & 8 & 2404713 & 35481 \\ 08-\mathrm{p} & 8 & 85.289 & 358.398 \\ 09-\mathrm{t} & 8 & 2435960 & 34702 \\ 09-\mathrm{p} & 8 & 87.458 & 361.481 \\ 10-\mathrm{t} & 8 & 2462347 & 34332 \\ 10-\mathrm{p} & 8 & 87.24 & 346.792 \\ 11-\mathrm{t} & 8 & 2482623 & 36647 \\ 11-\mathrm{p} & 8 & 89.191 & 381.741 \\ 12-\mathrm{t} & 8 & 2452448 & 36224 \\ 12-\mathrm{p} & 8 & 86.929 & 365.899 \\ 13-\mathrm{t} & 8 & 2392083 & 32214 \\ 13-\mathrm{p} & 8 & 84.649 & 325.395 \\ 14-\mathrm{t} & 8 & 2383071 & 35404 \\ 14-\mathrm{p} & 8 & 84.416 & 361.267 \\ 15-\mathrm{t} & 8 & 2329433 & 36237 \\ 15-\mathrm{p} & 8 & 82.689 & 373.583 \\ 16-\mathrm{t} & 8 & 2386638 & 33343 \\ 16-\mathrm{p} & 8 & 84.561 & 336.805 \\ 17-\mathrm{t} & 8 & 2395654 & 32406 \\ 17-\mathrm{p} & 8 & 84.817 & 327.334 \\ 18-\mathrm{t} & 8 & 2434119 & 37214 \\ 18-\mathrm{p} & 8 & 86.243 & 383.653 \\ 19-\mathrm{t} & 8 & 2381673 & 34104 \\ 19-\mathrm{p} & 8 & 84.215 & 344.491 \\ 20-\mathrm{t} & 8 & 2382809 & 36042 \\ 20-\mathrm{p} & 8 & 84.383 & 364.068 \\ 21-\mathrm{t} & 8 & 2372667 & 35056 \\ 21-\mathrm{p} & 8 & 84.287 & 354.107 \\ 22-\mathrm{t} & 8 & 2361300 & 32858 \\ 22-\mathrm{p} & 8 & 83.601 & 331.908 \\ 23-\mathrm{t} & 8 & 2374794 & 33006 \\ 23-\mathrm{p} & 8 & 84.344 & 333.4 \\ 24-\mathrm{t} & 8 & 2438126 & 32609 \\ 24-\mathrm{p} & 8 & 86.266 & 339.679 \\ 25-\mathrm{t} & 8 & 2420531 & 34587 \\ 25-\mathrm{p} & 8 & 85.78 & 349.366 \\ 26-\mathrm{t} & 8 & 2381781 & 33427 \\ 26-\mathrm{p} & 8 & 84.472 & 337.654 \\ 27-\mathrm{t} & 8 & 2390115 & 32561 \\ 27-\mathrm{p} & 8 & 84.738 & 328.904 \\ 28-\mathrm{t} & 8 & 2435568 & 40070 \\ 28-\mathrm{p} & 8 & 86.429 & 404.75 \\ 29-\mathrm{t} & 8 & 2381480 & 32421 \\ 29-\mathrm{p} & 8 & 84.08 & 327.494 \\ 30-\mathrm{t} & 8 & 2315337 & 32824 \\ 30-\mathrm{p} & 8 & 82.031 & 331.561\end{array}$

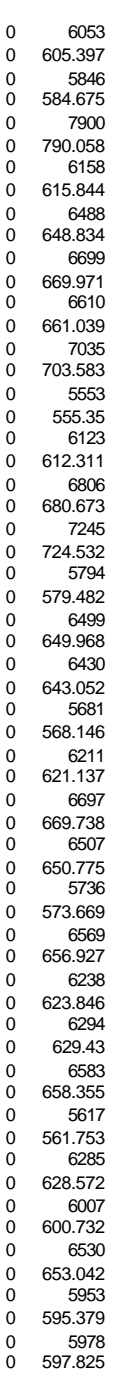

\begin{tabular}{|c|c|c|}
\hline & 2449034 & total \\
\hline & 86.581 - & total \\
\hline & 2529971 - & total \\
\hline 0 & 90.234 - & total \\
\hline 0 & 2530381 - & total \\
\hline 0 & 89.079 - & total \\
\hline 0 & $2408963-$ & total \\
\hline 0 & 85.041 - & total \\
\hline & $2388564-$ & total \\
\hline 0 & 84.384 - & total \\
\hline 0 & $2505218-$ & total \\
\hline 0 & 88.299 - & total \\
\hline 0 & 2498635 - & total \\
\hline 0 & 88.216 - & total \\
\hline 0 & $2447230-$ & total \\
\hline 0 & 86.462 - & total \\
\hline U & 2476216 - & total \\
\hline 0 & 88.566 - & total \\
\hline 0 & $2502802-$ & total \\
\hline 0 & 88.332 - & total \\
\hline 0 & 2526077 - & total \\
\hline . & 90.408 - & total \\
\hline 0 & 2495918 - & total \\
\hline 0 & 88.13 - & total \\
\hline 0 & $2430092-$ & total \\
\hline 0 & 85.663 - & total \\
\hline 0 & 2424975 - & total \\
\hline 0 & 85.573 - & total \\
\hline 0 & 2372101 - & total \\
\hline 0 & 83.885 - & total \\
\hline 0 & $2425663-$ & total \\
\hline 0 & 85.613 - & total \\
\hline 0 & 2434271 - & total \\
\hline 0 & $85.853-$ & total \\
\hline 0 & 2478030 - & total \\
\hline 0 & 87.467 - & total \\
\hline 0 & 2422286 - & total \\
\hline 0 & 85.322 - & total \\
\hline 0 & 2424589 - & total \\
\hline 0 & 85.532 - & total \\
\hline 0 & 2414293 - & total \\
\hline 0 & 85.434 - & total \\
\hline 0 & 2400398 - & total \\
\hline 0 & 84.658 - & total \\
\hline 0 & 2414094 - & tot \\
\hline 0 & 85.409 - & total \\
\hline 0 & 2477319 - & total \\
\hline 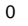 & 87.325 - & total \\
\hline 0 & $2460736-$ & total \\
\hline 0 & 86.869 - & total \\
\hline 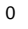 & 2421494 - & tot \\
\hline 0 & 85.55 - & total \\
\hline $\begin{array}{l}0 \\
0\end{array}$ & $\begin{array}{r}2428684 \text { - } \\
85774\end{array}$ & total \\
\hline 0 & & \\
\hline 0 & $87743-$ & total \\
\hline 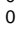 & 2419856 - & total \\
\hline U & 85.107 - & tot \\
\hline & 2354139 - & total \\
\hline & 83.085 - & total \\
\hline
\end{tabular}

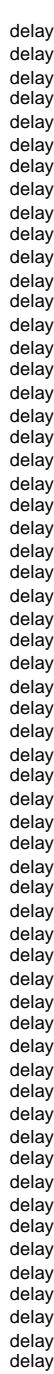

\begin{tabular}{lrr} 
occup $=$ & 23 & \\
\#veh & 28176.88 & 98.99715 \\
\#veh & 27932.95 & 94.99806 \\
\#veh & 28298.07 & 97.99935 \\
\#veh & 28218.13 & 98.99928 \\
\#veh & 28197.06 & 98.99818 \\
\#veh & 28262.96 & 99.00009 \\
\#veh & 28215.04 & 98.99946 \\
\#veh & 28194.88 & 98.99888 \\
\#veh & 27852.91 & 95.99951 \\
\#veh & 28224.98 & 98.99882 \\
\#veh & 27834.9 & 95.99964 \\
\#veh & 28212.08 & 99 \\
\#veh & 28258.85 & 98.99968 \\
\#veh & 28230.09 & 97.99954 \\
\#veh & 28171.01 & 96.99853 \\
\#veh & 28225.15 & 98.99837 \\
\#veh & 28223.86 & 98.99794 \\
\#veh & 28244.97 & 98.9998 \\
\#veh & 28223.96 & 96.99911 \\
\#veh & 28280.86 & 98.99823 \\
\#veh & 28238.02 & 98.99799 \\
\#veh & 28149.86 & 98.99833 \\
\#veh & 28217.89 & 98.99933 \\
\#veh & 2824196.88 & 98.99731 \\
\hline & 28156.05 & 98.9982 \\
\hline & 28262.88 & 95.99946 \\
\hline
\end{tabular}

\begin{tabular}{|c|c|}
\hline 9.998398 & $\begin{array}{r}28285.87 \\
103.455\end{array}$ \\
\hline 9.998717 & $\begin{array}{l}28037.95 \\
107.0268\end{array}$ \\
\hline 9.999266 & 28406.07 \\
\hline 9.999286 & $\begin{array}{l}109.1955 \\
28327.13 \\
102.6194\end{array}$ \\
\hline 9.999476 & $\begin{array}{l}28306.06 \\
100.7355\end{array}$ \\
\hline 9.99894 & $\begin{array}{l}28371.96 \\
107.3082\end{array}$ \\
\hline 9.99941 & $\begin{array}{l}28324.04 \\
107.6442\end{array}$ \\
\hline 9.99882 & $\begin{array}{l}28303.88 \\
104.9354\end{array}$ \\
\hline 9.9991 & $\begin{array}{l}27958.91 \\
106.7942\end{array}$ \\
\hline 9.99982 & $\begin{array}{l}106.1942 \\
2833.98 \\
105.8451\end{array}$ \\
\hline 9.998928 & $\begin{array}{l}27940.9 \\
109.881\end{array}$ \\
\hline 9.999558 & $\begin{array}{l}28321.08 \\
106.9874\end{array}$ \\
\hline 9.998585 & $\begin{array}{l}28367.84 \\
101.8603\end{array}$ \\
\hline 9.998954 & $\begin{array}{l}28338.09 \\
104.1296\end{array}$ \\
\hline 9.999191 & $\begin{array}{l}28278.01 \\
103.2829\end{array}$ \\
\hline 9.99919 & $\begin{array}{l}28332.86 \\
102.6438\end{array}$ \\
\hline 9.999404 & $\begin{array}{l}28353.97 \\
102.1673\end{array}$ \\
\hline 9.999433 & $\begin{array}{l}28330.96 \\
107.2494\end{array}$ \\
\hline 9.998848 & $\begin{array}{l}28389.86 \\
102.8637\end{array}$ \\
\hline 9.998797 & $\begin{array}{l}28347.02 \\
104.4913\end{array}$ \\
\hline 9.999589 & $\begin{array}{l}28258.85 \\
103.7238\end{array}$ \\
\hline 9.999263 & $\begin{array}{l}28353.87 \\
101.3888\end{array}$ \\
\hline 9.999523 & $\begin{array}{l}28265.05 \\
102.2337\end{array}$ \\
\hline 9.999165 & $\begin{array}{r}28368.88 \\
103.874\end{array}$ \\
\hline 9.999057 & 28326.89 \\
\hline 9.998855 & $\begin{array}{r}104.6978 \\
28305.1 \\
102.6433\end{array}$ \\
\hline 9.999467 & $\begin{array}{l}28314.94 \\
102.2323\end{array}$ \\
\hline 9.999357 & $\begin{array}{l}28288.98 \\
109.4296\end{array}$ \\
\hline 9.998673 & $\begin{array}{l}28432.97 \\
101.4563\end{array}$ \\
\hline 9.999582 & $\begin{array}{l}28334.14 \\
99.93189\end{array}$ \\
\hline
\end{tabular}




\section{Delay Table for Priority Cases}

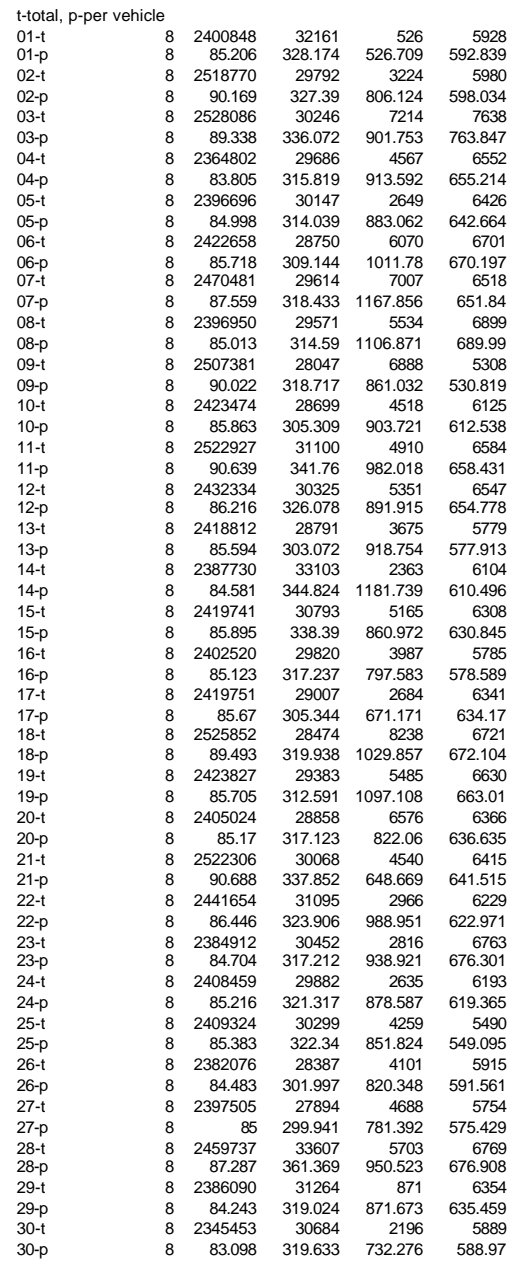

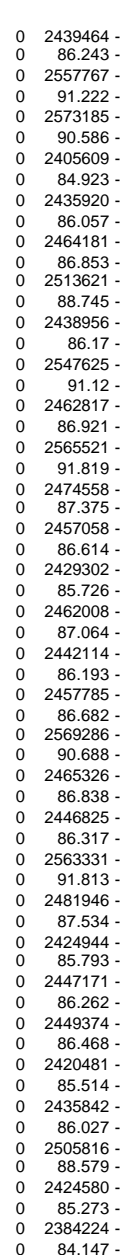

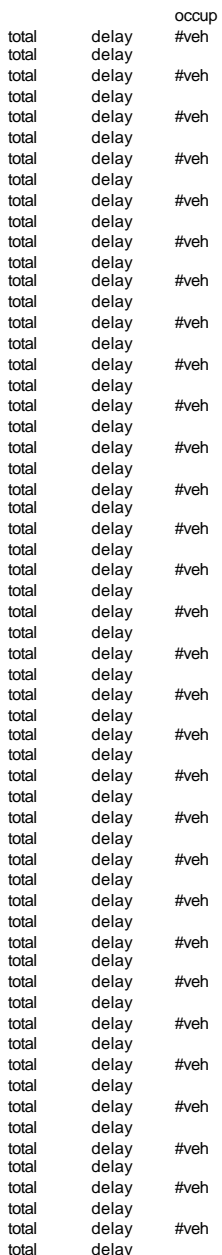

$\begin{array}{rrrr}23 & 97.9994 & 0.998654 & 9.999342 \\ 28176.98 & 97.998\end{array}$

$27933.88 \quad 90.9985 \quad 3.999385 \quad 9.999431$

$\begin{array}{lllll}28297.99 & 89.99857 & 7.999973 & 9.999385\end{array}$

$\begin{array}{lllll}28217.91 & 93.99688 & 4.998949 & 9.999786\end{array}$

$\begin{array}{lllll}28197.09 & 95.99763 & 2.999789 & 9.999004\end{array}$

$\begin{array}{lllll}28263.12 & 92.99873 & 5.999328 & 9.998553\end{array}$

$28215.04 \quad 92.99916 \quad 5.999884 \quad 9.999386$

$28195.1 \quad 93.99854 \quad 4.9996799 .998696$

$27852.98 \quad 87.9997 \quad 7.999703 \quad 9.999642$

$\begin{array}{lllll}28224.89 & 93.99985 & 4.999331 & 9.99938\end{array}$

$\begin{array}{lllll}27834.89 & 90.99953 & 4.999908 & 9.999529\end{array}$

$\begin{array}{llll}28212.1 & 92.99922 & 5.999451 & 9.998809\end{array}$

$\begin{array}{lllll}28259.13 & 94.99723 & 3.999983 & 9.999775\end{array}$

$\begin{array}{llll}28230.1 & 95.9997 & 1.999596 & 9.998428\end{array}$

$\begin{array}{lllll}28170.92 & 90.99855 & 5.999034 & 9.999287\end{array}$

$28224.1 \quad 93.99912 \quad 4.998853 \quad 9.998462$

$\begin{array}{lllll}28245.02 & 94.99777 & 3.998981 & 9.998896\end{array}$

$\begin{array}{llll}28224.02 & 88.99849 & 7.999169 & 9.99994\end{array}$

$\begin{array}{llll}28281.05 & 93.99823 & 4.999508 & 9.999849\end{array}$

$\begin{array}{lllll}28237.92 & 90.99939 & 7.999416 & 9.99945\end{array}$

$\begin{array}{lllll}27813.01 & 88.99755 & 6.998947 & 9.999766\end{array}$

$\begin{array}{llll}28244.85 & 96.00007 & 2.999137 & 9.99886\end{array}$

$\begin{array}{llll}28155.84 & 95.99889 & 2.999187 & 9.999985\end{array}$

$\begin{array}{lllll}28262.99 & 92.9985 & 2.999134 & 9.998951\end{array}$

$\begin{array}{llll}28217.84 & 93.99702 & 4.999859 & 9.99827\end{array}$

$\begin{array}{lllll}28195.92 & 93.99762 & 4.999098 & 9.998969\end{array}$

$\begin{array}{llll}28205.94 & 92.99829 & 5.99955 & 9.999496\end{array}$

$\begin{array}{lllll}28179.88 & 92.99912 & 5.999855 & 9.999882\end{array}$

$\begin{array}{llll}28323.9 & 97.9989 & 0.999228 & 9.999072\end{array}$

$\begin{array}{llll}28225.14 & 95.9976 & 2.998869 & 9.998811\end{array}$ $\begin{array}{r}28285.98 \\ 102.7727 \\ 28038.88 \\ 108.0426 \\ 28405.99 \\ 110.1509 \\ 28326.91 \\ 102.6371 \\ 28306.08 \\ 102.6536 \\ 28372.12 \\ 104.7908 \\ 28324.04 \\ 107.859 \\ 28304.1 \\ 104.3998 \\ 27958.98 \\ 109.3279 \\ 28333.89 \\ 103.746 \\ 27940.89 \\ 110.7277 \\ 28321.09 \\ 105.9202 \\ 28368.13 \\ 102.9166 \\ 28338.1 \\ 104.3265 \\ 28277.91 \\ 106.0216 \\ 28333.1 \\ 103.5075 \\ 28354.02 \\ 102.4166 \\ 28331.02 \\ 109.8626 \\ 28390.04 \\ 104.8033 \\ 28346.92 \\ 104.7613 \\ 27919 \\ 109.721 \\ 28353.84 \\ 104.9015 \\ 28264.83 \\ 102.7624 \\ 28368.99 \\ 102.8373 \\ 28326.84 \\ 104.3113 \\ 28304.92 \\ 101.949 \\ 28314.94 \\ 102.4878 \\ 28288.88 \\ 109.6487 \\ 28432.89 \\ 101.394 \\ 28334.14 \\ 100.9537 \\ \hline\end{array}$ 
Results of Analysis of Arrival Reliability at Individual Trip Level

Trip scheduled to depart at $1350 \mathrm{sec}$. Arriving at GM at $1560 \mathrm{~s}, \mathrm{NA}$ at $2100 \mathrm{~s}$

\begin{tabular}{|c|c|c|}
\hline \multicolumn{3}{|c|}{ NP } \\
\hline Run & GM & Dev NA \\
\hline 1 & 1735.6 & 122.7 \\
\hline 2 & 1738.9 & 196 \\
\hline 3 & 1635.5 & -78.4 \\
\hline 4 & 1688.3 & 6.8 \\
\hline 5 & 1735 & 118.6 \\
\hline 6 & 1846 & 408.2 \\
\hline 7 & 2235.7 & 1336.2 \\
\hline 8 & 2235.3 & 1251.6 \\
\hline 9 & 1740.1 & 133.1 \\
\hline 10 & 1766.8 & 121.9 \\
\hline 11 & 1835.7 & 390.8 \\
\hline 12 & 1767.1 & 176.2 \\
\hline 13 & 1935.6 & 634.5 \\
\hline 14 & 1635.5 & -68.3 \\
\hline 15 & 1688.5 & 510.5 \\
\hline 16 & 1735.6 & 94.9 \\
\hline 17 & 1678.8 & -12.5 \\
\hline 18 & 1735.6 & 121.4 \\
\hline 19 & 1690.3 & 92 \\
\hline 20 & 1935.2 & 552.6 \\
\hline 21 & 1735.6 & 115 \\
\hline 22 & 1935.2 & 552.6 \\
\hline 23 & 1687.3 & 109.7 \\
\hline 24 & 1659.3 & 44.2 \\
\hline 25 & 1741.4 & 141 \\
\hline 26 & 1635.6 & -77.7 \\
\hline 27 & 1768 & 182.4 \\
\hline 28 & 1841 & 422.2 \\
\hline 29 & 1841 & 422.2 \\
\hline 30 & 1735.5 & 118.9 \\
\hline & & $\begin{array}{c}271.31 \\
340.8089\end{array}$ \\
\hline
\end{tabular}

$\begin{array}{ccc}\text { GM } & \text { Dev NA } & \\ 1694.2 & 42.4 & \\ 1705.4 & 125.7 & \\ 1637.6 & -77.8 & \\ 1733.4 & 101.1 & \\ 1705.6 & 70.4 & \\ 1807.2 & 285.4 & \\ 2214.2 & 1336.2 & \\ 2143.2 & 1132.8 & \\ 1729.8 & 147.2 & \\ 1736 & 123.5 & \\ 1807.3 & 309.1 & \\ 1770.2 & 147 & \\ 1936.3 & 593.3 & \\ 1635.6 & -33.7 & \\ 1677.8 & 509.6 & \\ 1709.2 & 37.3 & \\ 1680.9 & 23.2 & \\ 1705.5 & 111.8 & \\ 1690.4 & 94.5 & \\ 1845.8 & 457.9 & \\ 1705.6 & 80.1 & \\ 1768.8 & 186.9 & \\ 1680.1 & 18.6 & \\ 1669.2 & 49.8 & \\ 1743.1 & 181.2 & \\ 1633.8 & -80.5 & \\ 1768.1 & 179.5 & \\ 1733.8 & 602.9 & \\ 1844.6 & 385.3 & \\ 1724.1 & 107.1 & \\ & 241.5933 & -11 \% \\ & 325.7345 & -4 \%\end{array}$




\section{Variability of Auto Travel Time in Base (No Priority) Runs}

$n=866$

Avg. Travel Time $=369 \mathrm{~s}$

Avg. Standard Deviation of Travel Time within a Run $=41.9 \mathrm{~s}$

\begin{tabular}{|c|c|c|c|c|c|c|}
\hline Run \# & t @ G Mason & veh id & $\mathrm{t} @ N A$ & veh id & Trav. Time. & Stdev TT (for run) \\
\hline 1 & 381.6 & 469 & 708.6 & 469 & 327 & \\
\hline 1 & 541.6 & 819 & 898.1 & 819 & 356.5 & \\
\hline 1 & 1244.1 & 3001 & 1586.5 & 3001 & 342.4 & \\
\hline 1 & 1281.6 & 3225 & 1607.9 & 3225 & 326.3 & \\
\hline 1 & 1341.6 & 3140 & 1700.6 & 3140 & 359 & \\
\hline 1 & 2554.2 & 7128 & 2897.7 & 7128 & 343.5 & \\
\hline 1 & 2637.7 & 7170 & 2999.2 & 7170 & 361.5 & \\
\hline 1 & 3344.1 & 9956 & 3711.5 & 9956 & 367.4 & \\
\hline 1 & 3433.8 & 9963 & 3808.7 & 9963 & 374.9 & \\
\hline 1 & 3641 & 10669 & 4004.7 & 10669 & 363.7 & \\
\hline 1 & 4046.8 & 12553 & 4418.8 & 12553 & 372 & \\
\hline 1 & 4135.9 & 12808 & 4556.1 & 12808 & 420.2 & \\
\hline 1 & 4453 & 13766 & 4811.8 & 13766 & 358.8 & \\
\hline 1 & 4938.1 & 15696 & 5307.8 & 15696 & 369.7 & \\
\hline 1 & 5033.7 & 15955 & 5452.2 & 15955 & 418.5 & \\
\hline 1 & 5581.2 & 18198 & 5891.7 & 18198 & 310.5 & \\
\hline 1 & 5676.4 & 18295 & 6020.4 & 18295 & 344 & \\
\hline 1 & 5835.5 & 18919 & 6210.5 & 18919 & 375 & \\
\hline 1 & 5933.7 & 19539 & 6356.1 & 19539 & 422.4 & \\
\hline 1 & 6082.2 & 20155 & 6465.4 & 20155 & 383.2 & \\
\hline 1 & 6356.9 & 21068 & 6702.8 & 21068 & 345.9 & \\
\hline 1 & 6433.7 & 21262 & 6812.6 & 21262 & 378.9 & \\
\hline 1 & 6659.6 & 22450 & 7012 & 22450 & 352.4 & \\
\hline 1 & 7055.7 & 23484 & 7405.3 & 23484 & 349.6 & \\
\hline 1 & 7333.8 & 24184 & 7772.3 & 24184 & 438.5 & \\
\hline 1 & 7369 & 24739 & 7785.4 & 24739 & 416.4 & \\
\hline 1 & 7646 & 25363 & 7995.9 & 25363 & 349.9 & \\
\hline 1 & 7767 & 26253 & 8105 & 26253 & 338 & 31.73 \\
\hline 2 & 240.4 & 7 & 587.4 & 7 & 347 & \\
\hline 2 & 388.3 & 400 & 704.1 & 400 & 315.8 & \\
\hline 2 & 787.5 & 1494 & 1101.8 & 1494 & 314.3 & \\
\hline 2 & 1242.4 & 2990 & 1604.4 & 2990 & 362 & \\
\hline 2 & 1540.4 & 3897 & 1887.4 & 3897 & 347 & \\
\hline 2 & 1841.4 & 4786 & 2214 & 4786 & 372.6 & \\
\hline 2 & 2235.6 & 5921 & 2606.3 & 5921 & 370.7 & \\
\hline 2 & 3040 & 8834 & 3408.8 & 8834 & 368.8 & \\
\hline 2 & 3238.3 & 9369 & 3587.3 & 9369 & 349 & \\
\hline 2 & 3251.9 & 9599 & 3616.4 & 9599 & 364.5 & \\
\hline 2 & 3433.8 & 10111 & 3801.6 & 10111 & 367.8 & \\
\hline 2 & 3739.7 & 10918 & 4105.9 & 10918 & 366.2 & \\
\hline 2 & 3969.2 & 11869 & 4304.1 & 11869 & 334.9 & \\
\hline 2 & 4050.1 & 12489 & 4398 & 12489 & 347.9 & \\
\hline 2 & 4052.1 & 12425 & 4461.2 & 12425 & 409.1 & \\
\hline 2 & 4474.2 & 14130 & 4823.6 & 14130 & 349.4 & \\
\hline 2 & 5040.4 & 16015 & 5401.1 & 16015 & 360.7 & \\
\hline 2 & 5145 & 16534 & 5553.9 & 16534 & 408.9 & \\
\hline 2 & 5182.1 & 16798 & 5580.2 & 16798 & 398.1 & \\
\hline 2 & 6042.5 & 19882 & 6455.3 & 19882 & 412.8 & \\
\hline
\end{tabular}




\begin{tabular}{|c|c|c|c|c|c|}
\hline 2 & 6033.5 & 19752 & 6467.4 & 19752 & 433.9 \\
\hline 2 & 6535.1 & 21849 & 6877.3 & 21849 & 342.2 \\
\hline 2 & 6944.1 & 23452 & 7365.8 & 23452 & 421.7 \\
\hline 2 & 7338.5 & 24687 & 7685.3 & 24687 & 346.8 \\
\hline 2 & 7435.3 & 24859 & 7752.7 & 24859 & 317.4 \\
\hline 2 & 7733.8 & 26203 & 8078.7 & 26203 & 344.9 \\
\hline 2 & 8236.3 & 27917 & 8492.8 & 27917 & 256.5 \\
\hline 2 & 8285.8 & 28056 & 8562.7 & 28056 & 276.9 \\
\hline 3 & 233.8 & 72 & 555.5 & 72 & 321.7 \\
\hline 3 & 742 & 1290 & 1098 & 1290 & 356 \\
\hline 3 & 1553.3 & 4000 & 1905.1 & 4000 & 351.8 \\
\hline 3 & 1637.6 & 4228 & 1932.1 & 4228 & 294.5 \\
\hline 3 & 2264 & 6351 & 2606.6 & 6351 & 342.6 \\
\hline 3 & 2383.7 & 6419 & 2699.1 & 6419 & 315.4 \\
\hline 3 & 2541.8 & 6926 & 2916.9 & 6926 & 375.1 \\
\hline 3 & 3135.4 & 8841 & 3628.3 & 8841 & 492.9 \\
\hline 3 & 3186.3 & 9234 & 3683.7 & 9234 & 497.4 \\
\hline 3 & 3289.7 & 9639 & 3717.4 & 9639 & 427.7 \\
\hline 3 & 3842.3 & 11442 & 4191.6 & 11442 & 349.3 \\
\hline 3 & 4035.6 & 12461 & 4401.3 & 12461 & 365.7 \\
\hline 3 & 4257.4 & 13105 & 4618 & 13105 & 360.6 \\
\hline 3 & 4635.5 & 14706 & 4998.4 & 14706 & 362.9 \\
\hline 3 & 4888.7 & 15797 & 5216.2 & 15797 & 327.5 \\
\hline 3 & 5037.7 & 16383 & 5445.9 & 16383 & 408.2 \\
\hline 3 & 5556.9 & 18019 & 5906 & 18019 & 349.1 \\
\hline 3 & 5562.2 & 18278 & 5917.1 & 18278 & 354.9 \\
\hline 3 & 5838.1 & 19371 & 6215 & 19371 & 376.9 \\
\hline 3 & 6137.4 & 20221 & 6512.3 & 20221 & 374.9 \\
\hline 3 & 6357.7 & 20985 & 6774.5 & 20985 & 416.8 \\
\hline 3 & 6565.2 & 22077 & 6960.2 & 22077 & 395 \\
\hline 3 & 7033.8 & 23743 & 7369.5 & 23743 & 335.7 \\
\hline 3 & 7570.2 & 25295 & 7995.4 & 25295 & 425.2 \\
\hline 3 & 7554.3 & 25369 & 8078.6 & 25369 & 524.3 \\
\hline 3 & 7789.3 & 26504 & 8211.2 & 26504 & 421.9 \\
\hline 3 & 8075.1 & 27293 & 8379.9 & 27293 & 304.8 \\
\hline 3 & 8186.6 & 27756 & 8498.9 & 27756 & 312.3 \\
\hline 4 & 638 & 990 & 987.5 & 990 & 349.5 \\
\hline 4 & 1339.3 & 3247 & 1681.4 & 3247 & 342.1 \\
\hline 4 & 1835.5 & 4703 & 2199.1 & 4703 & 363.6 \\
\hline 4 & 2087.8 & 5439 & 2454.5 & 5439 & 366.7 \\
\hline 4 & 2451.3 & 6853 & 2799.1 & 6853 & 347.8 \\
\hline 4 & 2537.8 & 7135 & 2889.7 & 7135 & 351.9 \\
\hline 4 & 2646.7 & 7304 & 3001.2 & 7304 & 354.5 \\
\hline 4 & 2760.4 & 7741 & 3109.7 & 7741 & 349.3 \\
\hline 4 & 3636 & 10821 & 4011.2 & 10821 & 375.2 \\
\hline 4 & 3845.1 & 11449 & 4208.1 & 11449 & 363 \\
\hline 4 & 4145.1 & 12752 & 4522.1 & 12752 & 377 \\
\hline 4 & 4345 & 13716 & 4802.8 & 13716 & 457.8 \\
\hline 4 & 4541.8 & 14139 & 4963.8 & 14139 & 422 \\
\hline 4 & 5041.2 & 16167 & 5470.6 & 16167 & 429.4 \\
\hline 4 & 5148.4 & 16617 & 5583.5 & 16617 & 435.1 \\
\hline 4 & 5384.3 & 17552 & 5712.1 & 17552 & 327.8 \\
\hline 4 & 5477.9 & 17963 & 5906 & 17963 & 428.1 \\
\hline 4 & 5548.6 & 18065 & 5987 & 18065 & 438.4 \\
\hline 4 & 5668 & 18837 & 6015.1 & 18837 & 347.1 \\
\hline 4 & 5741.5 & 18824 & 6114.5 & 18824 & 373 \\
\hline 4 & 5954.7 & 19856 & 6318 & 19856 & 363.3 \\
\hline 4 & 7239.2 & 24578 & 7702.6 & 24578 & 463.4 \\
\hline
\end{tabular}

40.43

58.22 


\begin{tabular}{|c|c|c|c|c|c|c|}
\hline 4 & 7336.5 & 24539 & 7779.2 & 24539 & 442.7 & \\
\hline 4 & 8039.6 & 27192 & 8356.5 & 27192 & 316.9 & \\
\hline 4 & 8136.6 & 27269 & 8464.5 & 27269 & 327.9 & \\
\hline 4 & 8237.7 & 28017 & 8489.6 & 28017 & 251.9 & 50.28 \\
\hline 5 & 389.4 & 429 & 695.5 & 429 & 306.1 & \\
\hline 5 & 1074.7 & 2224 & 1403.5 & 2224 & 328.8 & \\
\hline 5 & 1762.1 & 4459 & 2090.3 & 4459 & 328.2 & \\
\hline 5 & 2080.4 & 5625 & 2459.1 & 5625 & 378.7 & \\
\hline 5 & 2752.6 & 7804 & 3091.9 & 7804 & 339.3 & \\
\hline 5 & 2738.4 & 7690 & 3097 & 7690 & 358.6 & \\
\hline 5 & 2839.8 & 7977 & 3211.4 & 7977 & 371.6 & \\
\hline 5 & 3041.9 & 8803 & 3399.7 & 8803 & 357.8 & \\
\hline 5 & 3335.3 & 9637 & 3731.2 & 9637 & 395.9 & \\
\hline 5 & 3333.8 & 9768 & 3755.6 & 9768 & 421.8 & \\
\hline 5 & 3637.3 & 11021 & 3984.9 & 11021 & 347.6 & \\
\hline 5 & 4171.5 & 12817 & 4567.6 & 12817 & 396.1 & \\
\hline 5 & 4535.9 & 14079 & 4919.8 & 14079 & 383.9 & \\
\hline 5 & 4637.4 & 14564 & 5014.5 & 14564 & 377.1 & \\
\hline 5 & 4933.7 & 15626 & 5300.6 & 15626 & 366.9 & \\
\hline 5 & 4954.6 & 15943 & 5310.2 & 15943 & 355.6 & \\
\hline 5 & 5433.5 & 17774 & 5799.7 & 17774 & 366.2 & \\
\hline 5 & 5766.6 & 18996 & 6154.9 & 18996 & 388.3 & \\
\hline 5 & 6038.9 & 20289 & 6400.9 & 20289 & 362 & \\
\hline 5 & 6044.6 & 20143 & 6417.6 & 20143 & 373 & \\
\hline 5 & 6835.5 & 22923 & 7207 & 22923 & 371.5 & \\
\hline 5 & 7133.8 & 23445 & 7567 & 23445 & 433.2 & \\
\hline 5 & 7150.6 & 24051 & 7589.2 & 24051 & 438.6 & \\
\hline 5 & 8033.7 & 27242 & 8369.6 & 27242 & 335.9 & \\
\hline 5 & 8233.5 & 27709 & 8495.7 & 27709 & 262.2 & \\
\hline 5 & 8185.9 & 27794 & 8503.4 & 27794 & 317.5 & 38.75 \\
\hline 6 & 435.6 & 685 & 796.6 & 685 & 361 & \\
\hline 6 & 633.8 & 1206 & 970.4 & 1206 & 336.6 & \\
\hline 6 & 876.8 & 1945 & 1250.3 & 1945 & 373.5 & \\
\hline 6 & 1633.7 & 4132 & 1910.2 & 4132 & 276.5 & \\
\hline 6 & 1836.7 & 4674 & 2207 & 4674 & 370.3 & \\
\hline 6 & 1848.8 & 4722 & 2214.1 & 4722 & 365.3 & \\
\hline 6 & 2240.3 & 6008 & 2595.8 & 6008 & 355.5 & \\
\hline 6 & 2368.2 & 6313 & 2705.9 & 6313 & 337.7 & \\
\hline 6 & 3148 & 8763 & 3517.9 & 8763 & 369.9 & \\
\hline 6 & 3333.8 & 9640 & 3727.3 & 9640 & 393.5 & \\
\hline 6 & 3335.3 & 9851 & 3771.1 & 9851 & 435.8 & \\
\hline 6 & 3444.3 & 10247 & 3833.1 & 10247 & 388.8 & \\
\hline 6 & 3733.8 & 11104 & 4145.2 & 11104 & 411.4 & \\
\hline 6 & 3945.3 & 11960 & 4358.9 & 11960 & 413.6 & \\
\hline 6 & 4733.8 & 14945 & 5082.5 & 14945 & 348.7 & \\
\hline 6 & 4754.2 & 14737 & 5089.7 & 14737 & 335.5 & \\
\hline 6 & 4847.1 & 15461 & 5205.1 & 15461 & 358 & \\
\hline 6 & 4939.5 & 15657 & 5308.5 & 15657 & 369 & \\
\hline 6 & 5236.4 & 17028 & 5653.9 & 17028 & 417.5 & \\
\hline 6 & 5641.9 & 18177 & 6009.3 & 18177 & 367.4 & \\
\hline 6 & 5743 & 18945 & 6147.3 & 18945 & 404.3 & \\
\hline 6 & 6551.8 & 21956 & 6910.8 & 21956 & 359 & \\
\hline 6 & 6568.5 & 21999 & 6952.2 & 21999 & 383.7 & \\
\hline 6 & 6752.6 & 22755 & 7096.3 & 22755 & 343.7 & \\
\hline 6 & 7039.3 & 23911 & 7409.8 & 23911 & 370.5 & \\
\hline 6 & 7360.5 & 24884 & 7690.2 & 24884 & 329.7 & \\
\hline 6 & 7935.3 & 26995 & 8276.3 & 26995 & 341 & \\
\hline 6 & 8251.2 & 28003 & 8570.9 & 28003 & 319.7 & 33.75 \\
\hline
\end{tabular}




\begin{tabular}{|c|c|c|c|c|c|}
\hline 7 & 536.4 & 734 & 802 & 734 & 265.6 \\
\hline 7 & 586.3 & 913 & 887.6 & 913 & 301.3 \\
\hline 7 & 643.8 & 1059 & 1009.4 & 1059 & 365.6 \\
\hline 7 & 840.4 & 1813 & 1200.3 & 1813 & 359.9 \\
\hline 7 & 1436.4 & 3459 & 1795 & 3459 & 358.6 \\
\hline 7 & 1540.2 & 3802 & 1907 & 3802 & 366.8 \\
\hline 7 & 1839 & 4666 & 2184.3 & 4666 & 345.3 \\
\hline 7 & 2545.8 & 7103 & 2975.9 & 7103 & 430.1 \\
\hline 7 & 2554.4 & 6889 & 2987.2 & 6889 & 432.8 \\
\hline 7 & 2847.1 & 8117 & 3284.8 & 8117 & 437.7 \\
\hline 7 & 3174.2 & 9197 & 3607.1 & 9197 & 432.9 \\
\hline 7 & 3241.8 & 9545 & 3652.5 & 9545 & 410.7 \\
\hline 7 & 3451.3 & 10492 & 3811.8 & 10492 & 360.5 \\
\hline 7 & 3774.3 & 11228 & 4117.7 & 11228 & 343.4 \\
\hline 7 & 3844.3 & 11351 & 4188 & 11351 & 343.7 \\
\hline 7 & 4236.4 & 13010 & 4620.7 & 13010 & 384.3 \\
\hline 7 & 4556.6 & 14427 & 4912.5 & 14427 & 355.9 \\
\hline 7 & 4753 & 14769 & 5107.8 & 14769 & 354.8 \\
\hline 7 & 5039.1 & 16028 & 5415.3 & 16028 & 376.2 \\
\hline 7 & 5259.7 & 17174 & 5685.9 & 17174 & 426.2 \\
\hline 7 & 5437.3 & 17515 & 5892.7 & 17515 & 455.4 \\
\hline 7 & 5538.7 & 17696 & 5917.4 & 17696 & 378.7 \\
\hline 7 & 6135.3 & 20351 & 6526 & 20351 & 390.7 \\
\hline 7 & 6253.8 & 20697 & 6616.5 & 20697 & 362.7 \\
\hline 7 & 6339.2 & 20680 & 6781.1 & 20680 & 441.9 \\
\hline 7 & 6837.1 & 23112 & 7203.9 & 23112 & 366.8 \\
\hline 7 & 7041.1 & 23447 & 7490.3 & 23447 & 449.2 \\
\hline 7 & 7337.2 & 24552 & 7772.1 & 24552 & 434.9 \\
\hline 7 & 7437.2 & 25224 & 7806.2 & 25224 & 369 \\
\hline 7 & 7939.9 & 26875 & 8284 & 26875 & 344.1 \\
\hline 7 & 8033.7 & 27216 & 8366.9 & 27216 & 333.2 \\
\hline 8 & 435.4 & 558 & 713 & 558 & 277.6 \\
\hline 8 & 641.2 & 1144 & 997.7 & 1144 & 356.5 \\
\hline 8 & 936.3 & 1911 & 1284.8 & 1911 & 348.5 \\
\hline 8 & 1064 & 2213 & 1388.5 & 2213 & 324.5 \\
\hline 8 & 1237.7 & 2886 & 1661.6 & 2886 & 423.9 \\
\hline 8 & 1386.1 & 3518 & 1700 & 3518 & 313.9 \\
\hline 8 & 1440.2 & 3442 & 1786.5 & 3442 & 346.3 \\
\hline 8 & 1582.7 & 3899 & 1969.8 & 3899 & 387.1 \\
\hline 8 & 2633.7 & 7259 & 3092.6 & 7259 & 458.9 \\
\hline 8 & 2845.1 & 7912 & 3350.3 & 7912 & 505.2 \\
\hline 8 & 3260.7 & 9286 & 3621 & 9286 & 360.3 \\
\hline 8 & 3540.2 & 10471 & 3989 & 10471 & 448.8 \\
\hline 8 & 3740.2 & 10899 & 4165.9 & 10899 & 425.7 \\
\hline 8 & 3842.3 & 11560 & 4216.2 & 11560 & 373.9 \\
\hline 8 & 3939.4 & 11851 & 4317.5 & 11851 & 378.1 \\
\hline 8 & 4154.1 & 12728 & 4493.5 & 12728 & 339.4 \\
\hline 8 & 4339.1 & 13698 & 4719.5 & 13698 & 380.4 \\
\hline 8 & 4654 & 14586 & 5009 & 14586 & 355 \\
\hline 8 & 5154.4 & 16916 & 5519.5 & 16916 & 365.1 \\
\hline 8 & 5548.7 & 18042 & 5906.8 & 18042 & 358.1 \\
\hline 8 & 5663.5 & 18361 & 6054.6 & 18361 & 391.1 \\
\hline 8 & 5939.5 & 19274 & 6335 & 19274 & 395.5 \\
\hline 8 & 5945.6 & 19678 & 6368.1 & 19678 & 422.5 \\
\hline 8 & 6137.4 & 20435 & 6508.2 & 20435 & 370.8 \\
\hline 8 & 6235.4 & 20640 & 6588.7 & 20640 & 353.3 \\
\hline 8 & 6262.3 & 20989 & 6682.1 & 20989 & 419.8 \\
\hline 8 & 6954.5 & 23460 & 7323.1 & 23460 & 368.6 \\
\hline
\end{tabular}

45.47 


\begin{tabular}{|c|c|c|c|c|c|}
\hline 8 & 7533.8 & 25273 & 7826.1 & 25273 & 292.3 \\
\hline 8 & 7742 & 26228 & 8104.3 & 26228 & 362.3 \\
\hline 8 & 8087.9 & 27425 & 8389.8 & 27425 & 301.9 \\
\hline 9 & 477.9 & 739 & 791.7 & 739 & 313.8 \\
\hline 9 & 1142 & 2582 & 1491.4 & 2582 & 349.4 \\
\hline 9 & 1166.5 & 2837 & 1501 & 2837 & 334.5 \\
\hline 9 & 1249 & 3097 & 1588.3 & 3097 & 339.3 \\
\hline 9 & 1969.1 & 5125 & 2298.6 & 5125 & 329.5 \\
\hline 9 & 2169.5 & 5729 & 2496.7 & 5729 & 327.2 \\
\hline 9 & 2238.3 & 5572 & 2578.9 & 5572 & 340.6 \\
\hline 9 & 2389.1 & 6372 & 2751.1 & 6372 & 362 \\
\hline 9 & 3157.3 & 9000 & 3570.3 & 9000 & 413 \\
\hline 9 & 3254.4 & 9702 & 3608 & 9702 & 353.6 \\
\hline 9 & 3358.6 & 9917 & 3704.1 & 9917 & 345.5 \\
\hline 9 & 3456.1 & 10312 & 3879.8 & 10312 & 423.7 \\
\hline 9 & 3552.5 & 10405 & 3966.4 & 10405 & 413.9 \\
\hline 9 & 3946.4 & 11886 & 4315.3 & 11886 & 368.9 \\
\hline 9 & 4033.7 & 12171 & 4353 & 12171 & 319.3 \\
\hline 9 & 4435.4 & 14049 & 4811.4 & 14049 & 376 \\
\hline 9 & 4745.8 & 14897 & 5085.5 & 14897 & 339.7 \\
\hline 9 & 4874.9 & 15331 & 5214.8 & 15331 & 339.9 \\
\hline 9 & 5035.3 & 15994 & 5496.1 & 15994 & 460.8 \\
\hline 9 & 5437.3 & 17576 & 5813.4 & 17576 & 376.1 \\
\hline 9 & 5489.8 & 18094 & 5915.9 & 18094 & 426.1 \\
\hline 9 & 5557.7 & 18123 & 5955.5 & 18123 & 397.8 \\
\hline 9 & 5753.5 & 18744 & 6148.6 & 18744 & 395.1 \\
\hline 9 & 5840.9 & 19185 & 6283.3 & 19185 & 442.4 \\
\hline 9 & 6071.4 & 20318 & 6473.8 & 20318 & 402.4 \\
\hline 9 & 6144 & 20251 & 6521.9 & 20251 & 377.9 \\
\hline 9 & 6744 & 22343 & 7127.3 & 22343 & 383.3 \\
\hline 9 & 7135.2 & 23877 & 7507.7 & 23877 & 372.5 \\
\hline 9 & 7283.2 & 24676 & 7628.8 & 24676 & 345.6 \\
\hline 9 & 7739.9 & 26092 & 8096.6 & 26092 & 356.7 \\
\hline 9 & 8041.1 & 27246 & 8372.5 & 27246 & 331.4 \\
\hline 9 & 8333.8 & 28172 & 8581.9 & 28172 & 248.1 \\
\hline 10 & 645.3 & 1268 & 984.7 & 1268 & 339.4 \\
\hline 10 & 1655.2 & 4183 & 1998 & 4183 & 342.8 \\
\hline 10 & 1738.4 & 4363 & 2015.8 & 4363 & 277.4 \\
\hline 10 & 2239.3 & 6081 & 2586.7 & 6081 & 347.4 \\
\hline 10 & 2553.4 & 7013 & 2900.9 & 7013 & 347.5 \\
\hline 10 & 2785.5 & 7822 & 3190 & 7822 & 404.5 \\
\hline 10 & 3048.8 & 8709 & 3406.4 & 8709 & 357.6 \\
\hline 10 & 3440.9 & 10306 & 3882.5 & 10306 & 441.6 \\
\hline 10 & 3540 & 10760 & 3917.2 & 10760 & 377.2 \\
\hline 10 & 3781.8 & 11229 & 4156.1 & 11229 & 374.3 \\
\hline 10 & 3886.5 & 11990 & 4289.9 & 11990 & 403.4 \\
\hline 10 & 4139.5 & 12813 & 4493.9 & 12813 & 354.4 \\
\hline 10 & 4744.8 & 14986 & 5101 & 14986 & 356.2 \\
\hline 10 & 4747 & 14916 & 5110.1 & 14916 & 363.1 \\
\hline 10 & 4884.3 & 15598 & 5214.6 & 15598 & 330.3 \\
\hline 10 & 4941.3 & 15801 & 5366.6 & 15801 & 425.3 \\
\hline 10 & 5685.3 & 18653 & 6066.9 & 18653 & 381.6 \\
\hline 10 & 5742.8 & 19118 & 6097.3 & 19118 & 354.5 \\
\hline 10 & 6138.1 & 20377 & 6558.8 & 20377 & 420.7 \\
\hline 10 & 6143.8 & 20545 & 6567 & 20545 & 423.2 \\
\hline 10 & 6335.4 & 20972 & 6716.7 & 20972 & 381.3 \\
\hline 10 & 6635.6 & 22209 & 7003.1 & 22209 & 367.5 \\
\hline 10 & 6844.4 & 23066 & 7212.1 & 23066 & 367.7 \\
\hline
\end{tabular}

49.91

43.28 


\begin{tabular}{|c|c|c|c|c|c|c|}
\hline 10 & 7249.8 & 24375 & 7600.6 & 24375 & 350.8 & \\
\hline 10 & 8087.7 & 27425 & 8392.7 & 27425 & 305 & \\
\hline 10 & 8239.6 & 27797 & 8565.5 & 27797 & 325.9 & 38.01 \\
\hline 11 & 541 & 822 & 892.1 & 822 & 351.1 & \\
\hline 11 & 890.2 & 1872 & 1217.2 & 1872 & 327 & \\
\hline 11 & 942 & 1932 & 1282.2 & 1932 & 340.2 & \\
\hline 11 & 1581.4 & 3993 & 1954.6 & 3993 & 373.2 & \\
\hline 11 & 1845.4 & 4680 & 2206.6 & 4680 & 361.2 & \\
\hline 11 & 1869 & 4905 & 2223.1 & 4905 & 354.1 & \\
\hline 11 & 2238.5 & 6082 & 2607.4 & 6082 & 368.9 & \\
\hline 11 & 2379.3 & 6392 & 2713.8 & 6392 & 334.5 & \\
\hline 11 & 2847 & 8021 & 3260.3 & 8021 & 413.3 & \\
\hline 11 & 2935.2 & 8526 & 3317.9 & 8526 & 382.7 & \\
\hline 11 & 3239.5 & 9149 & 3562.4 & 9149 & 322.9 & \\
\hline 11 & 3483.5 & 10408 & 3825 & 10408 & 341.5 & \\
\hline 11 & 3543.4 & 10418 & 3990.7 & 10418 & 447.3 & \\
\hline 11 & 3744.3 & 11008 & 4194.1 & 11008 & 449.8 & \\
\hline 11 & 4247.1 & 13079 & 4687 & 13079 & 439.9 & \\
\hline 11 & 4451.5 & 13994 & 4810.7 & 13994 & 359.2 & \\
\hline 11 & 4655.2 & 14343 & 5047.7 & 14343 & 392.5 & \\
\hline 11 & 4739.6 & 14870 & 5121.2 & 14870 & 381.6 & \\
\hline 11 & 4887.6 & 15567 & 5218 & 15567 & 330.4 & \\
\hline 11 & 5050.4 & 16134 & 5506.3 & 16134 & 455.9 & \\
\hline 11 & 5080 & 16303 & 5570.5 & 16303 & 490.5 & \\
\hline 11 & 5883.9 & 19465 & 6218.3 & 19465 & 334.4 & \\
\hline 11 & 6146.5 & 20339 & 6511.6 & 20339 & 365.1 & \\
\hline 11 & 6556.2 & 22024 & 6915.8 & 22024 & 359.6 & \\
\hline 11 & 6689.3 & 22393 & 7073.5 & 22393 & 384.2 & \\
\hline 11 & 6739.2 & 22785 & 7105.9 & 22785 & 366.7 & \\
\hline 11 & 6867.7 & 22736 & 7247.5 & 22736 & 379.8 & \\
\hline 11 & 7240.8 & 24335 & 7617.5 & 24335 & 376.7 & \\
\hline 11 & 7335.3 & 24506 & 7701.1 & 24506 & 365.8 & \\
\hline 11 & 7540.1 & 25563 & 7879.6 & 25563 & 339.5 & \\
\hline 11 & 7933.8 & 26857 & 8281 & 26857 & 347.2 & \\
\hline 11 & 7975.7 & 26843 & 8296.9 & 26843 & 321.2 & 42.65 \\
\hline 12 & 238.1 & 147 & 512.2 & 147 & 274.1 & \\
\hline 12 & 639.3 & 1165 & 988.6 & 1165 & 349.3 & \\
\hline 12 & 939.2 & 2118 & 1246.5 & 2118 & 307.3 & \\
\hline 12 & 1274.1 & 3180 & 1614.2 & 3180 & 340.1 & \\
\hline 12 & 1835.5 & 4759 & 2205.7 & 4759 & 370.2 & \\
\hline 12 & 2155.9 & 5919 & 2515.9 & 5919 & 360 & \\
\hline 12 & 2484 & 6778 & 2812.1 & 6778 & 328.1 & \\
\hline 12 & 2768.7 & 7476 & 3095.7 & 7476 & 327 & \\
\hline 12 & 3069.1 & 8878 & 3481.7 & 8878 & 412.6 & \\
\hline 12 & 3443.6 & 10240 & 3824 & 10240 & 380.4 & \\
\hline 12 & 3579 & 10612 & 3973.9 & 10612 & 394.9 & \\
\hline 12 & 3778.3 & 11166 & 4266.4 & 11166 & 488.1 & \\
\hline 12 & 4243.7 & 13171 & 4697.4 & 13171 & 453.7 & \\
\hline 12 & 4240.3 & 12994 & 4705.6 & 12994 & 465.3 & \\
\hline 12 & 4772.2 & 15187 & 5114 & 15187 & 341.8 & \\
\hline 12 & 5035.5 & 15997 & 5487.1 & 15997 & 451.6 & \\
\hline 12 & 5058 & 16019 & 5502.6 & 16019 & 444.6 & \\
\hline 12 & 5082.4 & 16220 & 5532.2 & 16220 & 449.8 & \\
\hline 12 & 5360.1 & 17513 & 5780.3 & 17513 & 420.2 & \\
\hline 12 & 5546.9 & 18258 & 5915.6 & 18258 & 368.7 & \\
\hline 12 & 5840.7 & 18794 & 6209 & 18794 & 368.3 & \\
\hline 12 & 6058.2 & 20096 & 6427 & 20096 & 368.8 & \\
\hline 12 & 6080.2 & 20179 & 6446.1 & 20179 & 365.9 & \\
\hline
\end{tabular}




\begin{tabular}{|c|c|c|c|c|c|}
\hline 12 & 6245.2 & 20652 & 6618.6 & 20652 & 373.4 \\
\hline 12 & 6939.4 & 23312 & 7332 & 23312 & 392.6 \\
\hline 12 & 7264.4 & 24388 & 7608.5 & 24388 & 344.1 \\
\hline 12 & 7341.1 & 24746 & 7707.1 & 24746 & 366 \\
\hline 12 & 7584 & 25811 & 7899.1 & 25811 & 315.1 \\
\hline 12 & 7633.8 & 25781 & 7979.8 & 25781 & 346 \\
\hline 12 & 8246.9 & 27874 & 8576.9 & 27874 & 330 \\
\hline 13 & 739.2 & 1311 & 1092.7 & 1311 & 353.5 \\
\hline 13 & 1042.9 & 2256 & 1391.4 & 2256 & 348.5 \\
\hline 13 & 1138.6 & 2521 & 1489.6 & 2521 & 351 \\
\hline 13 & 1733.8 & 4422 & 2005.8 & 4422 & 272 \\
\hline 13 & 1943.9 & 5013 & 2314.4 & 5013 & 370.5 \\
\hline 13 & 2241.2 & 6034 & 2615.4 & 6034 & 374.2 \\
\hline 13 & 2243.9 & 5967 & 2625.6 & 5967 & 381.7 \\
\hline 13 & 2833.7 & 7600 & 3196.2 & 7600 & 362.5 \\
\hline 13 & 2841.3 & 8066 & 3204.6 & 8066 & 363.3 \\
\hline 13 & 3236.4 & 9446 & 3604.7 & 9446 & 368.3 \\
\hline 13 & 3333.8 & 9696 & 3620.1 & 9696 & 286.3 \\
\hline 13 & 3473.1 & 10248 & 3826.6 & 10248 & 353.5 \\
\hline 13 & 3567.8 & 10451 & 3904.6 & 10451 & 336.8 \\
\hline 13 & 4154.3 & 12817 & 4565 & 12817 & 410.7 \\
\hline 13 & 4451.2 & 13765 & 4814.4 & 13765 & 363.2 \\
\hline 13 & 5338.7 & 17332 & 5705.5 & 17332 & 366.8 \\
\hline 13 & 5537.1 & 17900 & 5901.6 & 17900 & 364.5 \\
\hline 13 & 5538.3 & 17889 & 5916.3 & 17889 & 378 \\
\hline 13 & 5637.8 & 18539 & 6018.5 & 18539 & 380.7 \\
\hline 13 & 5652.1 & 18559 & 6026.5 & 18559 & 374.4 \\
\hline 13 & 5833.8 & 18827 & 6196.1 & 18827 & 362.3 \\
\hline 13 & 6140.8 & 20613 & 6504.8 & 20613 & 364 \\
\hline 13 & 6443.3 & 21414 & 6850.5 & 21414 & 407.2 \\
\hline 13 & 6481.9 & 21645 & 6899.2 & 21645 & 417.3 \\
\hline 13 & 6835.5 & 22683 & 7196 & 22683 & 360.5 \\
\hline 13 & 6837.3 & 22873 & 7203 & 22873 & 365.7 \\
\hline 13 & 7339.4 & 24627 & 7701.1 & 24627 & 361.7 \\
\hline 13 & 7444.3 & 24964 & 7809.9 & 24964 & 365.6 \\
\hline 13 & 7588.4 & 25898 & 7957.5 & 25898 & 369.1 \\
\hline 13 & 8282 & 28049 & 8568.6 & 28049 & 286.6 \\
\hline 13 & 8335.6 & 28299 & 8658.3 & 28299 & 322.7 \\
\hline 14 & 845.6 & 1740 & 1118.9 & 1740 & 273.3 \\
\hline 14 & 1250.7 & 3049 & 1556.5 & 3049 & 305.8 \\
\hline 14 & 1344.9 & 3396 & 1695.8 & 3396 & 350.9 \\
\hline 14 & 1850.6 & 4539 & 2216.6 & 4539 & 366 \\
\hline 14 & 1951.5 & 5010 & 2295.2 & 5010 & 343.7 \\
\hline 14 & 2233.5 & 5910 & 2602.5 & 5910 & 369 \\
\hline 14 & 2936 & 8054 & 3334 & 8054 & 398 \\
\hline 14 & 3075.2 & 8822 & 3411.8 & 8822 & 336.6 \\
\hline 14 & 3082.2 & 8736 & 3456.3 & 8736 & 374.1 \\
\hline 14 & 3339.3 & 9668 & 3711.8 & 9668 & 372.5 \\
\hline 14 & 3687.8 & 10936 & 4008.6 & 10936 & 320.8 \\
\hline 14 & 4187.5 & 12904 & 4596.3 & 12904 & 408.8 \\
\hline 14 & 4235.6 & 13107 & 4611.8 & 13107 & 376.2 \\
\hline 14 & 4454.1 & 14182 & 4870 & 14182 & 415.9 \\
\hline 14 & 4544.4 & 14401 & 4947.6 & 14401 & 403.2 \\
\hline 14 & 4842.2 & 15563 & 5206.6 & 15563 & 364.4 \\
\hline 14 & 5036.2 & 16265 & 5388.6 & 16265 & 352.4 \\
\hline 14 & 5339 & 17147 & 5704.2 & 17147 & 365.2 \\
\hline 14 & 5565.4 & 18246 & 5977.2 & 18246 & 411.8 \\
\hline 14 & 6033.8 & 19816 & 6422.7 & 19816 & 388.9 \\
\hline
\end{tabular}




\begin{tabular}{|c|c|c|c|c|c|}
\hline 14 & 6141.4 & 20367 & 6567.5 & 20367 & 426.1 \\
\hline 14 & 6137.1 & 20538 & 6574 & 20538 & 436.9 \\
\hline 14 & 6487.8 & 21901 & 6848.8 & 21901 & 361 \\
\hline 14 & 6957.6 & 23382 & 7307.3 & 23382 & 349.7 \\
\hline 14 & 7276.1 & 24452 & 7645.6 & 24452 & 369.5 \\
\hline 14 & 8236.5 & 27904 & 8485.9 & 27904 & 249.4 \\
\hline 15 & 446.5 & 536 & 794.5 & 536 & 348 \\
\hline 15 & 957.1 & 2204 & 1284.7 & 2204 & 327.6 \\
\hline 15 & 943.2 & 2035 & 1290 & 2035 & 346.8 \\
\hline 15 & 1545.5 & 3838 & 1920.7 & 3838 & 375.2 \\
\hline 15 & 1936.4 & 5010 & 2416.6 & 5010 & 480.2 \\
\hline 15 & 2037.7 & 5245 & 2471.7 & 5245 & 434 \\
\hline 15 & 2146.1 & 5700 & 2522.1 & 5700 & 376 \\
\hline 15 & 2236.6 & 5985 & 2604.8 & 5985 & 368.2 \\
\hline 15 & 2237.3 & 5948 & 2614.8 & 5948 & 377.5 \\
\hline 15 & 2365.6 & 6469 & 2682 & 6469 & 316.4 \\
\hline 15 & 3061.3 & 8562 & 3416.5 & 8562 & 355.2 \\
\hline 15 & 3189.4 & 9072 & 3572.3 & 9072 & 382.9 \\
\hline 15 & 3485.6 & 10459 & 3960.6 & 10459 & 475 \\
\hline 15 & 3849.1 & 11513 & 4268.9 & 11513 & 419.8 \\
\hline 15 & 4088.5 & 12540 & 4476.6 & 12540 & 388.1 \\
\hline 15 & 4436.8 & 13756 & 4800.1 & 13756 & 363.3 \\
\hline 15 & 4635.6 & 14601 & 5000.4 & 14601 & 364.8 \\
\hline 15 & 4942.3 & 15656 & 5311.3 & 15656 & 369 \\
\hline 15 & 5175.1 & 16864 & 5575.3 & 16864 & 400.2 \\
\hline 15 & 5467.7 & 17513 & 5910 & 17513 & 442.3 \\
\hline 15 & 5649.4 & 18659 & 6005.6 & 18659 & 356.2 \\
\hline 15 & 5736.4 & 18821 & 6108.1 & 18821 & 371.7 \\
\hline 15 & 5887.7 & 19589 & 6268.5 & 19589 & 380.8 \\
\hline 15 & 5988.9 & 19731 & 6325.6 & 19731 & 336.7 \\
\hline 15 & 6144.4 & 20396 & 6524.6 & 20396 & 380.2 \\
\hline 15 & 6142.9 & 20283 & 6527 & 20283 & 384.1 \\
\hline 15 & 6651.4 & 22188 & 7011.4 & 22188 & 360 \\
\hline 15 & 6741.7 & 22447 & 7108.2 & 22447 & 366.5 \\
\hline 15 & 6982.1 & 23290 & 7315.2 & 23290 & 333.1 \\
\hline 15 & 7439 & 24938 & 7795.2 & 24938 & 356.2 \\
\hline 15 & 7768.7 & 26339 & 8092 & 26339 & 323.3 \\
\hline 15 & 8137.4 & 27305 & 8459.6 & 27305 & 322.2 \\
\hline 16 & 440.4 & 440 & 783.1 & 440 & 342.7 \\
\hline 16 & 733.8 & 1281 & 1084.9 & 1281 & 351.1 \\
\hline 16 & 1135.5 & 2594 & 1489.4 & 2594 & 353.9 \\
\hline 16 & 1538.1 & 3878 & 1914.2 & 3878 & 376.1 \\
\hline 16 & 2333.8 & 6204 & 2689.9 & 6204 & 356.1 \\
\hline 16 & 2436.7 & 6534 & 2813.5 & 6534 & 376.8 \\
\hline 16 & 2954.4 & 8549 & 3358.1 & 8549 & 403.7 \\
\hline 16 & 3133.8 & 8826 & 3503.1 & 8826 & 369.3 \\
\hline 16 & 3444 & 10299 & 3882.9 & 10299 & 438.9 \\
\hline 16 & 3740.4 & 11253 & 4105.8 & 11253 & 365.4 \\
\hline 16 & 4057.1 & 12570 & 4445.4 & 12570 & 388.3 \\
\hline 16 & 4238.9 & 13300 & 4599.5 & 13300 & 360.6 \\
\hline 16 & 4236.5 & 13115 & 4605.5 & 13115 & 369 \\
\hline 16 & 4738.6 & 15018 & 5091.3 & 15018 & 352.7 \\
\hline 16 & 4943 & 15677 & 5294.1 & 15677 & 351.1 \\
\hline 16 & 5189.1 & 16941 & 5551.8 & 16941 & 362.7 \\
\hline 16 & 5239.1 & 16912 & 5704.8 & 16912 & 465.7 \\
\hline 16 & 5440.6 & 17651 & 5847.9 & 17651 & 407.3 \\
\hline 16 & 5875.3 & 19371 & 6286.3 & 19371 & 411 \\
\hline 16 & 6035.1 & 20196 & 6415.8 & 20196 & 380.7 \\
\hline
\end{tabular}

43.87

40.05 


\begin{tabular}{|c|c|c|c|c|c|}
\hline 16 & 6059.5 & 20155 & 6419.7 & 20155 & 360.2 \\
\hline 16 & 6139.1 & 20429 & 6506.6 & 20429 & 367.5 \\
\hline 16 & 6953.1 & 23428 & 7321.3 & 23428 & 368.2 \\
\hline 16 & 7267.2 & 24630 & 7621.5 & 24630 & 354.3 \\
\hline 16 & 7283.2 & 24508 & 7657.3 & 24508 & 374.1 \\
\hline 16 & 7338.1 & 24659 & 7696.3 & 24659 & 358.2 \\
\hline 16 & 7839.4 & 26594 & 8202.9 & 26594 & 363.5 \\
\hline 16 & 8160 & 27498 & 8474.3 & 27498 & 314.3 \\
\hline 17 & 739.3 & 1242 & 1079.8 & 1242 & 340.5 \\
\hline 17 & 847 & 1814 & 1195.2 & 1814 & 348.2 \\
\hline 17 & 1544.9 & 3935 & 1887.5 & 3935 & 342.6 \\
\hline 17 & 2544.5 & 6657 & 2882.2 & 6657 & 337.7 \\
\hline 17 & 2933.7 & 8083 & 3285.6 & 8083 & 351.9 \\
\hline 17 & 3363.7 & 9621 & 3707.8 & 9621 & 344.1 \\
\hline 17 & 3737.6 & 10986 & 4111.9 & 10986 & 374.3 \\
\hline 17 & 3755.7 & 11211 & 4115.4 & 11211 & 359.7 \\
\hline 17 & 4343.4 & 13726 & 4700.6 & 13726 & 357.2 \\
\hline 17 & 4345.4 & 13406 & 4702.6 & 13406 & 357.2 \\
\hline 17 & 4557.5 & 14485 & 4904.7 & 14485 & 347.2 \\
\hline 17 & 4490.3 & 14164 & 4906.3 & 14164 & 416 \\
\hline 17 & 4937 & 15582 & 5307.6 & 15582 & 370.6 \\
\hline 17 & 5139.5 & 16535 & 5522.6 & 16535 & 383.1 \\
\hline 17 & 5544.6 & 18086 & 5957.6 & 18086 & 413 \\
\hline 17 & 5741.7 & 18565 & 6087.1 & 18565 & 345.4 \\
\hline 17 & 5956.1 & 19797 & 6350.3 & 19797 & 394.2 \\
\hline 17 & 6441.8 & 21362 & 6785.4 & 21362 & 343.6 \\
\hline 17 & 6548.2 & 22143 & 6916.7 & 22143 & 368.5 \\
\hline 17 & 6733.8 & 22654 & 7096.8 & 22654 & 363 \\
\hline 17 & 6746.5 & 22245 & 7116.8 & 22245 & 370.3 \\
\hline 17 & 7138.4 & 24093 & 7490.1 & 24093 & 351.7 \\
\hline 17 & 7340.4 & 25112 & 7690.6 & 25112 & 350.2 \\
\hline 17 & 7739.6 & 26128 & 8023.6 & 26128 & 284 \\
\hline 17 & 7941.2 & 26818 & 8288.7 & 26818 & 347.5 \\
\hline 18 & 546.4 & 807 & 887.6 & 807 & 341.2 \\
\hline 18 & 557.5 & 900 & 897.3 & 900 & 339.8 \\
\hline 18 & 740.6 & 1318 & 1092.3 & 1318 & 351.7 \\
\hline 18 & 739.2 & 1557 & 1094.1 & 1557 & 354.9 \\
\hline 18 & 1250.8 & 3080 & 1616 & 3080 & 365.2 \\
\hline 18 & 2835.3 & 7535 & 3195.9 & 7535 & 360.6 \\
\hline 18 & 2842.6 & 7761 & 3199.7 & 7761 & 357.1 \\
\hline 18 & 2861.1 & 8009 & 3289.6 & 8009 & 428.5 \\
\hline 18 & 3269.6 & 9634 & 3700 & 9634 & 430.4 \\
\hline 18 & 3736.7 & 10994 & 4102 & 10994 & 365.3 \\
\hline 18 & 3746.3 & 11255 & 4114.8 & 11255 & 368.5 \\
\hline 18 & 3963.2 & 12065 & 4364.7 & 12065 & 401.5 \\
\hline 18 & 4061.8 & 12518 & 4414.9 & 12518 & 353.1 \\
\hline 18 & 4535.3 & 14112 & 4905 & 14112 & 369.7 \\
\hline 18 & 4635.5 & 14392 & 5016 & 14392 & 380.5 \\
\hline 18 & 4774.9 & 15184 & 5103.8 & 15184 & 328.9 \\
\hline 18 & 4939.9 & 15632 & 5374 & 15632 & 434.1 \\
\hline 18 & 5584.7 & 18287 & 5981.4 & 18287 & 396.7 \\
\hline 18 & 5644 & 18247 & 6060 & 18247 & 416 \\
\hline 18 & 5862.1 & 19213 & 6220.9 & 19213 & 358.8 \\
\hline 18 & 6235.5 & 20477 & 6661.5 & 20477 & 426 \\
\hline 18 & 6446.7 & 21485 & 6852 & 21485 & 405.3 \\
\hline 18 & 6535.5 & 22020 & 6951.4 & 22020 & 415.9 \\
\hline 18 & 6668.5 & 22586 & 6999.7 & 22586 & 331.2 \\
\hline 18 & 6658.5 & 22323 & 7010.1 & 22323 & 351.6 \\
\hline
\end{tabular}

30.08 


\begin{tabular}{|c|c|c|c|c|c|c|}
\hline 18 & 7538.8 & 25472 & 7903.6 & 25472 & 364.8 & \\
\hline 18 & 7739.5 & 26179 & 8120 & 26179 & 380.5 & \\
\hline 18 & 7933.8 & 26957 & 8218.9 & 26957 & 285.1 & 36.06 \\
\hline 19 & 1040.5 & 2436 & 1375 & 2436 & 334.5 & \\
\hline 19 & 1084.6 & 2605 & 1405.6 & 2605 & 321 & \\
\hline 19 & 1954.5 & 5111 & 2302.8 & 5111 & 348.3 & \\
\hline 19 & 2033.7 & 5339 & 2380.9 & 5339 & 347.2 & \\
\hline 19 & 2642.5 & 7390 & 3070.4 & 7390 & 427.9 & \\
\hline 19 & 2955.4 & 8254 & 3383 & 8254 & 427.6 & \\
\hline 19 & 3336.3 & 9752 & 3701 & 9752 & 364.7 & \\
\hline 19 & 3287.7 & 9847 & 3704.4 & 9847 & 416.7 & \\
\hline 19 & 3545.1 & 10505 & 3902.3 & 10505 & 357.2 & \\
\hline 19 & 3844.1 & 11506 & 4253.4 & 11506 & 409.3 & \\
\hline 19 & 4061.3 & 12669 & 4454.6 & 12669 & 393.3 & \\
\hline 19 & 4243.1 & 13102 & 4606.1 & 13102 & 363 & \\
\hline 19 & 4433.7 & 13717 & 4811 & 13717 & 377.3 & \\
\hline 19 & 4582.4 & 14607 & 4986.7 & 14607 & 404.3 & \\
\hline 19 & 4739.7 & 14857 & 5086.5 & 14857 & 346.8 & \\
\hline 19 & 4857.3 & 15688 & 5183.9 & 15688 & 326.6 & \\
\hline 19 & 4851.3 & 15617 & 5210.9 & 15617 & 359.6 & \\
\hline 19 & 5157.6 & 16715 & 5500 & 16715 & 342.4 & \\
\hline 19 & 5235.4 & 16747 & 5617.8 & 16747 & 382.4 & \\
\hline 19 & 5237.5 & 16904 & 5622.8 & 16904 & 385.3 & \\
\hline 19 & 5953.3 & 19406 & 6298.3 & 19406 & 345 & \\
\hline 19 & 5944.2 & 19690 & 6306.1 & 19690 & 361.9 & \\
\hline 19 & 6240.1 & 20767 & 6604.1 & 20767 & 364 & \\
\hline 19 & 6370.2 & 21091 & 6723.3 & 21091 & 353.1 & \\
\hline 19 & 6643.4 & 22314 & 6997.4 & 22314 & 354 & \\
\hline 19 & 6666 & 22414 & 7013.5 & 22414 & 347.5 & \\
\hline 19 & 7154.3 & 24144 & 7493.5 & 24144 & 339.2 & \\
\hline 19 & 7140.8 & 23925 & 7586.6 & 23925 & 445.8 & \\
\hline 19 & 7744.1 & 26310 & 8088.1 & 26310 & 344 & \\
\hline 19 & 7839 & 26681 & 8194.8 & 26681 & 355.8 & \\
\hline 19 & 8054.1 & 27073 & 8373.6 & 27073 & 319.5 & 32.80 \\
\hline 20 & 384.6 & 400 & 692.4 & 400 & 307.8 & \\
\hline 20 & 1037.3 & 2249 & 1392 & 2249 & 354.7 & \\
\hline 20 & 1063.5 & 2385 & 1401.3 & 2385 & 337.8 & \\
\hline 20 & 1269.9 & 3046 & 1755.8 & 3046 & 485.9 & \\
\hline 20 & 1937.6 & 4980 & 2280.2 & 4980 & 342.6 & \\
\hline 20 & 2069.4 & 5535 & 2459.9 & 5535 & 390.5 & \\
\hline 20 & 2935.6 & 8246 & 3288.8 & 8246 & 353.2 & \\
\hline 20 & 3356 & 10011 & 3790.2 & 10011 & 434.2 & \\
\hline 20 & 3641.7 & 10906 & 3991.2 & 10906 & 349.5 & \\
\hline 20 & 3736 & 10888 & 4098.4 & 10888 & 362.4 & \\
\hline 20 & 3848.2 & 11595 & 4218.4 & 11595 & 370.2 & \\
\hline 20 & 3954.5 & 11998 & 4298.2 & 11998 & 343.7 & \\
\hline 20 & 3951.7 & 12085 & 4306.4 & 12085 & 354.7 & \\
\hline 20 & 3981.7 & 12318 & 4319.1 & 12318 & 337.4 & \\
\hline 20 & 4556.9 & 14520 & 4894 & 14520 & 337.1 & \\
\hline 20 & 4753.5 & 14795 & 5108 & 14795 & 354.5 & \\
\hline 20 & 4936.7 & 15669 & 5309 & 15669 & 372.3 & \\
\hline 20 & 5186.5 & 16891 & 5597.4 & 16891 & 410.9 & \\
\hline 20 & 5471.6 & 17827 & 5814 & 17827 & 342.4 & \\
\hline 20 & 5549.2 & 17925 & 5924.3 & 17925 & 375.1 & \\
\hline 20 & 5533.7 & 17743 & 5929 & 17743 & 395.3 & \\
\hline 20 & 5874.4 & 19219 & 6219.4 & 19219 & 345 & \\
\hline 20 & 5940.3 & 19311 & 6314.4 & 19311 & 374.1 & \\
\hline 20 & 5980.5 & 19774 & 6362.4 & 19774 & 381.9 & \\
\hline
\end{tabular}




\begin{tabular}{|c|c|c|c|c|c|c|}
\hline 20 & 6638.9 & 22291 & 7021.7 & 22291 & 382.8 & \\
\hline 20 & 6733.8 & 22531 & 7072.9 & 22531 & 339.1 & \\
\hline 20 & 7142.6 & 24162 & 7596 & 24162 & 453.4 & \\
\hline 20 & 7250.7 & 24529 & 7623.6 & 24529 & 372.9 & \\
\hline 20 & 7635.6 & 25500 & 7967.8 & 25500 & 332.2 & \\
\hline 20 & 7741.7 & 26403 & 8101.6 & 26403 & 359.9 & \\
\hline 20 & 8035.4 & 27138 & 8375.4 & 27138 & 340 & 37.48 \\
\hline 21 & 871.6 & 1847 & 1196.7 & 1847 & 325.1 & \\
\hline 21 & 847.8 & 1669 & 1206.5 & 1669 & 358.7 & \\
\hline 21 & 940.8 & 2143 & 1290.4 & 2143 & 349.6 & \\
\hline 21 & 1339.5 & 3036 & 1685.5 & 3036 & 346 & \\
\hline 21 & 1976.8 & 5105 & 2363.7 & 5105 & 386.9 & \\
\hline 21 & 2344.1 & 6314 & 2721.2 & 6314 & 377.1 & \\
\hline 21 & 2433.7 & 6478 & 2863.1 & 6478 & 429.4 & \\
\hline 21 & 2646.1 & 7403 & 3059.2 & 7403 & 413.1 & \\
\hline 21 & 3054 & 8764 & 3393.2 & 8764 & 339.2 & \\
\hline 21 & 3247.8 & 9597 & 3596.3 & 9597 & 348.5 & \\
\hline 21 & 3249.2 & 9454 & 3605.7 & 9454 & 356.5 & \\
\hline 21 & 3737.9 & 11112 & 4167.4 & 11112 & 429.5 & \\
\hline 21 & 4135.3 & 12397 & 4521.2 & 12397 & 385.9 & \\
\hline 21 & 4633.8 & 14549 & 5012.4 & 14549 & 378.6 & \\
\hline 21 & 4638.2 & 14232 & 5058 & 14232 & 419.8 & \\
\hline 21 & 4976.7 & 15754 & 5393.6 & 15754 & 416.9 & \\
\hline 21 & 5044 & 16062 & 5473.7 & 16062 & 429.7 & \\
\hline 21 & 5240.7 & 16796 & 5657.9 & 16796 & 417.2 & \\
\hline 21 & 5385.7 & 17640 & 5763.2 & 17640 & 377.5 & \\
\hline 21 & 5442.7 & 17595 & 5819.8 & 17595 & 377.1 & \\
\hline 21 & 6086.9 & 20291 & 6511.1 & 20291 & 424.2 & \\
\hline 21 & 6139.6 & 20135 & 6517.1 & 20135 & 377.5 & \\
\hline 21 & 6561.2 & 21935 & 6924.3 & 21935 & 363.1 & \\
\hline 21 & 6785.8 & 22751 & 7162.9 & 22751 & 377.1 & \\
\hline 21 & 7037.1 & 23665 & 7449 & 23665 & 411.9 & \\
\hline 21 & 7341.1 & 24731 & 7699.3 & 24731 & 358.2 & \\
\hline 21 & 7368.1 & 24541 & 7717.7 & 24541 & 349.6 & \\
\hline 21 & 7573.7 & 25475 & 7900.3 & 25475 & 326.6 & \\
\hline 21 & 7739.5 & 26142 & 8013.4 & 26142 & 273.9 & \\
\hline 21 & 8135.5 & 27406 & 8469.3 & 27406 & 333.8 & 38.01 \\
\hline 22 & 1072.5 & 2330 & 1393.3 & 2330 & 320.8 & \\
\hline 22 & 1140.7 & 2439 & 1494.5 & 2439 & 353.8 & \\
\hline 22 & 1635.5 & 4108 & 1982.2 & 4108 & 346.7 & \\
\hline 22 & 1837.3 & 4765 & 2198.2 & 4765 & 360.9 & \\
\hline 22 & 2480.4 & 6699 & 2849 & 6699 & 368.6 & \\
\hline 22 & 2657.2 & 7568 & 3079.7 & 7568 & 422.5 & \\
\hline 22 & 2748.6 & 7536 & 3294.1 & 7536 & 545.5 & \\
\hline 22 & 3377.2 & 10120 & 3702.5 & 10120 & 325.3 & \\
\hline 22 & 3451.5 & 9971 & 3799.5 & 9971 & 348 & \\
\hline 22 & 3578.3 & 10678 & 4003.3 & 10678 & 425 & \\
\hline 22 & 3873.2 & 11919 & 4244.8 & 11919 & 371.6 & \\
\hline 22 & 4452.8 & 13857 & 4808.4 & 13857 & 355.6 & \\
\hline 22 & 4676.1 & 14805 & 5012.9 & 14805 & 336.8 & \\
\hline 22 & 4842.7 & 15410 & 5255.7 & 15410 & 413 & \\
\hline 22 & 5042 & 16278 & 5416.1 & 16278 & 374.1 & \\
\hline 22 & 5450.7 & 17904 & 5818.4 & 17904 & 367.7 & \\
\hline 22 & 5537.2 & 18166 & 5884.6 & 18166 & 347.4 & \\
\hline 22 & 5935.4 & 19471 & 6303.3 & 19471 & 367.9 & \\
\hline 22 & 5933.7 & 19229 & 6310 & 19229 & 376.3 & \\
\hline 22 & 6340.4 & 20995 & 6700.2 & 20995 & 359.8 & \\
\hline 22 & 6339 & 21158 & 6708.9 & 21158 & 369.9 & \\
\hline
\end{tabular}




\begin{tabular}{|c|c|c|c|c|c|c|}
\hline 22 & 6744.9 & 22509 & 7175.1 & 22509 & 430.2 & \\
\hline 22 & 6936.4 & 23374 & 7311.5 & 23374 & 375.1 & \\
\hline 22 & 7145.7 & 23744 & 7508.4 & 23744 & 362.7 & \\
\hline 22 & 7776.2 & 26093 & 8110.2 & 26093 & 334 & \\
\hline 22 & 8035.5 & 27093 & 8321.5 & 27093 & 286 & \\
\hline 22 & 8335.6 & 28158 & 8585.9 & 28158 & 250.3 & 52.72 \\
\hline 23 & 1061.7 & 2254 & 1384.6 & 2254 & 322.9 & \\
\hline 23 & 1236.8 & 3021 & 1603.8 & 3021 & 367 & \\
\hline 23 & 1437.8 & 3516 & 1753.7 & 3516 & 315.9 & \\
\hline 23 & 1538.2 & 3957 & 1864.7 & 3957 & 326.5 & \\
\hline 23 & 2638.6 & 7139 & 2987.7 & 7139 & 349.1 & \\
\hline 23 & 2937.3 & 8382 & 3289.6 & 8382 & 352.3 & \\
\hline 23 & 3151.2 & 9122 & 3511.8 & 9122 & 360.6 & \\
\hline 23 & 3287.9 & 9444 & 3607.6 & 9444 & 319.7 & \\
\hline 23 & 3665.3 & 10925 & 4023.7 & 10925 & 358.4 & \\
\hline 23 & 3641.7 & 10821 & 4029.1 & 10821 & 387.4 & \\
\hline 23 & 4173.9 & 12671 & 4561.5 & 12671 & 387.6 & \\
\hline 23 & 4340.2 & 13589 & 4760.9 & 13589 & 420.7 & \\
\hline 23 & 4572.7 & 14361 & 4919.1 & 14361 & 346.4 & \\
\hline 23 & 4776.2 & 15136 & 5165.9 & 15136 & 389.7 & \\
\hline 23 & 4874.7 & 15453 & 5223.9 & 15453 & 349.2 & \\
\hline 23 & 5039 & 16018 & 5392.5 & 16018 & 353.5 & \\
\hline 23 & 5133.8 & 16301 & 5607.3 & 16301 & 473.5 & \\
\hline 23 & 5863.2 & 18970 & 6216.9 & 18970 & 353.7 & \\
\hline 23 & 5948.3 & 19217 & 6312.3 & 19217 & 364 & \\
\hline 23 & 6038.8 & 19911 & 6499.8 & 19911 & 461 & \\
\hline 23 & 6364.6 & 20969 & 6692.1 & 20969 & 327.5 & \\
\hline 23 & 6446.1 & 21398 & 6817 & 21398 & 370.9 & \\
\hline 23 & 6676.4 & 22239 & 6998.6 & 22239 & 322.2 & \\
\hline 23 & 7141.1 & 24056 & 7490.9 & 24056 & 349.8 & \\
\hline 23 & 7235.9 & 24306 & 7578.7 & 24306 & 342.8 & \\
\hline 23 & 7355.9 & 24765 & 7694.3 & 24765 & 338.4 & \\
\hline 23 & 7786.2 & 26471 & 8116.1 & 26471 & 329.9 & \\
\hline 23 & 7984.5 & 26722 & 8299.9 & 26722 & 315.4 & \\
\hline 23 & 8137.8 & 27352 & 8410 & 27352 & 272.2 & 42.05 \\
\hline 24 & 965.1 & 2089 & 1280.1 & 2089 & 315 & \\
\hline 24 & 1244.3 & 2686 & 1609.3 & 2686 & 365 & \\
\hline 24 & 1841.6 & 4731 & 2205.1 & 4731 & 363.5 & \\
\hline 24 & 2033.8 & 5445 & 2393.7 & 5445 & 359.9 & \\
\hline 24 & 2241.8 & 6061 & 2587 & 6061 & 345.2 & \\
\hline 24 & 2633.8 & 7381 & 2998.5 & 7381 & 364.7 & \\
\hline 24 & 2933.8 & 8096 & 3301.3 & 8096 & 367.5 & \\
\hline 24 & 2943 & 8403 & 3411.3 & 8403 & 468.3 & \\
\hline 24 & 3233.7 & 9490 & 3657.5 & 9490 & 423.8 & \\
\hline 24 & 3337.1 & 9789 & 3771.7 & 9789 & 434.6 & \\
\hline 24 & 3441.4 & 10157 & 3873.2 & 10157 & 431.8 & \\
\hline 24 & 3543.4 & 10422 & 4008 & 10422 & 464.6 & \\
\hline 24 & 3737.8 & 11168 & 4110.3 & 11168 & 372.5 & \\
\hline 24 & 3875.9 & 11976 & 4275.8 & 11976 & 399.9 & \\
\hline 24 & 4337.4 & 13362 & 4694.2 & 13362 & 356.8 & \\
\hline 24 & 4458.9 & 14237 & 4870.1 & 14237 & 411.2 & \\
\hline 24 & 5150.2 & 16759 & 5600.3 & 16759 & 450.1 & \\
\hline 24 & 5247.3 & 17062 & 5668.5 & 17062 & 421.2 & \\
\hline 24 & 5635.4 & 18083 & 6016.9 & 18083 & 381.5 & \\
\hline 24 & 5769.2 & 19086 & 6156 & 19086 & 386.8 & \\
\hline 24 & 5790.1 & 18872 & 6174.6 & 18872 & 384.5 & \\
\hline 24 & 6433.8 & 21399 & 6784.2 & 21399 & 350.4 & \\
\hline 24 & 6481 & 21793 & 6804.2 & 21793 & 323.2 & \\
\hline
\end{tabular}




\begin{tabular}{|c|c|c|c|c|c|c|}
\hline 24 & 6539.4 & 21604 & 6900.2 & 21604 & 360.8 & \\
\hline 24 & 6833.5 & 22806 & 7220.8 & 22806 & 387.3 & \\
\hline 24 & 7075.1 & 23795 & 7508 & 23795 & 432.9 & \\
\hline 24 & 7139.1 & 24141 & 7518.1 & 24141 & 379 & \\
\hline 24 & 7439 & 25351 & 7792.1 & 25351 & 353.1 & \\
\hline 24 & 7743 & 26293 & 8099.2 & 26293 & 356.2 & \\
\hline 24 & 7933.7 & 26738 & 8272.7 & 26738 & 339 & \\
\hline 24 & 8163.8 & 27659 & 8468.6 & 27659 & 304.8 & 42.30 \\
\hline 25 & 233.8 & 77 & 508.3 & 77 & 274.5 & \\
\hline 25 & 1169.6 & 2541 & 1484 & 2541 & 314.4 & \\
\hline 25 & 1236.7 & 3144 & 1601.8 & 3144 & 365.1 & \\
\hline 25 & 2539.2 & 6866 & 2915 & 6866 & 375.8 & \\
\hline 25 & 2535.5 & 7051 & 2925.1 & 7051 & 389.6 & \\
\hline 25 & 2664.3 & 7364 & 2996.1 & 7364 & 331.8 & \\
\hline 25 & 2844.7 & 7819 & 3210.9 & 7819 & 366.2 & \\
\hline 25 & 3039.1 & 8864 & 3507.1 & 8864 & 468 & \\
\hline 25 & 3037 & 8712 & 3517.9 & 8712 & 480.9 & \\
\hline 25 & 3435.4 & 10006 & 3803.4 & 10006 & 368 & \\
\hline 25 & 3959 & 12137 & 4302 & 12137 & 343 & \\
\hline 25 & 4441.7 & 13870 & 4796.7 & 13870 & 355 & \\
\hline 25 & 4465.5 & 14177 & 4803.4 & 14177 & 337.9 & \\
\hline 25 & 4542.7 & 14291 & 4895.6 & 14291 & 352.9 & \\
\hline 25 & 5035.5 & 15922 & 5413.7 & 15922 & 378.2 & \\
\hline 25 & 5149.8 & 16555 & 5504.2 & 16555 & 354.4 & \\
\hline 25 & 5151.7 & 16503 & 5514 & 16503 & 362.3 & \\
\hline 25 & 5146.5 & 16367 & 5677.8 & 16367 & 531.3 & \\
\hline 25 & 5450.3 & 17661 & 5868.5 & 17661 & 418.2 & \\
\hline 25 & 5942 & 19312 & 6365.5 & 19312 & 423.5 & \\
\hline 25 & 6251.8 & 20673 & 6650.7 & 20673 & 398.9 & \\
\hline 25 & 6335.5 & 20926 & 6712.5 & 20926 & 377 & \\
\hline 25 & 6358.1 & 21009 & 6716.9 & 21009 & 358.8 & \\
\hline 25 & 6679.4 & 22378 & 7010.8 & 22378 & 331.4 & \\
\hline 25 & 6681.5 & 22642 & 7017.7 & 22642 & 336.2 & \\
\hline 25 & 6684 & 22605 & 7065.2 & 22605 & 381.2 & \\
\hline 25 & 6841.9 & 22961 & 7199.4 & 22961 & 357.5 & \\
\hline 25 & 7252 & 24344 & 7607.1 & 24344 & 355.1 & \\
\hline 25 & 7538.5 & 25458 & 7899.2 & 25458 & 360.7 & \\
\hline 25 & 7544.1 & 25357 & 7907.8 & 25357 & 363.7 & \\
\hline 25 & 8256.9 & 27727 & 8504.5 & 27727 & 247.6 & 54.51 \\
\hline 26 & 753.4 & 1592 & 1099 & 1592 & 345.6 & \\
\hline 26 & 780.3 & 1587 & 1108.4 & 1587 & 328.1 & \\
\hline 26 & 1768.5 & 4576 & 2114.3 & 4576 & 345.8 & \\
\hline 26 & 2233.7 & 5722 & 2588.1 & 5722 & 354.4 & \\
\hline 26 & 2947.7 & 8467 & 3315.5 & 8467 & 367.8 & \\
\hline 26 & 3055.1 & 8896 & 3412.8 & 8896 & 357.7 & \\
\hline 26 & 3354.4 & 9953 & 3704.5 & 9953 & 350.1 & \\
\hline 26 & 3742.7 & 10830 & 4117.1 & 10830 & 374.4 & \\
\hline 26 & 4049.7 & 12384 & 4397.4 & 12384 & 347.7 & \\
\hline 26 & 4638.4 & 14322 & 5015.5 & 14322 & 377.1 & \\
\hline 26 & 4944.1 & 15762 & 5308.6 & 15762 & 364.5 & \\
\hline 26 & 4940.5 & 15802 & 5318.6 & 15802 & 378.1 & \\
\hline 26 & 5546.8 & 18179 & 5951.3 & 18179 & 404.5 & \\
\hline 26 & 5749.4 & 18693 & 6108.4 & 18693 & 359 & \\
\hline 26 & 6037.2 & 19953 & 6404.2 & 19953 & 367 & \\
\hline 26 & 6040.7 & 19888 & 6412.9 & 19888 & 372.2 & \\
\hline 26 & 6044.5 & 19821 & 6459.1 & 19821 & 414.6 & \\
\hline 26 & 6641.5 & 22627 & 7050.6 & 22627 & 409.1 & \\
\hline 26 & 6862.3 & 22971 & 7188.9 & 22971 & 326.6 & \\
\hline
\end{tabular}




\begin{tabular}{|c|c|c|c|c|c|}
\hline 26 & 6952.3 & 23527 & 7362.7 & 23527 & 410.4 \\
\hline 26 & 7339.1 & 24427 & 7691.4 & 24427 & 352.3 \\
\hline 26 & 7681.1 & 25805 & 8087.9 & 25805 & 406.8 \\
\hline 26 & 7850.8 & 26705 & 8203.5 & 26705 & 352.7 \\
\hline 26 & 8240 & 27886 & 8501.4 & 27886 & 261.4 \\
\hline 27 & 433.8 & 374 & 719.9 & 374 & 286.1 \\
\hline 27 & 1088.9 & 2445 & 1396.4 & 2445 & 307.5 \\
\hline 27 & 1736.5 & 4499 & 2008.4 & 4499 & 271.9 \\
\hline 27 & 1863.5 & 4920 & 2210.5 & 4920 & 347 \\
\hline 27 & 2074.6 & 5399 & 2403.5 & 5399 & 328.9 \\
\hline 27 & 2146 & 5854 & 2522.1 & 5854 & 376.1 \\
\hline 27 & 2262.5 & 6187 & 2611.9 & 6187 & 349.4 \\
\hline 27 & 2769.2 & 7519 & 3150.2 & 7519 & 381 \\
\hline 27 & 3045.9 & 8763 & 3400.9 & 8763 & 355 \\
\hline 27 & 3345.5 & 9565 & 3714.5 & 9565 & 369 \\
\hline 27 & 3453.7 & 10131 & 3852.3 & 10131 & 398.6 \\
\hline 27 & 3485.1 & 10228 & 3912 & 10228 & 426.9 \\
\hline 27 & 3467.8 & 10452 & 3916.6 & 10452 & 448.8 \\
\hline 27 & 3936.6 & 12040 & 4291.1 & 12040 & 354.5 \\
\hline 27 & 4235.6 & 13116 & 4605.1 & 13116 & 369.5 \\
\hline 27 & 4639.6 & 14637 & 5003.8 & 14637 & 364.2 \\
\hline 27 & 4643.8 & 14695 & 5015.7 & 14695 & 371.9 \\
\hline 27 & 4988.8 & 16146 & 5360.6 & 16146 & 371.8 \\
\hline 27 & 5033.4 & 16222 & 5418.6 & 16222 & 385.2 \\
\hline 27 & 5134.9 & 16622 & 5521.5 & 16622 & 386.6 \\
\hline 27 & 5162.5 & 16705 & 5570.4 & 16705 & 407.9 \\
\hline 27 & 5585.7 & 18195 & 5994.8 & 18195 & 409.1 \\
\hline 27 & 6086.5 & 20330 & 6488.4 & 20330 & 401.9 \\
\hline 27 & 6141.1 & 20443 & 6523.6 & 20443 & 382.5 \\
\hline 27 & 6339.4 & 21237 & 6721.3 & 21237 & 381.9 \\
\hline 27 & 6388.5 & 21144 & 6755 & 21144 & 366.5 \\
\hline 27 & 6648.1 & 22346 & 7002.5 & 22346 & 354.4 \\
\hline 27 & 6837.5 & 22899 & 7190.1 & 22899 & 352.6 \\
\hline 27 & 7158.2 & 24221 & 7519.3 & 24221 & 361.1 \\
\hline 27 & 7176 & 24287 & 7567.7 & 24287 & 391.7 \\
\hline 27 & 7346.3 & 24765 & 7696.3 & 24765 & 350 \\
\hline 27 & 7589.3 & 25686 & 7894.3 & 25686 & 305 \\
\hline 27 & 7664 & 25798 & 7984.9 & 25798 & 320.9 \\
\hline 27 & 8290.2 & 28049 & 8571.3 & 28049 & 281.1 \\
\hline 28 & 233.5 & 25 & 515.4 & 25 & 281.9 \\
\hline 28 & 1133.8 & 2529 & 1475.5 & 2529 & 341.7 \\
\hline 28 & 1154.3 & 2464 & 1502 & 2464 & 347.7 \\
\hline 28 & 1687 & 4371 & 2049.1 & 4371 & 362.1 \\
\hline 28 & 2147.1 & 5746 & 2616.4 & 5746 & 469.3 \\
\hline 28 & 2437.4 & 6531 & 2798.1 & 6531 & 360.7 \\
\hline 28 & 2481.8 & 6555 & 2812.3 & 6555 & 330.5 \\
\hline 28 & 2761.4 & 7722 & 3113.6 & 7722 & 352.2 \\
\hline 28 & 3137.7 & 9127 & 3503.4 & 9127 & 365.7 \\
\hline 28 & 3178.2 & 9373 & 3559.6 & 9373 & 381.4 \\
\hline 28 & 3182.4 & 9481 & 3578.6 & 9481 & 396.2 \\
\hline 28 & 3643.4 & 10973 & 4108.4 & 10973 & 465 \\
\hline 28 & 3737.4 & 11032 & 4160.5 & 11032 & 423.1 \\
\hline 28 & 4366.3 & 13724 & 4756.5 & 13724 & 390.2 \\
\hline 28 & 4368.4 & 13625 & 4773.4 & 13625 & 405 \\
\hline 28 & 4733.8 & 14816 & 5079.3 & 14816 & 345.5 \\
\hline 28 & 5033.7 & 16090 & 5418.4 & 16090 & 384.7 \\
\hline 28 & 4942.5 & 15894 & 5473.3 & 15894 & 530.8 \\
\hline 28 & 5471.1 & 17860 & 5878.2 & 17860 & 407.1 \\
\hline
\end{tabular}

33.33

40.05 


\begin{tabular}{|c|c|c|c|c|c|c|}
\hline 28 & 5533.7 & 17916 & 5928.5 & 17916 & 394.8 & \\
\hline 28 & 5542.5 & 17824 & 5981.8 & 17824 & 439.3 & \\
\hline 28 & 5778.3 & 18876 & 6091.9 & 18876 & 313.6 & \\
\hline 28 & 6037.3 & 19881 & 6416.7 & 19881 & 379.4 & \\
\hline 28 & 6435.3 & 21368 & 6806.3 & 21368 & 371 & \\
\hline 28 & 6456.3 & 21382 & 6864.8 & 21382 & 408.5 & \\
\hline 28 & 6537.7 & 21764 & 6985.3 & 21764 & 447.6 & \\
\hline 28 & 6836.3 & 22907 & 7194.4 & 22907 & 358.1 & \\
\hline 28 & 7140.8 & 24102 & 7619.5 & 24102 & 478.7 & \\
\hline 28 & 7436.5 & 25209 & 7797.5 & 25209 & 361 & \\
\hline 28 & 8073.4 & 27128 & 8373.9 & 27128 & 300.5 & \\
\hline 28 & 8241.2 & 28034 & 8565.6 & 28034 & 324.4 & \\
\hline 28 & 8363.6 & 28188 & 8599.8 & 28188 & 236.2 & 60.45 \\
\hline 29 & 552.8 & 821 & 896.7 & 821 & 343.9 & \\
\hline 29 & 738.8 & 1518 & 1016.5 & 1518 & 277.7 & \\
\hline 29 & 1346.9 & 3177 & 1707.2 & 3177 & 360.3 & \\
\hline 29 & 1460.8 & 3633 & 1878.2 & 3633 & 417.4 & \\
\hline 29 & 1942.5 & 4995 & 2282.7 & 4995 & 340.2 & \\
\hline 29 & 2545.7 & 7169 & 2890.8 & 7169 & 345.1 & \\
\hline 29 & 2843.1 & 7959 & 3283 & 7959 & 439.9 & \\
\hline 29 & 3452.7 & 10380 & 3814.5 & 10380 & 361.8 & \\
\hline 29 & 3574.3 & 10578 & 3986.7 & 10578 & 412.4 & \\
\hline 29 & 3644.5 & 11061 & 4026.7 & 11061 & 382.2 & \\
\hline 29 & 4247.9 & 13151 & 4674.7 & 13151 & 426.8 & \\
\hline 29 & 4438.1 & 13881 & 4790.7 & 13881 & 352.6 & \\
\hline 29 & 4541.7 & 14305 & 4906.8 & 14305 & 365.1 & \\
\hline 29 & 4637.1 & 14621 & 5015.4 & 14621 & 378.3 & \\
\hline 29 & 4733.8 & 14957 & 5106.9 & 14957 & 373.1 & \\
\hline 29 & 4960.6 & 15837 & 5401.7 & 15837 & 441.1 & \\
\hline 29 & 4986.7 & 16059 & 5468.5 & 16059 & 481.8 & \\
\hline 29 & 5237.1 & 17040 & 5611.5 & 17040 & 374.4 & \\
\hline 29 & 6433.5 & 21157 & 6797.9 & 21157 & 364.4 & \\
\hline 29 & 6488.7 & 21464 & 6819.4 & 21464 & 330.7 & \\
\hline 29 & 6558.8 & 21515 & 6949.7 & 21515 & 390.9 & \\
\hline 29 & 6687.8 & 22367 & 7058.9 & 22367 & 371.1 & \\
\hline 29 & 7256.2 & 24484 & 7613.5 & 24484 & 357.3 & \\
\hline 29 & 7344.8 & 25029 & 7695.5 & 25029 & 350.7 & \\
\hline 29 & 7681 & 26280 & 8048.2 & 26280 & 367.2 & \\
\hline 29 & 7781.8 & 26515 & 8114.6 & 26515 & 332.8 & \\
\hline 29 & 8287.1 & 28237 & 8568.1 & 28237 & 281 & 45.14 \\
\hline 30 & 733.8 & 1285 & 1059.6 & 1285 & 325.8 & \\
\hline 30 & 1688.5 & 4389 & 2011.9 & 4389 & 323.4 & \\
\hline 30 & 2839.7 & 7835 & 3259.1 & 7835 & 419.4 & \\
\hline 30 & 2838.7 & 7730 & 3268.4 & 7730 & 429.7 & \\
\hline 30 & 2936.4 & 8364 & 3317 & 8364 & 380.6 & \\
\hline 30 & 3290.3 & 9582 & 3613.5 & 9582 & 323.2 & \\
\hline 30 & 3333.8 & 9731 & 3696.8 & 9731 & 363 & \\
\hline 30 & 3454.5 & 10091 & 3800.6 & 10091 & 346.1 & \\
\hline 30 & 4245 & 12767 & 4613.1 & 12767 & 368.1 & \\
\hline 30 & 4552.5 & 14349 & 4915.5 & 14349 & 363 & \\
\hline 30 & 4545.8 & 14213 & 4921.9 & 14213 & 376.1 & \\
\hline 30 & 4643.5 & 14723 & 5009.7 & 14723 & 366.2 & \\
\hline 30 & 5278.4 & 17088 & 5607.6 & 17088 & 329.2 & \\
\hline 30 & 5457 & 17635 & 5866.5 & 17635 & 409.5 & \\
\hline 30 & 5439.1 & 17481 & 5872.1 & 17481 & 433 & \\
\hline 30 & 5558.9 & 18045 & 5909.1 & 18045 & 350.2 & \\
\hline 30 & 5949.7 & 19657 & 6312.1 & 19657 & 362.4 & \\
\hline 30 & 6045.8 & 19993 & 6489.1 & 19993 & 443.3 & \\
\hline
\end{tabular}




$\begin{array}{lllllll}30 & 6537.4 & 21710 & 6933.4 & 21710 & 396 & \\ 30 & 7181.5 & 24059 & 7602.1 & 24059 & 420.6 & \\ 30 & 7435.4 & 25014 & 7763.8 & 25014 & 328.4 & \\ 30 & 7842.8 & 26658 & 8217.3 & 26658 & 374.5 & \\ 30 & 8033.8 & 27222 & 8377.3 & 27222 & 343.5 & \\ 30 & 8335.3 & 28050 & 8592.2 & 28050 & 256.9 & 44.02\end{array}$




\section{Appendix G: Statistical Tests}

Standard Deviation of Deviation at Navy Annex

t-Test: Paired Two Sample for Means

\begin{tabular}{lrr}
\hline & Variable 1 & Variable 2 \\
\hline Mean & 209.0459 & 202.3611 \\
Variance & 2062.751 & 2187.926 \\
Observations & 30 & 30 \\
Pearson Correlation & 0.965839 & \\
Hypothesized Mean Difference & 0 & \\
df & 29 & \\
t Stat & 3.019989 & \\
$\mathrm{P}(T<=t)$ one-tail & 0.002616 & \\
t Critical one-tail & 1.699127 & \\
$\mathrm{P}(\mathrm{T}<=t)$ two-tail & 0.005231 & \\
t Critical two-tail & 2.045231 & \\
\hline
\end{tabular}

Average Bus Run Time

t-Test: Paired Two Sample for Means

\begin{tabular}{lrr}
\hline & Variable 1 & Variable 2 \\
\hline Mean & 552.6018 & 547.8307 \\
Variance & 1779.006 & 1509.181 \\
Observations & 30 & 30 \\
Pearson Correlation & 0.963753 & \\
Hypothesized Mean Difference & 0 & \\
df & 29 \\
t Stat & 2.293052 \\
P $(T<=t)$ one-tail & 0.014643 \\
t Critical one-tail & 1.699127 \\
P $(T<=t)$ two-tail & 0.029285 \\
t Critical two-tail & 2.045231 \\
\hline
\end{tabular}




\section{Average Vehicle Delay}

t-Test: Paired Two Sample for Means

\begin{tabular}{lrr}
\hline & Variable 1 & Variable 2 \\
\hline Mean & 86.5198 & 87.38553 \\
Variance & 3.272702 & 4.663067 \\
Observations & 30 & 30 \\
Pearson Correlation & 0.685193 & \\
Hypothesized Mean Difference & 0 & \\
df & 29 & \\
t Stat & -2.95079 & \\
P $(T<=t)$ one-tail & 0.003108 & \\
t Critical one-tail & 1.699127 & \\
$\mathrm{P}(\mathrm{T}<=\mathrm{t})$ two-tail & 0.006215 & \\
t Critical two-tail & 2.045231 & \\
\hline
\end{tabular}

\section{Average Person Delay}

t-Test: Paired Two Sample for Means

\begin{tabular}{lrr}
\hline & Variable 1 & Variable 2 \\
\hline Mean & 104.4243 & 105.087 \\
Variance & 7.373114 & 8.678925 \\
Observations & 30 & 30 \\
Pearson Correlation & 0.822618 & \\
Hypothesized Mean Difference & 0 & \\
df & 29 & \\
t Stat & -2.135 & \\
P $(T<=t)$ one-tail & 0.020668 & \\
t Critical one-tail & 1.699127 & \\
$\mathrm{P}(\mathrm{T}<=\mathrm{t})$ two-tail & 0.041337 & \\
t Critical two-tail & 2.045231 & \\
\hline
\end{tabular}




\section{Individual Trip Level Arrival Reliability}

t-Test: Paired Two Sample for Means

\begin{tabular}{lrr}
\hline & Variable 1 & Variable 2 \\
\hline Mean & 271.31 & 241.5933 \\
Variance & 116150.7 & 106103 \\
Observations & 30 & 30 \\
Pearson Correlation & 0.96551 & \\
Hypothesized Mean Difference & 0 & \\
df & 29 & \\
t Stat & 1.833005 & \\
$\mathrm{P}(\mathrm{T}<=\mathrm{t})$ one-tail & 0.038543 & \\
t Critical one-tail & 1.699127 & \\
$\mathrm{P}(\mathrm{T}<=\mathrm{t})$ two-tail & 0.077087 & \\
t Critical two-tail & 2.045231 & \\
\hline
\end{tabular}

